\title{
BIOMECHANICAL MODELING AND SIMULATION OF THE SPIDER CRAB (MAJA BRACHYDACTYLA)
}

Rita Rynkevic

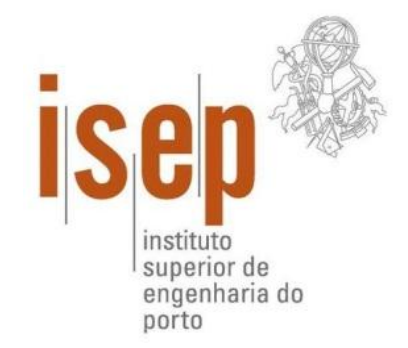

Mestrado em Computação e Instrumentação Médica

Departamento de Física

Instituto Superior de Engenharia do Porto

2012 

Este relatório satisfaz, parcialmente, os requisitos que constam da Ficha de Disciplina de Tese/Dissertação, do $2^{\circ}$ ano, do Mestrado em Engenharia de Computação e Instrumentação Médica

Candidato: Rita Rynkevic, № 1101331, r.rynkevic@gmail.com Orientação científica: Manuel Fernando dos Santos Silva, mss@ @isep.ipp.pt Co-orientação científica: Maria Arcelina Marques, mmr@ isep.ipp.pt

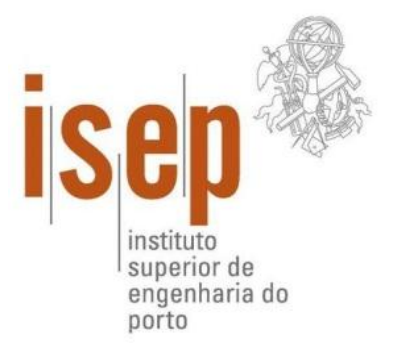

Mestrado em Computação e Instrumentação Médica

Departamento Física

Instituto Superior de Engenharia do Porto

8 de October de 2012 



\section{Acknowledgements}

Thanks to Estação Litoral da Aguda (ELA) and Professor Mike Weber for providing the laboratory, material and tools to studying crabs, and for permission to film the crabs and take photos inside the aquarium.

Thanks are also due to Professor João Pinho, for helping with SolidWorks, and to Dra. Marta Rufino, Prof. Fernando Carvalho, Prof. Paulo Vaz-Pinto and Dra. Sara Barrento, for giving suggestions and supplying several useful information about crabs. 



\section{Resumo}

Uma linha de pesquisa e desenvolvimento na área da robótica, que tem recebido atenção crescente nos últimos anos, é o desenvolvimento de robôs biologicamente inspirados. A ideia é adquirir conhecimento de seres biológicos, cuja evolução ocorreu ao longo de milhões de anos, e aproveitar o conhecimento assim adquirido para implementar a locomoção pelos mesmos métodos (ou pelo menos usar a inspiração biológica) nas máquinas que se constroem. Acredita-se que desta forma é possível desenvolver máquinas com capacidades semelhantes às dos seres biológicos em termos de capacidade e eficiência energética de locomoção.

Uma forma de compreender melhor o funcionamento destes sistemas, sem a necessidade de desenvolver protótipos dispendiosos e com longos tempos de desenvolvimento é usar modelos de simulação. Com base nestas ideias, o objectivo deste trabalho passa por efectuar um estudo da biomecânica da santola (Maja brachydactyla), uma espécie de caranguejo comestível pertencente à família Majidae de artrópodes decápodes, usando a biblioteca de ferramentas SimMechanics da aplicação Matlab / Simulink.

Esta tese descreve a anatomia e locomoção da santola, a sua modelação biomecânica e a simulação do seu movimento no ambiente Matlab / SimMechanics e SolidWorks.

\section{Palavras-Chave}

Maja brachydactyla, santola, locomoção, modelação, simulação, biomecânica, Matlab, Simulink, SimMechanics, SolidWorks. 



\section{Abstract}

One line of research and development in robotics, that has received increasing attention in recent years, is the development of biologically inspired robots. The idea is to gain knowledge of biological beings, whose evolution occurred over millions of years, and apply the knowledge thus acquired to implement the same methods of locomotion (or at least use the biological inspiration) on the machines we build. It is believed that this way it is possible to develop machines with capabilities similar to those of biological beings in terms of locomotion skills and energy efficiency.

One way to better understand the functioning of these systems, without the need to develop prototypes with long and costly development, is to use simulation models. Based on these ideas, in this work is developed a study of the biomechanics of the spider crab (Maja brachydactyla), a kind of eatable crab belonging to the family Majidae of decapod arthropods, using the SimMechanics toolbox of Matlab / Simulink.

This thesis describes the anatomy and locomotion of the spider crab, its modeling and the locomotion simulation of a crab within the Matlab/SimMechanics environment and SolidWorks.

\section{Keywords}

Maja brachydactyla, spider crab, locomotion, modeling, simulation, biomechanics, Matlab, Simulink, SimMechanics, Solidworks. 



\section{Table of Contents}

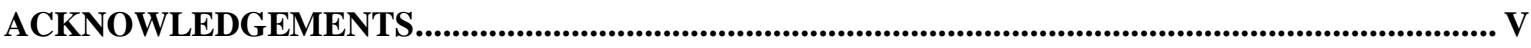

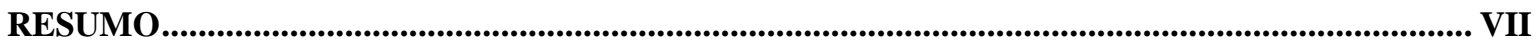

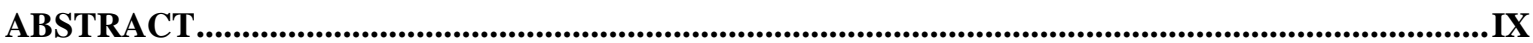

TABLE OF CONTENTS................................................................................................................................XI

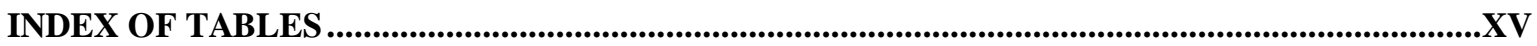

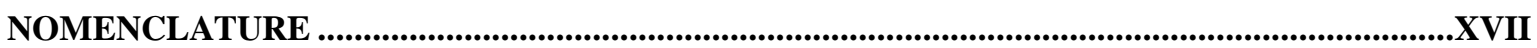

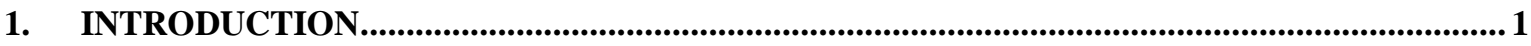

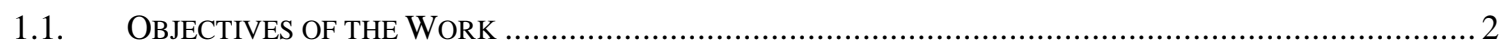

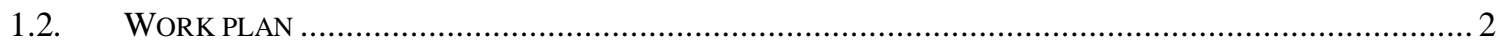

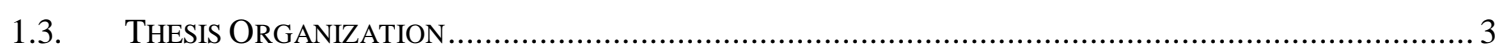

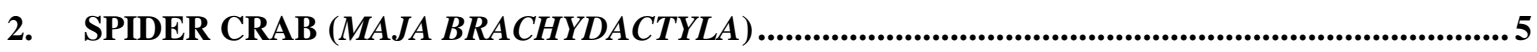

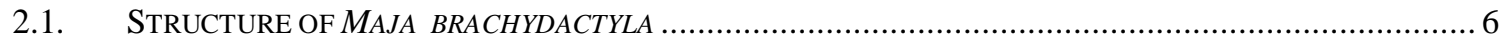

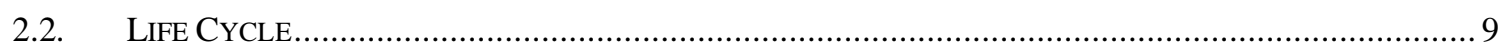

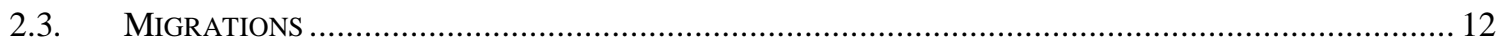

3. DETERMINATION OF BIOMETRIC INDICES .......................................................................... 13

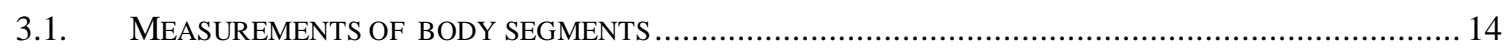

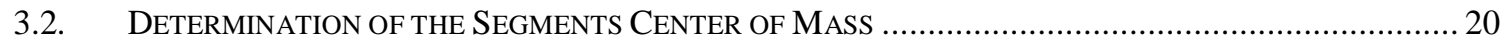

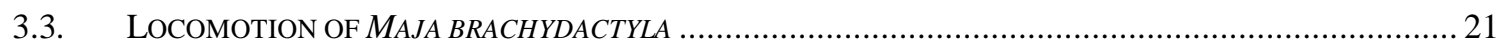

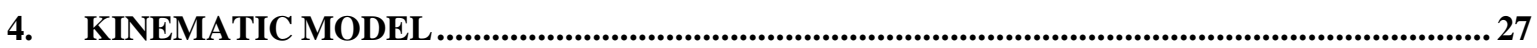

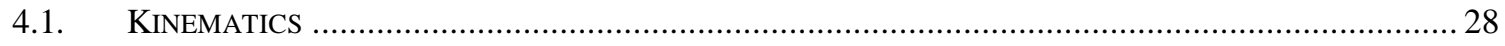

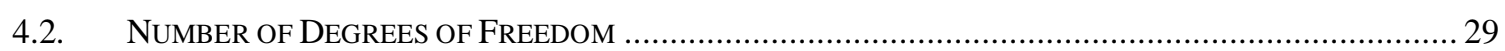

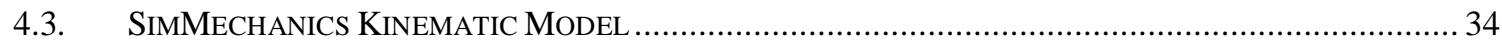

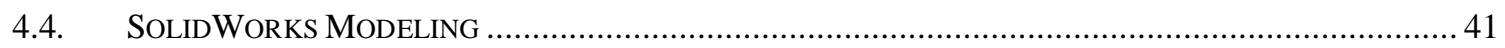

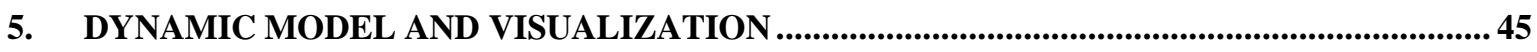

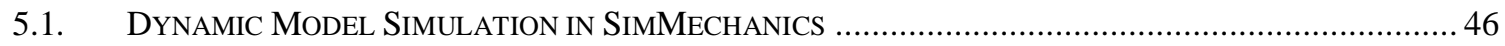

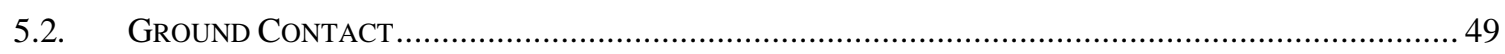

5.3. Modeling OF Discrete-Positional Control SySTEM IN Simulink ......................................... 51

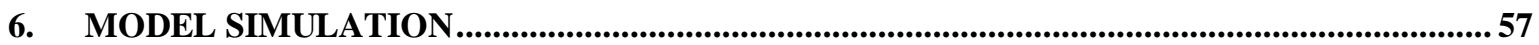

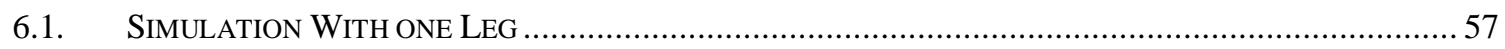

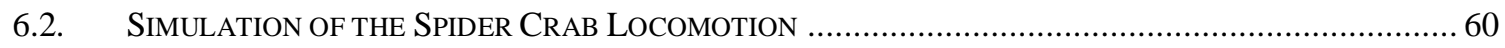

7. CONCLUSIONS AND PERSPECTIVES FOR FUTURE DEVELOPMENTS ........................... 65 
7.1. CONCLUSION

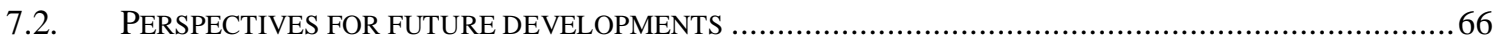

REFERENCES ..................................................................................................................................69

APPENDIX A- MEASUREMENTS OF THE SECOND SPECIMEN .............................................71 


\section{Index of Figures}

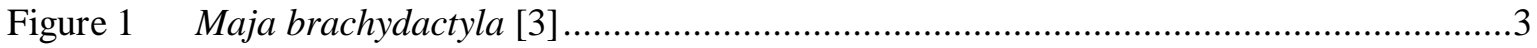

Figure 2 Dorsal view of the carapace of Maja brachydactyla [3] ............................................

Figure 3 A close-up of the upper surface of the carapace of Maja brachydactyla [3].................8

Figure 4 A close-up of one of the articulations on the underside of the carapace of Maja

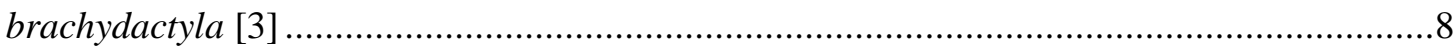

Figure 5 Left to right: larva Maja brachydactyla, Angular crab, Thia scutellata crab.................9

Figure 6 Grow phase of Maja brachydactyla (1 of March, 8 of April, 12 of June) .....................

Figure $7 \quad$ Sex of Maja brachydactyla (male and female).........................................................10

Figure $8 \quad$ Measurements of Maja brachydactyla in ELA ......................................................... 14

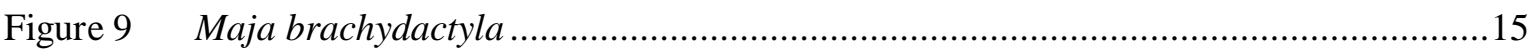

Figure 10 Instruments used for the anthropometric analysis of Maja brachydactyla: (a)- scales,

(b)- protractor, (c)- micrometer and scissors ………........................................................... 16

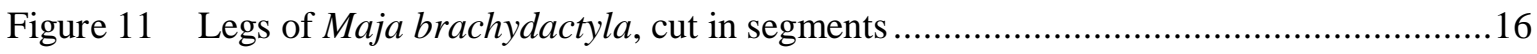

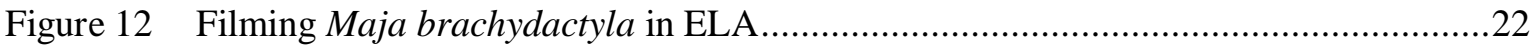

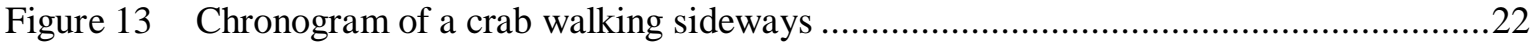

Figure 14 The chronogram of normal walking of Maja brachydactyla (scale 1:5),.....................23

Figure 15 Maja Brachydactyla locomoting in an aquarium .....................................................23

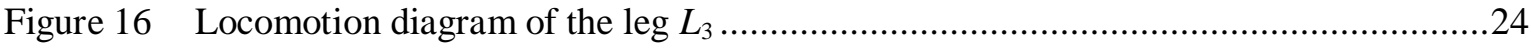

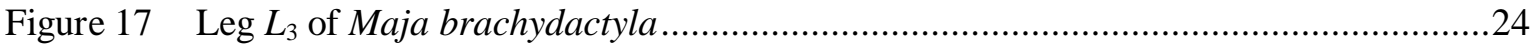

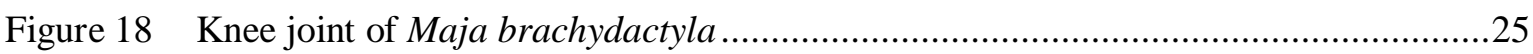

Figure 19 The scheme of free movements of the body in three dimensions [14] .......................29

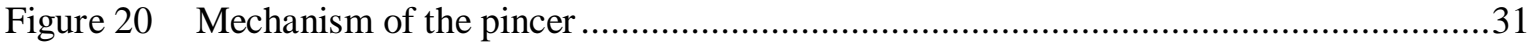

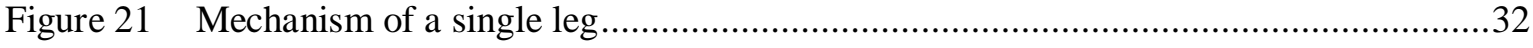

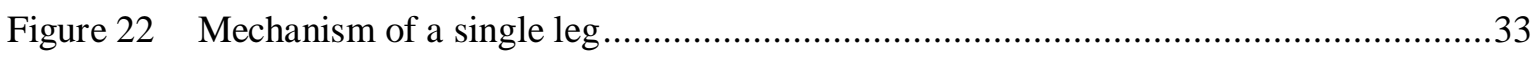

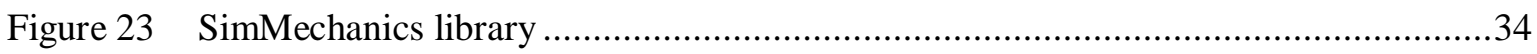

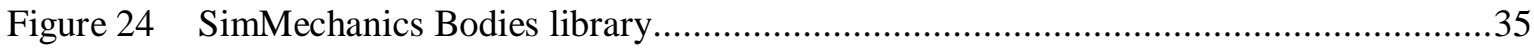

Figure 25 Leg segments setting window (Body setting window) ..............................................39

Figure 26 A simple model of a mechanical system with a block Machine Environment ..............39

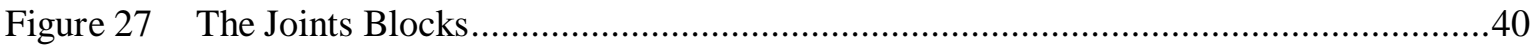

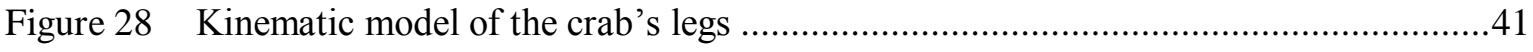

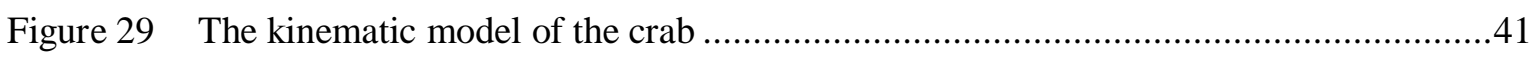

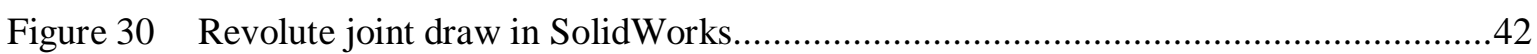

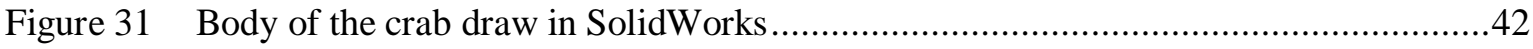

Figure 32 Full model of Spider crab in SolidWorks................................................................ 
Figure 33 The main window of the Crab model in SimMechanics

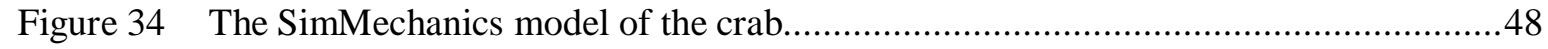

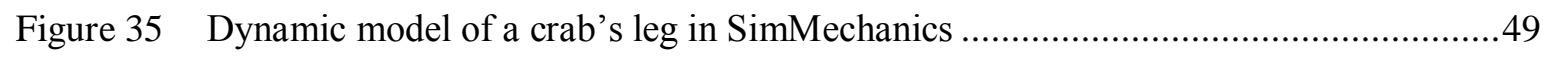

Figure 36 Ground contact model, which determines if the leg is on the ground or in the air .......50

Figure 38 The general scheme of model management system...................................................51

Figure 39 The integrated simulation model of the motion control............................................53

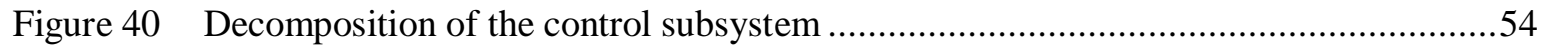

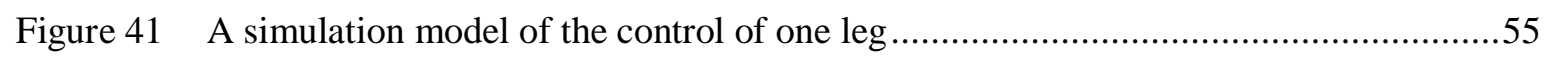

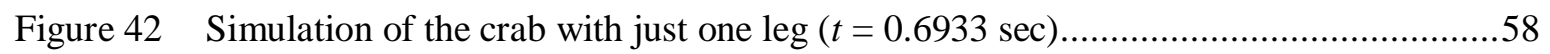

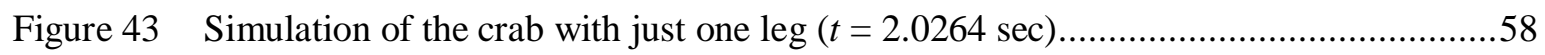

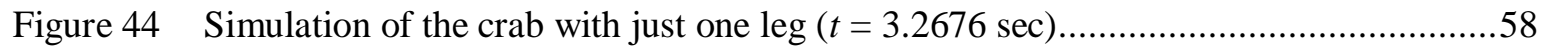

Figure 45 Plot of the normal force acting on the foot during simulation with one leg .................59

Figure 46 Plots of the crab body $x, y$ and $z$ positions during simulation with just one leg ...........59

Figure 47 Simulation of the Spider crab locomotion (during 10 seconds) .................................60

Figure 48 Plot of the normal force acting on the leg $\left(L_{4}\right)$....................................................61

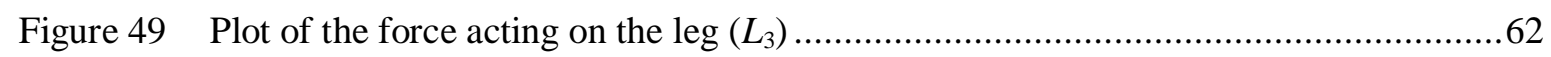

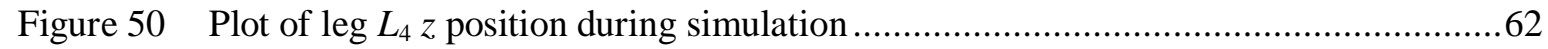

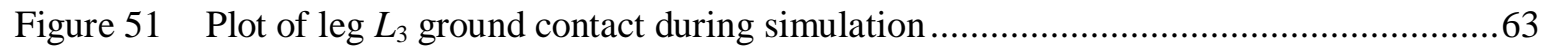

Figure 52 Plots of the crab's body $x, y$ and $z$ positions during simulation.................................64

Figure 53 Plots of PD controller during simulation, connected to leg $\left(L_{4}\right) \ldots \ldots \ldots \ldots \ldots \ldots \ldots \ldots \ldots \ldots . . . . . . . . . . . . . . . . .64$

Figure 54 Photo of the second specimen of Maja brachydactyla .............................................71 


\section{Index of Tables}

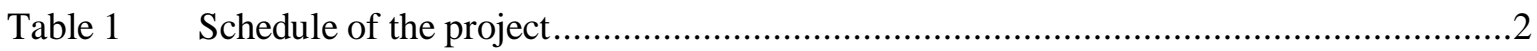

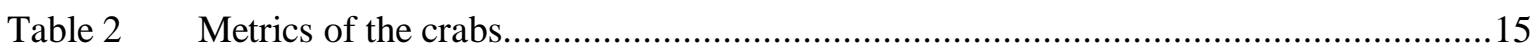

Table 3 Measurements of the left legs of the first specimen...............................................17

Table 4 Measurements of the right legs of the first specimen ..............................................18

Table 5 Average of the leg characteristic values of the first specimen ....................................20

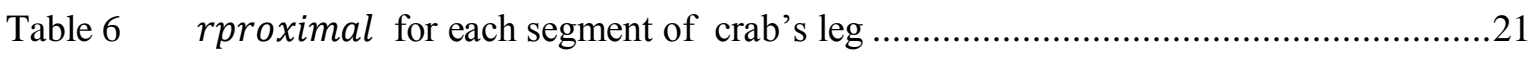

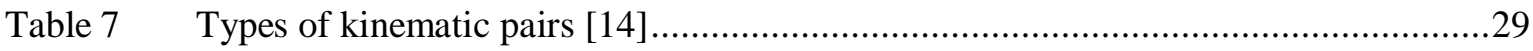

Table 8 The elements of the tensor of inertia for bodies of simple shape ................................36

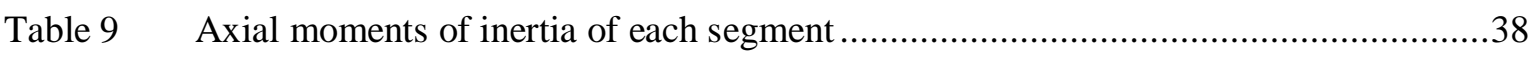

Table 10 Measurements of the left legs of the second specimen ...............................................72

Table 11 Measurements of the right legs of the second specimen ...........................................73 



\section{Nomenclature}

\section{Constants}

$g$

$\pi$

$R_{\text {proximal }}$
Gravitacional constante

Pi constante

Ratio of the center of mass

(proximal)
$9.80665 \mathrm{~m} / \mathrm{s}^{2}$

3.14159

0.433

\section{Variables}

$m_{n}$
$M, m$
$L, l$
$W$
$T$
$L_{x}$
$R_{X}$
$N$
$X$
$Z$
$Y$
$\mathrm{~A}$
$r_{p r o x i m a l}$
$D$
$S$
$P$

Mass of the segment

Mass

Length

$\mathrm{mm}$

Width

$\mathrm{mm}$

Thickness

$\mathrm{mm}$

Left leg

Right leg

Segments number

Cartesian $x$-coordinate

Cartesian $z$-coordinate

Cartesian $z$-coordinate

Amplitude

$\mathrm{mm}$

Segments diameter

$\mathrm{mm}$

Degrees of freedom

Index of mobility 



\section{INTRODUCTION}

In recent years, significant advances have been made in robotics, artificial intelligence and others fields that allow creating biomimetic systems. Scientists and engineers are using many of animals' performance characteristics for these advances. This work has resulted in machines that can recognize facial expressions, understand speech, and locomotion in robust bipedal gaits, similar to humans. Generally, with today's technology one can quite well graphically animate the appearance and behavior of biological creatures. Making biologically inspired robots requires understanding the biological models as well as advancements in analytical modeling, graphic simulation and the physical implementation of the related technology. The research and engineering areas that are involved with the development of biologically-inspired intelligent robots are multidisciplinary and they include materials, actuators, sensors, structures, functionality, control, intelligence and autonomy.

Nature uses unique forms of locomotion not seen in robotics. Bio-inspired designs may outperform traditional robots, traditional mobile robots are limited by natural terrain and nature's creatures are well adapted to and thrive in the natural world. Based on these ideas, the aim of this study was to conduct a study of the biomechanics of spider crab (Maja brachydactyla), a kind of edible crab belonging to the family Majidae arthropod decapod. Spider crabs are any of numerous crabs with very long legs and small triangular bodies. This crab can go out on the coast, also they can climb on the rocks. The structure of the body and anatomy was interesting, also was possibility to buy the crabs in the shop for studies, that's why was chosen this crab for the theses. 


\subsection{OBJECTIVES OF THE WORK}

The main objectives of the work are:

1. Make literature relevant information on the anatomy and locomotion of the crab.

2. Study the SimMechanics toolbox of Matlab / Simulink and the principle of modeling electromechanical systems underlying this application.

3. Develop a model of spider crab in SimMechanics toolbox.

4. Make a simulation of the behavior of the crab's body during locomotion.

5. Check the correct modeling of the system.

6. If there is time available after completing the above steps, introducing different dynamic nonlinear effects such as friction, backlash and saturation, the joints of the models implemented and analyze how the characteristics of the systems degrade.

\subsection{WORK PLAN}

Organization of the project is a necessary part of a good work. The work plan (see Table 1) helps to organize time and move from done work, to new one. The plan must be made deliberately, counting time and facilities, that everything that was intended, will be done.

Table 1 Schedule of the project

\begin{tabular}{|l|l|l|l|l|l|l|l|}
\hline \multicolumn{1}{|c|}{ Step name } & March & April & Mai & June & July & August & September \\
\hline Studying literature & & & & & & & \\
\hline Preparing material about Spider crab & & & & & & & \\
\hline Studying SimMechanics Toolbox & & & & & & & \\
\hline Creating kinematic model of Spider crab & & & & & & & \\
\hline Creating dynamic model of Spider crab & & & & & & & \\
\hline Model testing & & & & & & & \\
\hline Last patches & & & & & & & \\
\hline
\end{tabular}




\subsection{THESIS ORGANIZATION}

To achieve the plan and objectives, the following actions were implemented:

- A literature review on the relevant information about the anatomy and locomotion of the crab was made in second chapter.

- Third chapter describes the laboratory experiments. Here are introduced the biometric data, locomotion and chronogram. This data was used to create the kinematic and dynamic model in the simulation program.

- Was studied the SimMechanics toolbox of Matlab / Simulink and the principle of modeling electromechanical systems underlying this application. This chapter describes the kinematic model made in SimMechanics and calculations of degrees of freedom.

- Chapter fife describes the dynamic modeling of the Spider crab as an octopod robot. The model is made in Simulink, using the SimMechanics toolbox. Furthermore there is developed a model of the discrete-positional control, which controls the crab's movements, also were used frictions, forces, and ground contact model.

- In the last chapter, the conclusions of the developed work are presented and recommendations are given for future studies on the Spider crab model. 



\section{SPIDER CRAB $(M A J A$ BRACHYDACTYLA)}

Maja brachydactyla (see Figure 1) (the European spider crab, spiny spider crab) is a species of migratory crab found in the north-east Atlantic and the Mediterranean Sea [1].

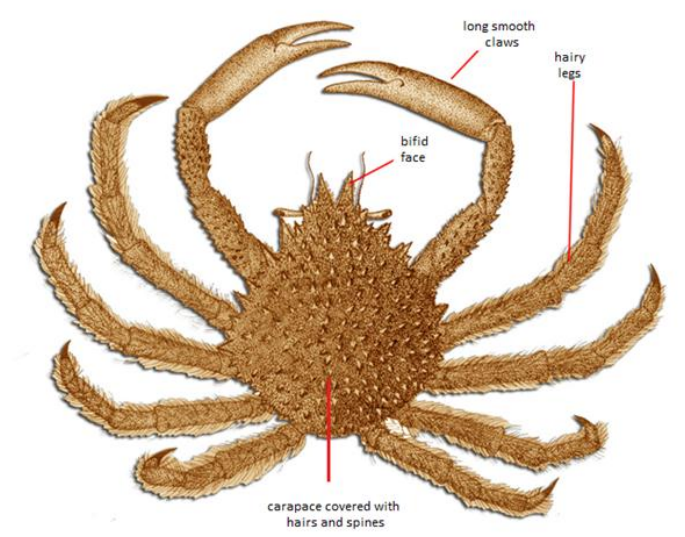

Figure $1 \quad$ Maja brachydactyla

The family Majidae, containing approximately 900 species, is widely distributed in marine waters. Although the vast majority of Majidae crabs are small and have no direct economic importance, some species support commercial fisheries. Commercially exploited Majids include the Canadian snow crab (Chionoecetes opilio) and the common European spider crab (Maja brachydactyla) [2]. 
The scientific classification of Maja brachydactyla:

- Kingdom: Animalia

- Phylum: Arthropoda

- Subphylum: Crustacea

- Class: Malacostraca

- Order: Decapoda

- Infraorder: Brachyura

- Family: Majidae

- Genus: Maja

- Species: Maja brachydactyla

Maja brachydactyla is the sole European representative of the subfamily Majidae and is the largest of approximately 66 species of Majidae crabs occurring in the north-eastern Atlantic. Maja brachydactyla also supports commercial fisheries in northern Spain (Galicia), Portugal and in the Adriatic Sea. There is considerable seasonal and demographic variation in the depth distribution of Maja. In general, depth distribution during the summer is coastal, extending from $20 \mathrm{~m}-30 \mathrm{~m}$ up to the low water mark and even into the intertidal zone, whereas during winter most Maja brachydactyla are found at depths of around $50 \mathrm{~m}$ - to $90 \mathrm{~m}$ and occasionally down to $120 \mathrm{~m}$. Aggregations of subsections of the Maja brachydactyla population (e.g. "juveniles" or "recently-molted adults") are often found in discrete areas of different depths. Generally, juveniles have a shallower distribution than adults, often occurring in well-defined, shallow inshore "nursery areas". Recently-molted adults tend to have a shallower distribution than the adults which did not molt in the current season. As a result of their migratory habit, however, representatives of all subsections of the population may be found at the same depth at certain times of the year. Predominantly, Maja brachydactyla is found in areas where the seabed is flat and composed of soft substrata, and crabs have been observed partially buried in areas of suitably soft substrata. Some Maja brachydactyla (particularly large adult males) may occur in areas where the seabed is very rocky, particularly during their seasonal migrations [2].

\subsection{STRUCTURE OF MAJA BRACHYDACTYLA}

We are all familiar to some extent with crabs and other crustaceans - the shell or carapace, the pointed walking legs, the first pair of legs with pincers and so on. Around the (mainly 
southern and western) coast of Britain, one large and distinctive species is the Spiny Spider Crab Maja brachydactyla which can have a carapace up to $20 \mathrm{~cm}$ long (not to mention the long legs), although the specimen below is about half this size. This is a fairly shallowwater species, found sub littoral to about $50 \mathrm{~m}$ depth, but sometimes also in deep littoral pools low on the shore [2].

Usually crab lives in sandy bottoms and rocky bottoms, where it hides among vegetation or in cracks. It feeds on algae, mollusks and echinoderms [1]. It has five pairs of legs of which two strong clamps (see Figure 1).

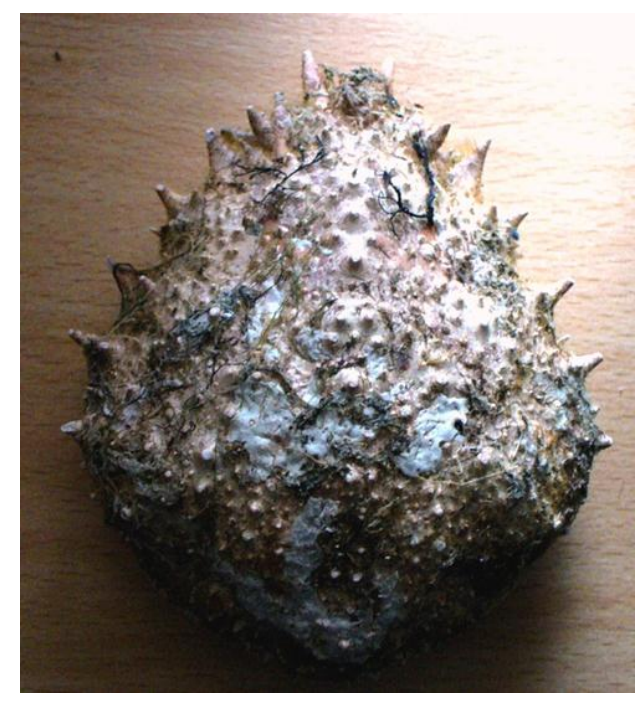

Figure 2 Dorsal view of the carapace of Maja brachydactyla [3]

Dorsal view of the carapace showing bumps (tubercles) and spines (see Figure 2), including the two larger frontal spines of the rostrum seen spreading apart at the top of the photo.

The spines serve as protection against predators, but can also be dangerous to the unwary swimmers, if a carapace is trodden on. Fortunately they are not poisonous like some organisms such as spider fish. Their ability to hide is enhanced by the range of other organisms that are used as a substrate to grow on e.g. sponges, hydroids and seaweeds, as can be seen in Figure 3. This allows them to blend in with other substrates supporting similar organisms [2]. 


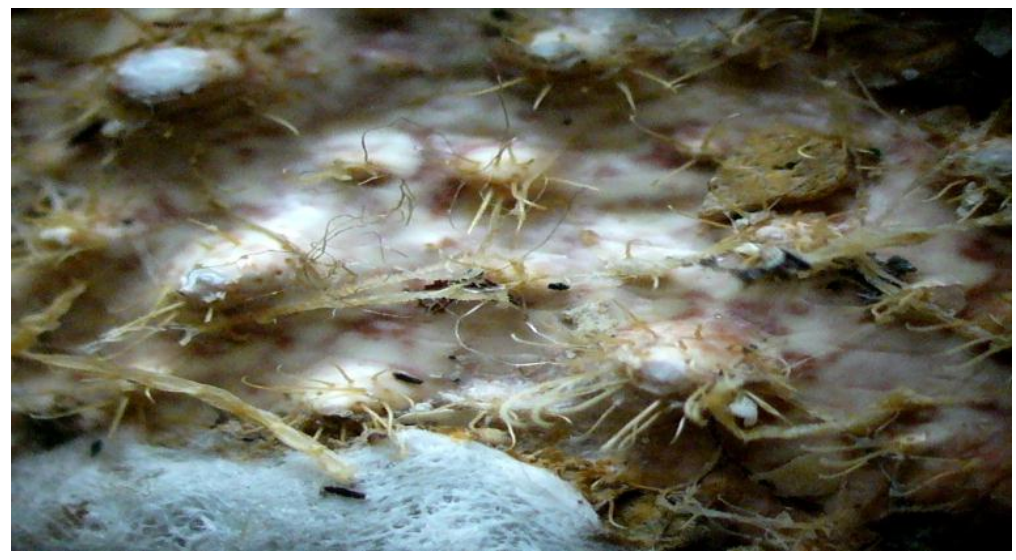

Figure 3 A close-up of the upper surface of the carapace of Maja brachydactyla [3]

Zooming in on the carapace (see Figure 3), the tubercles can be seen to have tufts of bristles - a close look shows that where some have broken off, tiny holes remain in the surface of the carapace. Such bristles or hairs are also seen on the legs following a molt, though these are gradually rubbed off [3].

Figure 4, shows such a brush of hairs in more detail. They are simple unjointed structures and are likely to be guard hairs with the function of keeping sand grains and other unwanted material out of delicate joints. The spaces between spines around the edge of the carapace show similar bristles. These may again be there to trap unwanted material (and maybe they help with camouflage by breaking up the outline, especially if they collect seaweed fragments and similar), but the crab also has much tinier, finer sensory hairs (not visible here) which also need to be protected by guard hairs. Of course, crabs do not rely solely on sensory hairs - they also have compound eyes on mobile stalks [3].

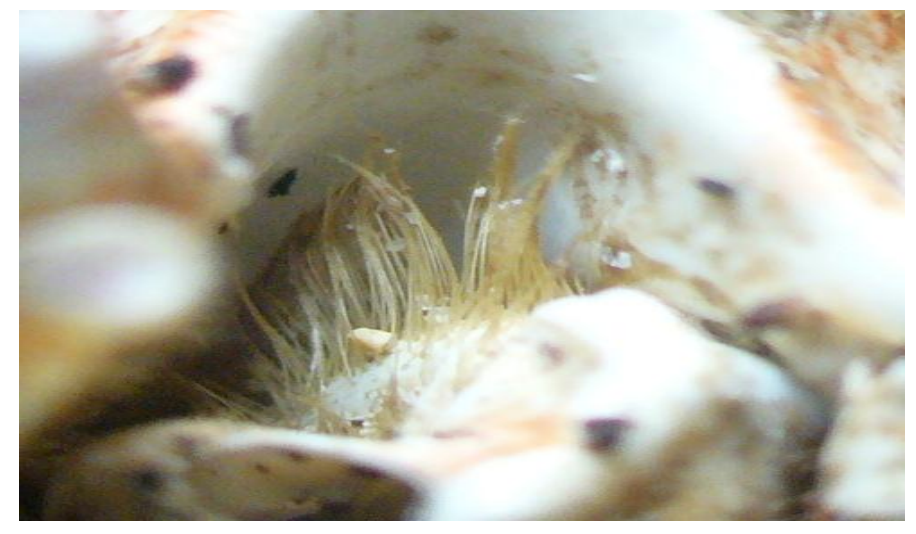

Figure 4 A close-up of one of the articulations on the underside of the carapace of Maja brachydactyla [3] 


\subsection{LIFE CYCLE}

Maja brachydactyla has a life cycle of between 5 - 8 years, consisting of two main phases (growth and reproductive phases) separated by a final molt. The growth phase consists of a planktonic larval phase followed by a benthic juvenile phase. The planktonic larval phase is shorter and less complicated than that of many other non-majids species of crab. The total duration of the growth phase in Maja brachydactyla is thought to be between 2 - 3 years. Adult crabs may live for up to six years after their terminal molt [2].

\subsubsection{Juvenile (growth) phase}

The developmental stages between the morphologically distinct planktonic larval and the adult phases of Maja brachydactyla are known as "juveniles" (see Figure 5).

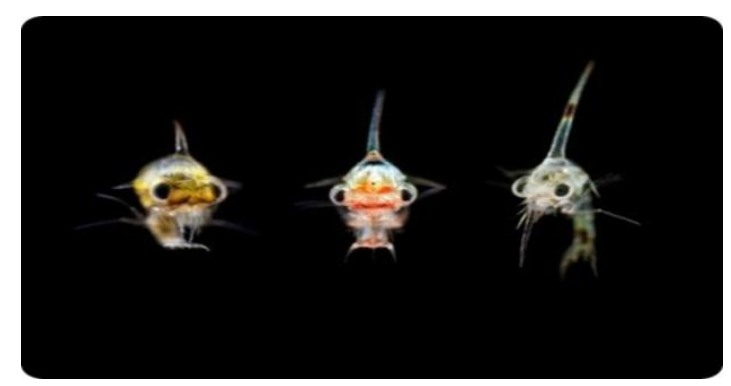

Figure 5 Left to right: larva Maja brachydactyla, Angular crab, Thia scutellata crab

In most cases, duration of the juvenile stage of Maja brachydactyla is approximately two years, although a minority may take between 2 - 3 years to complete the juvenile phase (see Figure 6).

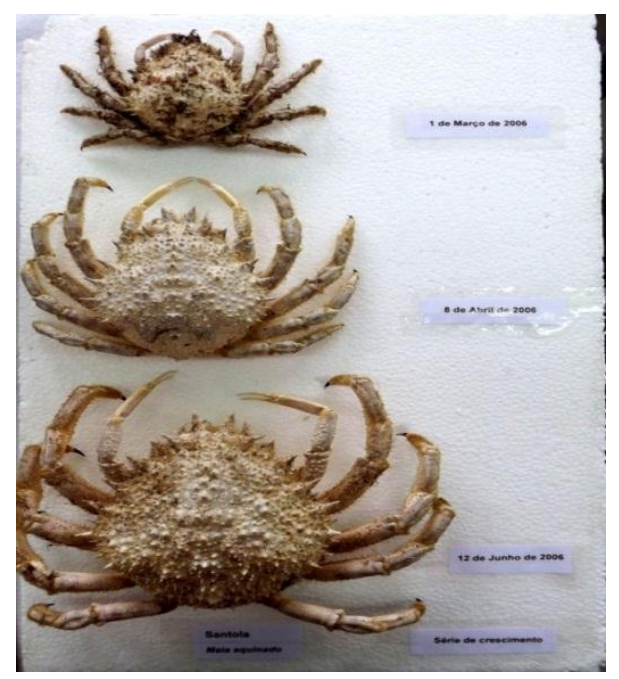

Figure 6 Grow phase of Maja brachydactyla (1 of March, 8 of April, 12 of June) 
The first post larval (juvenile) stage measures approximately $1.28 \mathrm{~mm}$ (carapace width) and possesses the characteristic "spider crab"" appearance of later stages. Juvenile growth is slightly non symmetric which results in minor morphometric differences between early and late stage juveniles. The number of molts which occur between the initial settlement of the first post larval stage and the onset of the first winter, when juvenile Maja brachydactyla achieve an average of between 10-15 mm carapace length, is unknown. Two molts are thought to occur in the second year and molt increments during the juvenile phase are relatively large (33\%) for males and females. In the course of successive juvenile molts, the male size range becomes progressively greater compared with females of the same age. The end of the juvenile stage is marked by a final "maturity" ("terminal") molt, at which time sexual maturity is achieved and pronounced morphometric changes occur; no further molting occurs after this terminal molt. The molt increment at the maturity molt in Maja brachydactyla is smaller than for preceding molts (29\%) for males and females [2].

\subsubsection{Adult (reproductive) phase}

One result of the terminal molt is the functional degeneration of the "Y" organ, which, in Maja brachydactyla, is thought to be responsible for production of the molt-inducing hormone, 20-hydroxy ecdysone. After the terminal molt, the gonads become enlarged and fully functional, and certain obvious external morphometric changes occur.

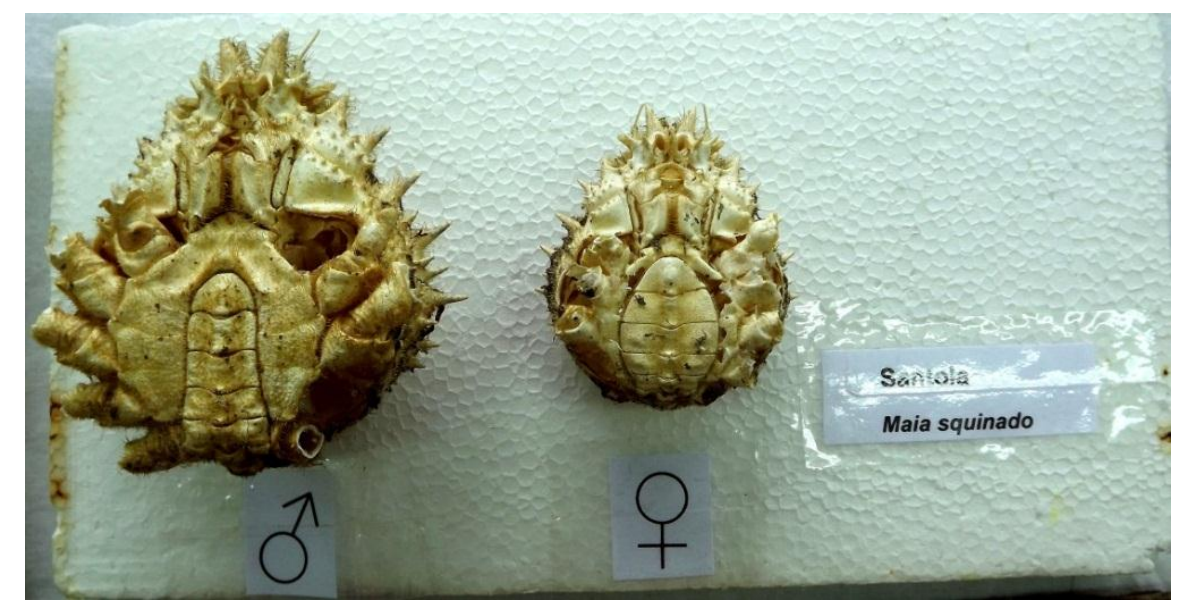

Figure 7 Sex of Maja brachydactyla (male and female)

For example, the chelae of males become greatly enlarged, and the female abdomen becomes enlarged and modified for egg carrying compared with juveniles (see Figure 7). Immediately after the terminal molt, adult spider crabs are typically bright orange or red. 
However, this color gradually fades with time to a dull reddish-brown. Also with age, the carapace and legs become increasingly worn and covered with epidictic fouling organisms. Irreparable wear of the carapace probably contributes to the limited post-terminal molt life span (3 - 6 years) of spider crabs. In the Normano-Breton Gulf, adult males range in size from 85 to $200 \mathrm{~mm}$ carapace length $($ mean $=138 \mathrm{~mm}$ ) and adult females from 80 to 170 $\mathrm{mm}($ mean $=128 \mathrm{~mm})$ carapace length. These measurements were collected using scallop dredges, a technique known to give a representative sample of the adult spider crab population. Males have a more variable size than females, and average size of Maja brachydactyla is known to increase with decreasing latitude [2].

\subsubsection{Reproduction}

Unlike many other species of Crustacea which require the female to molt into a soft condition prior to mating, Maja brachydactyla is able to copulate while the female is hard. Generally, mating occurs during the summer months. Various authors have cited evidence establishing the presence of sperm bag (or bursa copulatrix) in Maja brachydactyla. Some authors argue that Maja brachydactyla has no ability to store sperm in the sperm bag from a single mating for subsequent fertilization of several spawning.

A major argument against long-term storage of sperm in the sperm bag, is that vigorous females, with eggs in the final stage of embryonic development, have been observed in copula, both in captivity and in the natural environment and have spawned subsequently, 3 or 4 days after hatching their first brood. Vigorous females, which were kept separate from males during the incubation of their first brood, also spawned a second time but the eggs were non-viable. This conclusion receives further support from recent work in Spain, which has shown that adult female Maja brachydactyla, held in aquaria, spawned successfully up to five times after a single mating. In the English Channel and on the French Atlantic coast, vigorous female spider crabs occur from February to October; however, the majority of females carry eggs from May to September. Conflicting reports concerning the number of times a female spawns each year probably arise because observations have been made in different areas or in different years (with consequently different temperature regimes). Females spawn more than once a year, successive spawning occurs within $72 \mathrm{~h}$ of the hatching of the previous brood. It is unclear whether discrete spawning areas exist, however, aggregations of vigorous females have been observed in shallow $(<10 \mathrm{~m})$ coastal embayment during the early summer months (pers. 
obs.). The duration of egg development has been cited variously as $43-47$ days at $15^{\circ} \mathrm{C}$, and 47 and 74 days at $16.8^{\circ} \mathrm{C}$ and $14.0^{\circ} \mathrm{C}$ respectively. Initially, eggs are orange and become increasingly pigmented during development, being brown just prior to nocturnal hatching. The number of eggs carried by a single female Maja brachydactyla is directly proportional to female body size, and varies between 45,000 and 400,000; an "average sized" female of $128 \mathrm{~mm}$ carapace length (650 g wet weight) carries between 150,000155,000 eggs. It should be noted, however, that, as is the case with other crustaceans, the number of eggs spawned is a function of female age and seawater temperature at the time of spawning as well as female size. Low spawning temperatures result in large numbers of relatively small eggs and that the opposite (small numbers of relatively large eggs) occurs at higher spawning temperatures. Seawater temperatures above $22^{\circ} \mathrm{C}$ are fatal for developing eggs of Maja brachydactyla [2].

\subsection{MigRATIONS}

A notable feature of the biology of Maja brachydactyla in the Normano-Breton Gulf is their seasonal migrations. Newly-molted adult Maja brachydactyla undertake an autumn/winter migration from coastal nursery areas to offshore sites where they overwinter in depths of more than $50 \mathrm{~m}$. Adult Maja brachydactyla return to the coastal nursery areas during the spring. These migrations may be an evolutionary mechanism to avoid mortality resulting from excessive cooling of shallow coastal waters during the winter months [2]. 


\section{DETERMINATION OF BIOMETRIC INDICES}

Biometrics is the study, measurement and comparison of linear dimensions and other physical characteristics animal bodies. Biometric measurements are made by "conventional" methods with the use of special and standard tools. Some of the measured characteristics are: body length, body weight, etc.

Biometric standards are average values of the physical signs obtained during examination of a large contingent of animals, homogeneous in composition (age, sex etc.). Mean values (standards) biometric characteristics are determined by statistical analyses. The arithmetic mean value $(\mathrm{M}$ - medina $)$ is calculated for each attribute.

The indices of physical development represent the ratio of the different biometric characteristics, expressed in mathematical formulas. For example, to calculate individual body segment weight is used the following formula:

$$
m_{n}=k_{m} \cdot m_{i}
$$

Where:

$m_{n^{-}}$segment mass $(\mathrm{kg})$; 
$k_{m}$ - ratio of the weight of the segment;

$m_{i}$ - body weight $(\mathrm{kg})$.

The method of the index allows approximate estimates changes in the proportionality of physical development. When analyzing and comparing the data of mass measurements of characteristics of animals is absolutely necessary to use biometric (or variation-statistical) methods of processing materials. Biometric data processing technique should be widely introduced into the practice of livestock, animal breeders and biologists for the objective evaluation of the given productivity, measurements, weight gain of animals, etc.

\subsection{MEASUREMENTS OF BODY SEGMENTS}

Measurements of the crabs (Maja brachydactyla) were made in one of the laboratories of Estação Litoral da Aguda (ELA) (see Figure 8). The used materials were four Spider crabs (two of them were dead and two alive). The dead crabs were cut in segments and each segment was measured and weighted. Alive crabs were hold in aquarium, for filming.

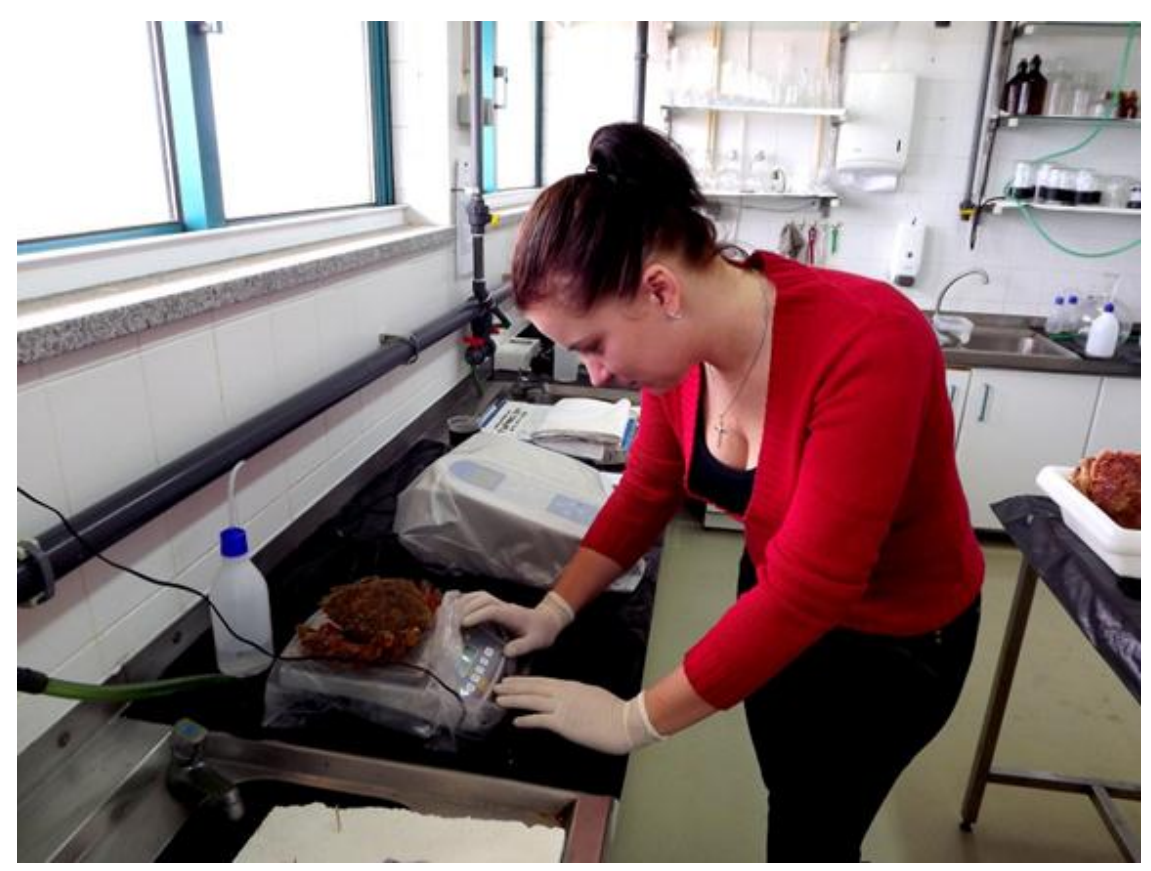

Figure 8 Measurements of Maja brachydactyla in ELA

To calculate a single body segment length and mass ratio (according to Figure 9), the dead crab specimens of Maja brachydactyla were analyzed. Length and weight of each segment 
were measured and, by taking the ratio of each segment, the average indices were calculated.

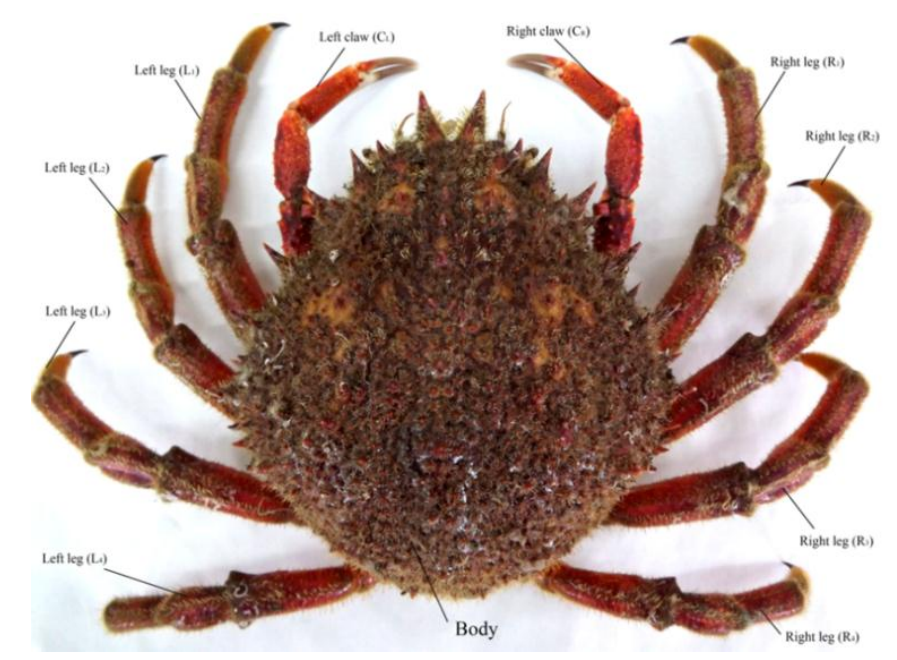

Figure 9 Maja brachydactyla

Both studied spider crabs were females. The first one is represented in Figure 8, and the second crab data is presented in Appendix A. Their overall dimensions are summarized in Table 2.

Table 2 Metrics of the crabs

\begin{tabular}{|c|c|c|c|c|}
\hline Spider crab & $\begin{array}{c}\text { Mass of the } \\
\text { body }(M)\end{array}$ & $\begin{array}{c}\text { Length of the } \\
\text { body }(L)\end{array}$ & $\begin{array}{c}\text { Width of the } \\
\text { body }(W)\end{array}$ & $\begin{array}{c}\text { Thickness of } \\
\text { the body }(T)\end{array}$ \\
\hline First specimen & $526.7 \mathrm{~g}$ & $142 \mathrm{~mm}$ & $117 \mathrm{~mm}$ & $58 \mathrm{~mm}$ \\
\hline Second specimen & $891 \mathrm{~g}$ & $160 \mathrm{~mm}$ & $133 \mathrm{~mm}$ & $80 \mathrm{~mm}$ \\
\hline
\end{tabular}

All body, legs and parts of spider crab measurements were made in laboratory using some equipment presented in Figure 10. A "KERN" scale, with maximum weight of $4000 \pm 0.1$ $\mathrm{g}$, was used to determine the mass of the parts and whole body. A protractor with $180^{\circ}$ was used to measure the angles and amplitude - range of motion - of every joint. Finally, a micrometer was used to measure the length and diameter of each segment of the leg and scissors were used to separate the various legs segments (see Figure 10). 


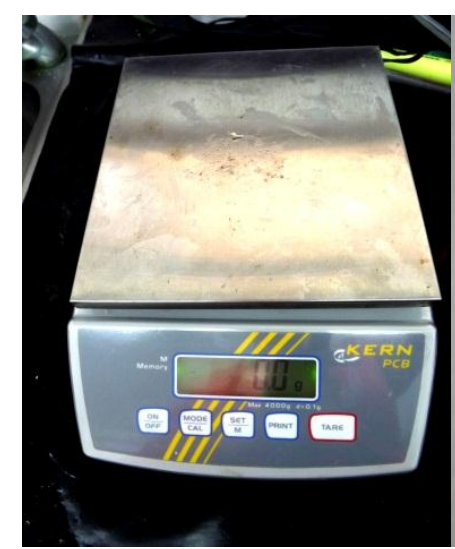

(a)

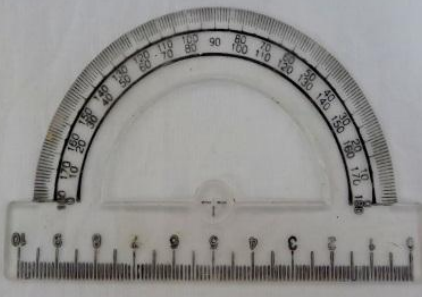

(b)

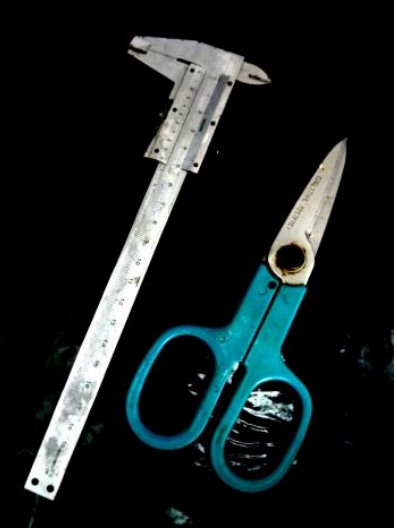

(c)

Figure 10 Instruments used for the anthropometric analysis of Maja brachydactyla: (a)- scales, (b)- protractor, (c)- micrometer and scissors

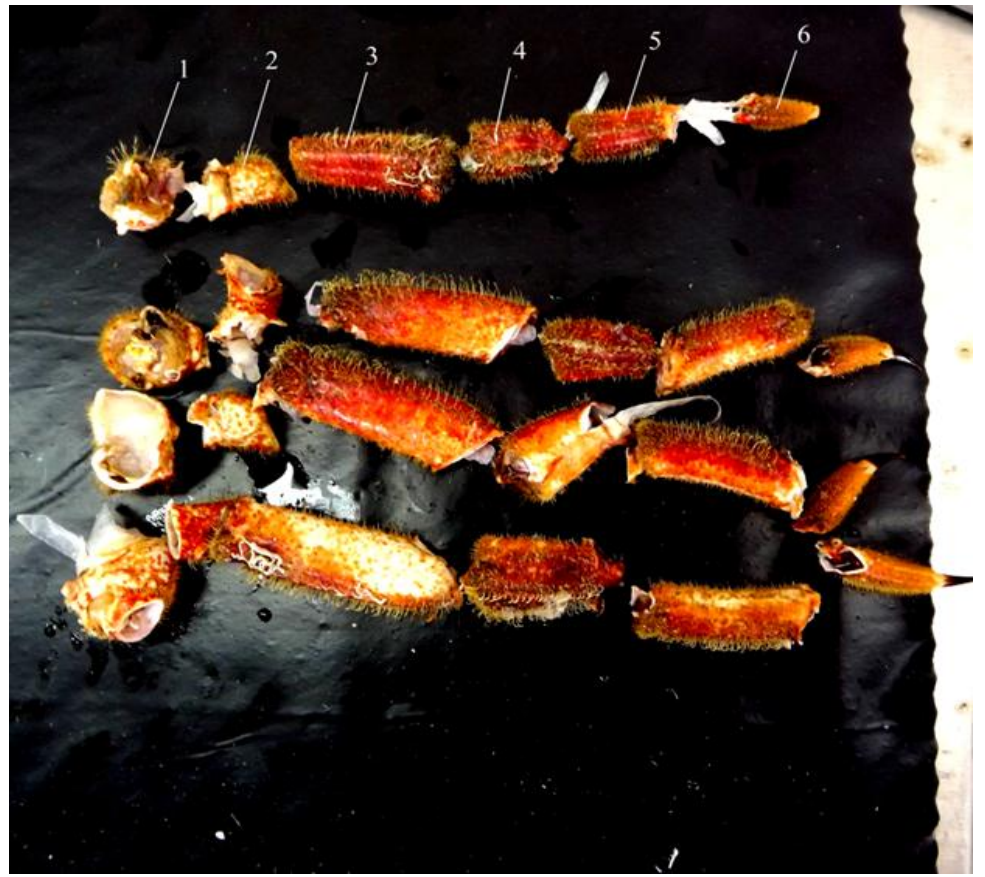

\section{Figure 11 Legs of Maja brachydactyla, cut in segments}

Figure 11 presents a photo of the Maja brachydactyla crab left legs, cut in segments. The segments were numbered by order and measured using the above mentioned equipment. The following tables (see Tables 3 and 4) include all the measurements data collected on the various segments of each leg. 
Table 3 Measurements of the left legs of the first specimen

\begin{tabular}{|c|c|c|c|c|c|c|}
\hline $\begin{array}{c}\text { Leg } \\
\text { Number }\end{array}$ & $\begin{array}{l}\text { Segments } \\
\text { of leg } n\end{array}$ & $\begin{array}{l}\text { Movement } \\
\text { of the leg } \\
\text { between } \\
\text { joints } \\
\text { around } \\
\text { axis: }\end{array}$ & $\begin{array}{l}\text { Amplitude } \\
\text { of } \\
\text { movement } \\
\text { between } \\
\text { joints } \alpha\left(^{\circ}\right)\end{array}$ & $\begin{array}{l}\text { Length of } \\
\text { the } \\
\text { segment } \\
l_{x}(\mathrm{~mm})\end{array}$ & $\begin{array}{l}\text { Diameter } \\
\text { of the } \\
\text { segment } \\
d_{x}(\mathrm{~mm})\end{array}$ & $\begin{array}{l}\text { Mass of } \\
\text { the } \\
\text { segment } \\
m_{x}(\mathrm{~g})\end{array}$ \\
\hline \multirow{6}{*}{ left leg $\boldsymbol{L}_{\mathbf{4}}$} & 1 & $z$ & $90^{\circ}$ & 12 & 16 & 1.6 \\
\hline & 2 & $y$ & $90^{\circ}$ & 10 & 10 & 1.1 \\
\hline & 3 & $z$ & $20^{\circ}$ & 34 & 12 & 3.4 \\
\hline & 4 & $y$ & $120^{\circ}$ & 21 & 10 & 1.8 \\
\hline & 5 & $z$ & $70^{\circ}$ & 21 & 9 & 1.6 \\
\hline & 6 & $y$ & $90^{\circ}$ & 23 & 5 & 0.4 \\
\hline \multirow{6}{*}{ left leg $\boldsymbol{L}_{3}$} & 1 & $z$ & $90^{\circ}$ & 11 & 20 & 2.8 \\
\hline & 2 & $y$ & $90^{\circ}$ & 14 & 10 & 1.3 \\
\hline & 3 & $z$ & $30^{\circ}$ & 37 & 13 & 5.6 \\
\hline & 4 & $y$ & $120^{\circ}$ & 23 & 11 & 2.4 \\
\hline & 5 & $z$ & $80^{\circ}$ & 26 & 9 & 1.8 \\
\hline & 6 & $y$ & $90^{\circ}$ & 23 & 6 & 0.5 \\
\hline \multirow{6}{*}{ left leg $\boldsymbol{L}_{\mathbf{2}}$} & 1 & $z$ & $90^{\circ}$ & 12 & 18 & 3.0 \\
\hline & 2 & $y$ & $100^{\circ}$ & 14 & 11 & 1.2 \\
\hline & 3 & $z$ & $30^{\circ}$ & 45 & 14 & 6.9 \\
\hline & 4 & $y$ & $120^{\circ}$ & 27 & 15 & 2.8 \\
\hline & 5 & $z$ & $90^{\circ}$ & 28 & 10 & 3.3 \\
\hline & 6 & $y$ & $90^{\circ}$ & 30 & 6 & 0.5 \\
\hline \multirow{6}{*}{ left leg $\boldsymbol{L}_{\mathbf{1}}$} & 1 & $z$ & $90^{\circ}$ & 12 & 18 & 3.7 \\
\hline & 2 & $y$ & $90^{\circ}$ & 11 & 12 & 1.1 \\
\hline & 3 & $z$ & $20^{\circ}$ & 45 & 14 & 7.6 \\
\hline & 4 & $y$ & $120^{\circ}$ & 27 & 12 & 3.6 \\
\hline & 5 & $z$ & $60^{\circ}$ & 34 & 10 & 3.1 \\
\hline & 6 & $y$ & $90^{\circ}$ & 33 & 7 & 0.8 \\
\hline \multirow{6}{*}{$\begin{array}{c}\text { left claw } \\
\boldsymbol{L}_{\boldsymbol{c}}\end{array}$} & 1 & $z$ & $90^{\circ}$ & 10 & 18 & 2.8 \\
\hline & 2 & $y$ & $130^{\circ}$ & 20 & 11 & 2.0 \\
\hline & 3 & $z$ & $90^{\circ}$ & 29 & 11 & 3.3 \\
\hline & 4 & $y$ & $120^{\circ}$ & 26 & 11 & 2.2 \\
\hline & 5 & $z$ & $140^{\circ}$ & 51 & 9 & 2.6 \\
\hline & 6 (claw) & $y$ & $30^{\circ}$ & 27 & 3 & 0.4 \\
\hline
\end{tabular}


Table 4 Measurements of the right legs of the first specimen

\begin{tabular}{|c|c|c|c|c|c|c|}
\hline $\begin{array}{c}\text { Leg } \\
\text { Number }\end{array}$ & $\begin{array}{l}\text { Segments } \\
\text { of leg } n\end{array}$ & $\begin{array}{l}\text { Movement } \\
\text { of the leg } \\
\text { between } \\
\text { joints } \\
\text { around } \\
\text { axis: }\end{array}$ & $\begin{array}{l}\text { Amplitude } \\
\text { of } \\
\text { movement } \\
\text { between } \\
\text { joints } \alpha\left(^{\circ}\right)\end{array}$ & $\begin{array}{c}\text { Length of } \\
\text { the } \\
\text { segment } \\
l_{x}(\mathrm{~mm})\end{array}$ & $\begin{array}{l}\text { Diameter } \\
\text { of the } \\
\text { segment } \\
d_{x}(\mathrm{~mm})\end{array}$ & $\begin{array}{c}\text { Mass of } \\
\text { the } \\
\text { segment } \\
m_{x}(\mathrm{~g})\end{array}$ \\
\hline \multirow{6}{*}{$\begin{array}{c}\text { right leg } \\
\boldsymbol{R}_{\mathbf{4}}\end{array}$} & 1 & $z$ & $90^{\circ}$ & 13 & 16 & 1.6 \\
\hline & 2 & $y$ & $90^{\circ}$ & 11 & 10 & 1.2 \\
\hline & 3 & $z$ & $20^{\circ}$ & 33 & 12 & 3.4 \\
\hline & 4 & $y$ & $120^{\circ}$ & 22 & 11 & 1.9 \\
\hline & 5 & $z$ & $80^{\circ}$ & 22 & 10 & 1.8 \\
\hline & 6 & $y$ & $90^{\circ}$ & 24 & 5 & 0.5 \\
\hline \multirow{6}{*}{$\begin{array}{c}\text { right leg } \\
\boldsymbol{R}_{\mathbf{3}}\end{array}$} & 1 & $z$ & $80^{\circ}$ & 12 & 18 & 2.6 \\
\hline & 2 & $y$ & $90^{\circ}$ & 15 & 11 & 1.4 \\
\hline & 3 & $z$ & $20^{\circ}$ & 38 & 13 & 5.4 \\
\hline & 4 & $y$ & $120^{\circ}$ & 22 & 10 & 2.4 \\
\hline & 5 & $z$ & $80^{\circ}$ & 26 & 10 & 2.3 \\
\hline & 6 & $y$ & $90^{\circ}$ & 24 & 6 & 0.5 \\
\hline \multirow{6}{*}{$\begin{array}{c}\text { right leg } \\
\boldsymbol{R}_{\mathbf{2}}\end{array}$} & 1 & $z$ & $90^{\circ}$ & 14 & 16 & 3.8 \\
\hline & 2 & $y$ & $100^{\circ}$ & 15 & 10 & 1.3 \\
\hline & 3 & $z$ & $20^{\circ}$ & 44 & 13 & 5.2 \\
\hline & 4 & $y$ & $120^{\circ}$ & 23 & 12 & 2.4 \\
\hline & 5 & $z$ & $80^{\circ}$ & 27 & 10 & 3.5 \\
\hline & 6 & $y$ & $90^{\circ}$ & 30 & 6 & 0.4 \\
\hline \multirow{6}{*}{$\begin{array}{c}\text { right leg } \\
\boldsymbol{R}_{\mathbf{1}}\end{array}$} & 1 & $z$ & $90^{\circ}$ & 12 & 16 & 3.8 \\
\hline & 2 & $y$ & $90^{\circ}$ & 13 & 11 & 1.5 \\
\hline & 3 & $z$ & $20^{\circ}$ & 50 & 14 & 7.3 \\
\hline & 4 & $y$ & $110^{\circ}$ & 29 & 12 & 3.4 \\
\hline & 5 & $z$ & $70^{\circ}$ & 33 & 10 & 3.4 \\
\hline & 6 & $y$ & $90^{\circ}$ & 29 & 6 & 0.7 \\
\hline \multirow{6}{*}{$\begin{array}{l}\text { right claw } \\
\boldsymbol{R}_{\boldsymbol{c}}\end{array}$} & 1 & $z$ & $90^{\circ}$ & 12 & 17 & 3.3 \\
\hline & 2 & $y$ & $120^{\circ}$ & 18 & 11 & 2.3 \\
\hline & 3 & $z$ & $90^{\circ}$ & 30 & 12 & 3.2 \\
\hline & 4 & $y$ & $130^{\circ}$ & 25 & 11 & 2.3 \\
\hline & 5 & $z$ & $120^{\circ}$ & 53 & 7 & 2.4 \\
\hline & 6 (claw) & $y$ & $30^{\circ}$ & 23 & 3 & 0.4 \\
\hline
\end{tabular}

During the experimental measurements, the legs of the crab were cut, and the mass of the body of the crab without legs was measured, being $M_{b}=335 \mathrm{~g}$. This result implies that the legs should have a mass of: 


$$
\Delta M=M-M_{b}=526.7-335=191.7 \mathrm{~g}
$$

From formula (2) it is possible to see the difference between the masses of the crab with and without legs. Summing the masses of each segment of every leg obtained during measurements, one gets.

$$
\begin{gathered}
\sum m_{L}=m_{L(4)}+m_{L(3)}+m_{L(2)}+m_{L(1)}+m_{L(c)}+ \\
+m_{R(4)}+m_{R(3)}+m_{R(2)}+m_{R(1)}+m_{R(c)} ; \\
\sum m_{L}=10.1+15.1+17.8+20.1+13.4+10.6+15.2+17.1+20.5+14.1=154 \mathrm{~g} . \\
\sum m_{x}=m_{L x(4)}+m_{L x(3)}+m_{L x(2)}+m_{L x(1)}+m_{x(c)}+ \\
+m_{R x(4)}+m_{R x(3)}+m_{R x(2)}+m_{R x(1)}+m_{R x(c)} ; \\
\sum m_{x}=9.9+14.4+17.7+19.9+12.9+10.4+14.6+16.6+20.1+13.5=150 \mathrm{~g} .
\end{gathered}
$$

These differences of mass can be easily explained, since while the crab was being cut, water was observed coming out from inside its body, accounting therefore for this difference, although we were not able to determine the water mass lost.

In order to establish the equivalent to an anthropometric table for this crustacean, the first specimen will be used since the full data for the second one is inexistent.

As can be seen from the tables with the measurements data, there is some difference in mass, length, amplitude and diameter between left and right legs. In order to simplify the biomechanical model that will be developed, data for the legs on both sides of the body should be the same. Therefore, the average of the values found (for the left and right legs) is determined and will be used in subsequent calculations (see Table 5). 
Table 5 Average of the leg characteristic values of the first specimen

\begin{tabular}{|c|c|c|c|c|c|c|}
\hline $\begin{array}{l}\text { Medium } \\
\text { average of } \\
\text { the leg }\end{array}$ & $\begin{array}{c}\text { Segmen } \\
\text { ts of leg } \\
n\end{array}$ & $\begin{array}{c}\text { Movement } \\
\text { of the leg } \\
\text { between } \\
\text { joints } \\
\text { around } \\
\text { axis: }\end{array}$ & $\begin{array}{l}\text { Amplitude } \\
\text { of } \\
\text { movement } \\
\text { between } \\
\text { joints } \alpha\left(^{\circ}\right)\end{array}$ & $\begin{array}{l}\text { Length of } \\
\text { the } \\
\text { segment } \\
l_{x}(\mathrm{~mm})\end{array}$ & $\begin{array}{l}\text { Diameter } \\
\text { of the } \\
\text { segment } \\
d_{x}(\mathrm{~mm})\end{array}$ & $\begin{array}{l}\text { Mass of } \\
\text { the } \\
\text { segment } \\
m_{x}(\mathrm{~g})\end{array}$ \\
\hline \multirow{6}{*}{$\left(\left(\boldsymbol{L}_{\mathbf{4}}+\boldsymbol{R}_{\mathbf{4}}\right) / 2\right)$} & 1 & $z$ & $90^{\circ}$ & 12.5 & 16 & 1.6 \\
\hline & 2 & $y$ & $90^{\circ}$ & 10.5 & 10 & 1.15 \\
\hline & 3 & $z$ & $20^{\circ}$ & 33.5 & 12 & 3.4 \\
\hline & 4 & $y$ & $120^{\circ}$ & 21.5 & 10.5 & 1.85 \\
\hline & 5 & $z$ & $75^{\circ}$ & 21.5 & 9.5 & 1.7 \\
\hline & 6 & $y$ & $90^{\circ}$ & 23.5 & 5 & 0.45 \\
\hline \multirow{6}{*}{$\left(\left(\boldsymbol{L}_{\mathbf{3}}+\boldsymbol{R}_{\mathbf{3}}\right) / 2\right)$} & 1 & $z$ & $85^{\circ}$ & 11.5 & 19 & 2.7 \\
\hline & 2 & $y$ & $90^{\circ}$ & 14.5 & 10.5 & 1.35 \\
\hline & 3 & $z$ & $25^{\circ}$ & 37.5 & 13 & 5.5 \\
\hline & 4 & $y$ & $120^{\circ}$ & 22.5 & 10.5 & 2.4 \\
\hline & 5 & $z$ & $80^{\circ}$ & 26 & 9.5 & 2.05 \\
\hline & 6 & $y$ & $90^{\circ}$ & 23.5 & 6 & 0.5 \\
\hline \multirow{6}{*}{$\left(\left(\boldsymbol{L}_{\mathbf{2}}+\boldsymbol{R}_{\mathbf{2}}\right) / 2\right)$} & 1 & $z$ & $90^{\circ}$ & 13 & 17 & 3.4 \\
\hline & 2 & $y$ & $100^{\circ}$ & 14.5 & 10.5 & 1.25 \\
\hline & 3 & $z$ & $25^{\circ}$ & 44.5 & 13.5 & 6.05 \\
\hline & 4 & $y$ & $120^{\circ}$ & 25 & 13.5 & 2.6 \\
\hline & 5 & $z$ & $80^{\circ}$ & 27.5 & 10 & 3.4 \\
\hline & 6 & $y$ & $90^{\circ}$ & 30 & 6 & 0.45 \\
\hline \multirow{6}{*}{$\left(\left(\boldsymbol{L}_{\mathbf{1}}+\boldsymbol{R}_{\mathbf{1}}\right) / 2\right)$} & 1 & $z$ & $90^{\circ}$ & 12 & 17 & 3.75 \\
\hline & 2 & $y$ & $90^{\circ}$ & 12 & 11.5 & 1.3 \\
\hline & 3 & $z$ & $20^{\circ}$ & 47.5 & 14 & 7.45 \\
\hline & 4 & $y$ & $115^{\circ}$ & 28 & 12 & 3.5 \\
\hline & 5 & $z$ & $65^{\circ}$ & 33.5 & 10 & 3.25 \\
\hline & 6 & $y$ & $90^{\circ}$ & 31 & 6.5 & 0.75 \\
\hline \multirow{6}{*}{$\left(\left(\boldsymbol{L}_{\boldsymbol{c}}+\boldsymbol{R}_{\boldsymbol{c}}\right) / 2\right)$} & 1 & $z$ & $90^{\circ}$ & 11 & 17.5 & 3.05 \\
\hline & 2 & $y$ & $125^{\circ}$ & 19 & 11 & 2.15 \\
\hline & 3 & $z$ & $90^{\circ}$ & 29.5 & 11.5 & 3.25 \\
\hline & 4 & $y$ & $125^{\circ}$ & 25.5 & 11 & 2.25 \\
\hline & 5 & $z$ & $130^{\circ}$ & 52 & 8 & 2.5 \\
\hline & 6 & $y$ & $30^{\circ}$ & 25 & 3 & 0.4 \\
\hline
\end{tabular}

\subsection{Determination Of The SEgments Center of Mass}

The center of mass coordinates are given as a percentage of the segment length on the subsequent (distal) and closer (proximal) end (this amount will be later called the coefficient) in the local (segment) referential. The segment center of mass for a particular 
segment is calculated by multiplying the relative position by the segment's length, according to the formula (5) (see Table 6):

$$
r_{\text {proximal }}=R_{\text {proximal }} \cdot l_{x}
$$

Where:

$r_{\text {proximal }}{ }^{-}$distance from the center of mass to proximal segment end $(\mathrm{mm})$;

$R_{\text {proximal }}$ - distance of segment center of mass proportional to the length of the segment

$\left(R_{\text {proximal }}=0.433\right)[17]$;

$l_{x}$ - segment length $(\mathrm{mm})$.

Table $6 r_{\text {proximal }}$ for each segment of crab's leg

\begin{tabular}{|c|c|c|c|c|c|c|}
\hline $\begin{array}{c}\text { Leg } \\
\text { number }\end{array}$ & $r_{\text {prox } 1}$ & $r_{\text {prox } 2}$ & $r_{\text {prox } 3}$ & $r_{\text {prox }}$ & $r_{\text {prox } 5}$ & $r_{\text {prox6 }}$ \\
\hline 4 & 5.4125 & 4.5465 & 14.5055 & 9.3095 & 9.3095 & 10.1755 \\
\hline 3 & 4.9795 & 6.2785 & 16.2375 & 9.7425 & 11.2580 & 10.1755 \\
\hline 2 & 5.6290 & 6.2785 & 19.2685 & 10.8250 & 11.9075 & 12.9900 \\
\hline 1 & 5.1960 & 5.1960 & 20.5675 & 12.1240 & 14.5055 & 13.4230 \\
\hline claw & 4.7630 & 8.2270 & 12.7735 & 11.0425 & 22.5160 & 10.8250 \\
\hline
\end{tabular}

\subsection{LOCOMOTION OF MAJA BRACHYDACTYLA}

This section deals with the biomechanics of walking and locomotion. Walking is an automatic motor action which occurs as a result of complex coordinated activity of the skeletal muscles of the trunk and extremities. The motion of the individual units of the free leg is determined not only by muscle contraction but also by inertia. The closer the link to the body, the less inertia and the sooner it may follow the body. From the perspective of a nervous mechanism, walking is an automated chain-reflex in which afferent impulses, which accompanies each element of the previous motion, signal the next [5]. 
Chronogram is a schedule when for each operation is given a well-defined amount of time on the chart, and all operations are arranged in series.

Videos were used to make the chronogram of walking crabs, which were made by filming alive crabs in ELA (see Figure 12). It was used a small aquarium, where was only one crab. On the bottom of the aquarium, was placed a waterproof centimeter paper, which was fixed with weights. Extra lights and a camera with the corresponding tripod were used for filming.

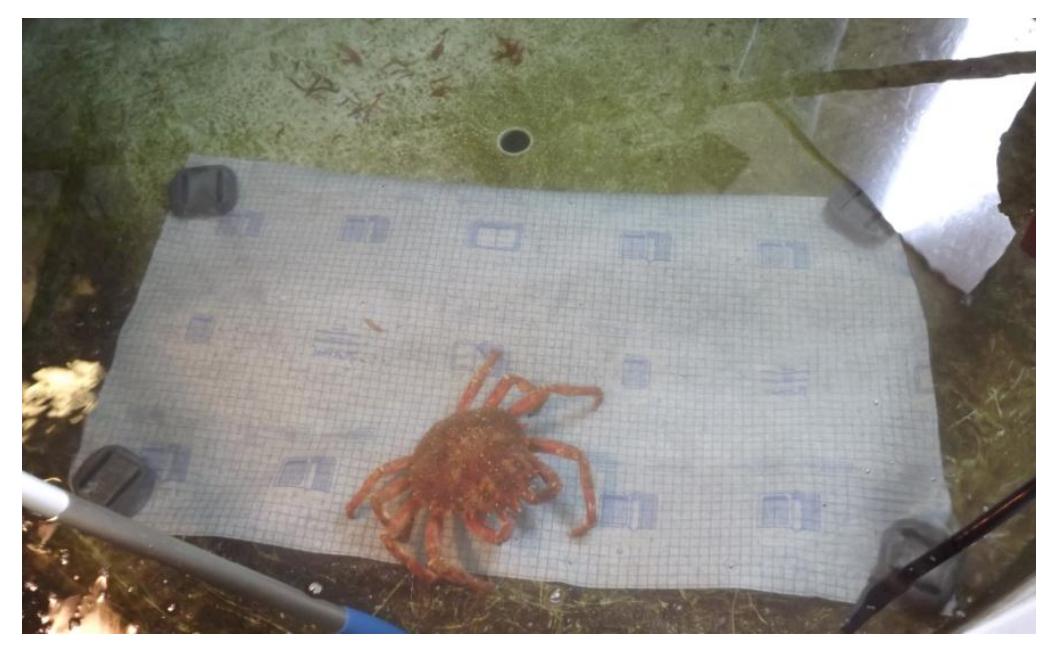

Figure 12 Filming Maja brachydactyla in ELA

Figure 13 presents a chronogram of the spider crab locomotion sideways. The shaded parts of the chronogram are the time instants when a leg is on the ground; the white ones are when a leg makes a movement in the air. The chronograms were made manually, by watching videos at low speed. Due to the video resolution, the filming material was not of good quality.

\begin{tabular}{|c|l|l|l|l|l|l|l|l|}
\hline & $1 \mathrm{sec}$ & $2 \mathrm{sec}$ & $3 \mathrm{sec}$ & $4 \mathrm{sec}$ & $5 \mathrm{sec}$ & $6 \mathrm{sec}$ & $7 \mathrm{sec}$ & $8 \mathrm{sec}$ \\
\hline$R_{4}$ & & & & & & & & \\
\hline$L_{4}$ & & & & & & & & \\
\hline$R_{3}$ & & & & & & & & \\
\hline$L_{3}$ & & & & & & & & \\
\hline$R_{2}$ & & & & & & & & \\
\hline$L_{2}$ & & & & & & & & \\
\hline$R_{1}$ & & & & & & & & \\
\hline$L_{1}$ & & & & & & & & \\
\hline
\end{tabular}

Figure 13 Chronogram of a crab walking sideways 
The next chronogram (presented in Figure 14), was made using the same video, while the crab was also moving sideways. The different colors show the movement of the leg during one second. The scale of the chronogram is 1:5, meaning that in one second the crab's leg can move $7.5 \mathrm{~cm}$. Also all legs move in different moments, chronogram shows that during the third second legs $L_{1}, L_{2}, L_{4}, R_{2}$ make less motion than legs $L_{3}, R_{1}, R_{3}, R_{4}$ (the crab is using these legs for support).

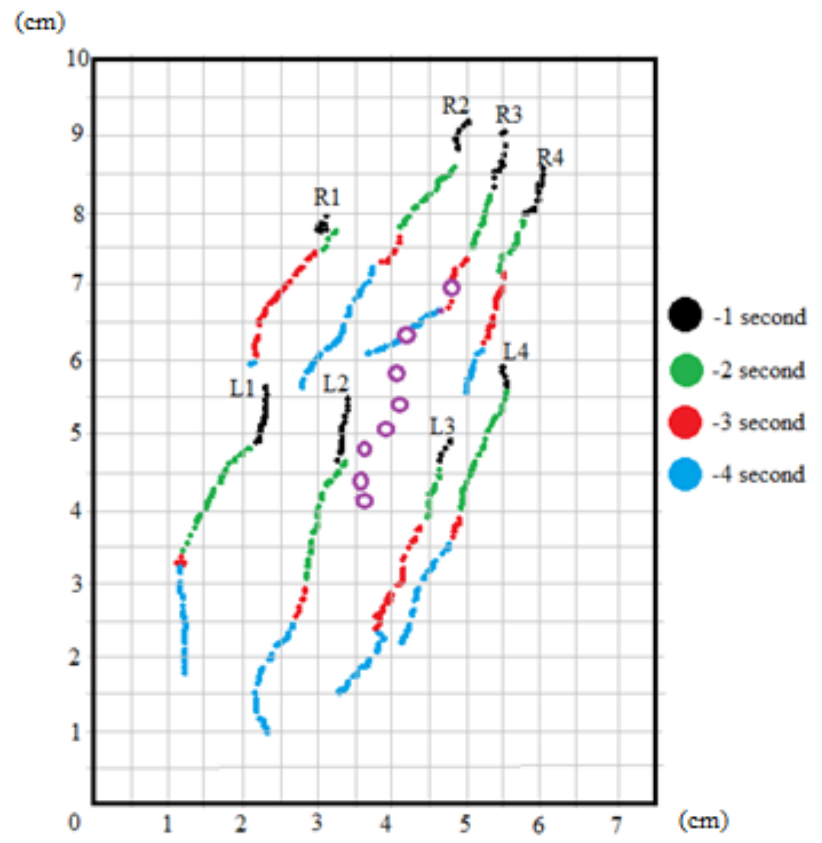

Figure 14 The chronogram of normal walking of Maja brachydactyla (scale 1:5)

The next video (a frame of which can be seen in Figure 15) was made in ELA, in the main aquarium, to see how the crab is moving in a natural environment. In contrast, this video was not made from the top, but from the side to see the trajectory of each moving leg.

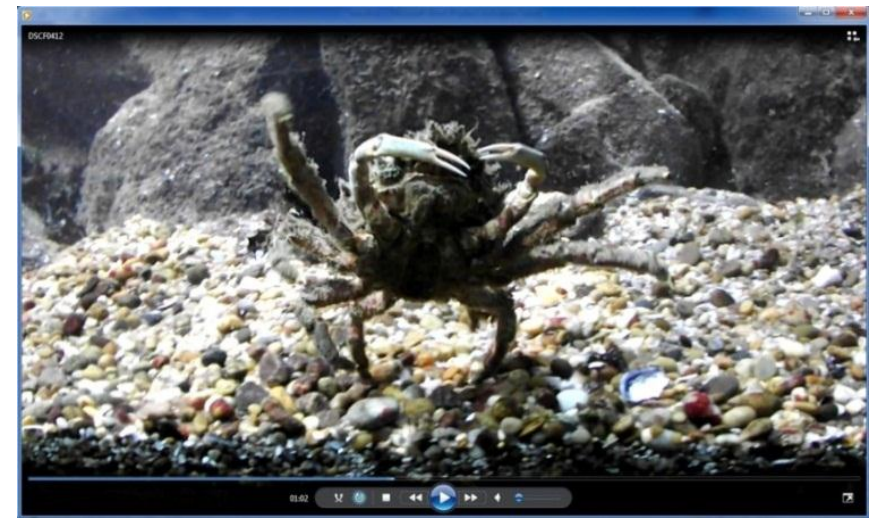

Figure 15 Maja Brachydactyla locomoting in an aquarium 
Figure 16 shows the trajectory of the left leg (L3) while moving. First, the crab moves the leg up (points 1-4) by rotating the "hip" joint; after this starts the movement of the "knee" joint (points 4-7) and, finally, using the "hip" joint, the crab moves the leg down and puts the foot on the ground (points 7-9, being 9 the final foothold). After this motion, the leg pushes the body and the crab "moves".

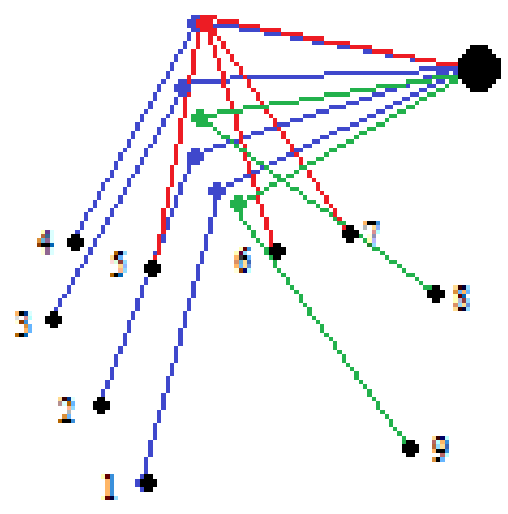

Figure 16 Locomotion diagram of the leg $L_{3}$

Figure 17 is a photo of the left leg $\left(L_{3}\right)$, with indications of the hip and knee. Crabs do not have a whole lot of movement from their "hip" joint (1 degrees of freedom, in $z$ plane), but they can bend their legs at the "knee" joints (see Figure 18). Because of the way their legs face (to the sides) this means that it's much easier for them to walk sideways.

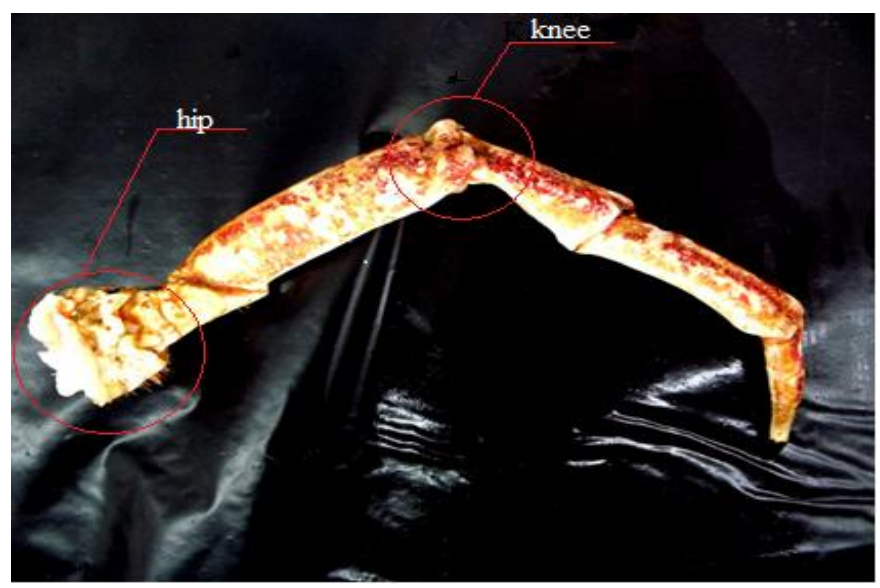

Figure 17 Leg $L_{3}$ of Maja brachydactyla 

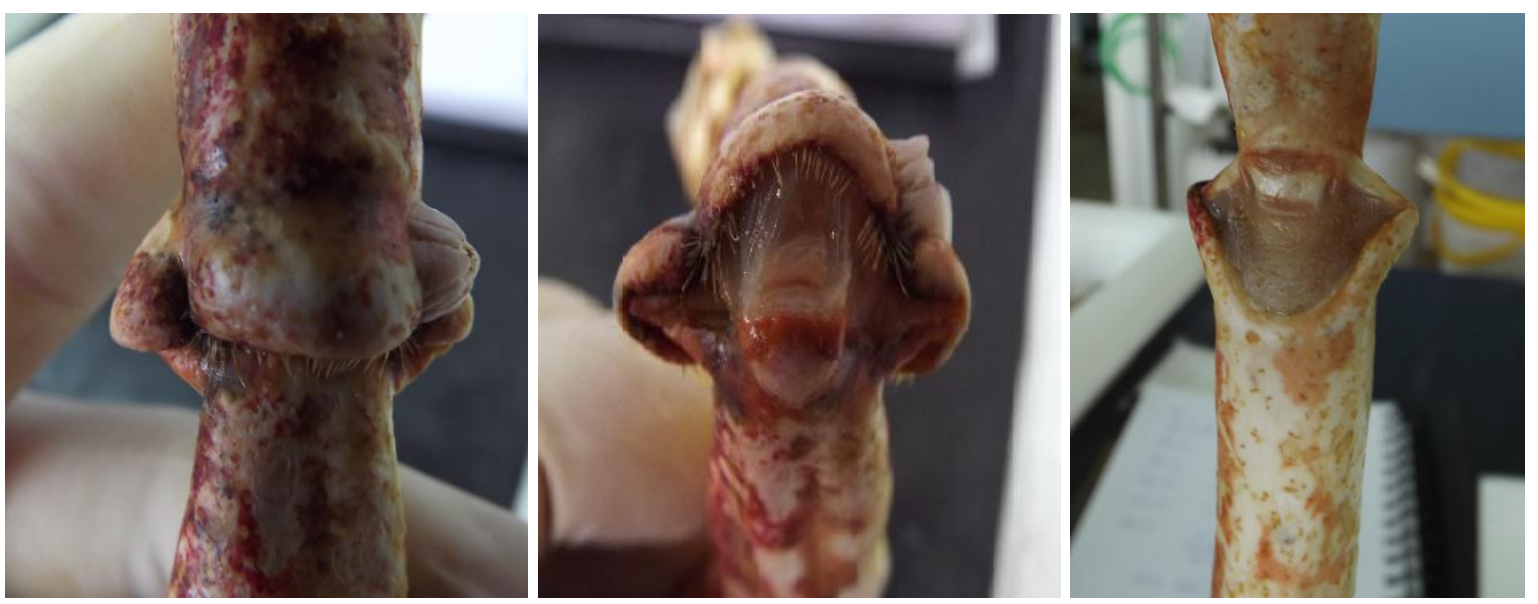

Figure 18 Knee joint of Maja brachydactyla

Some crabs are able to walk forward though. Crabs crawl along the bottom by using four pairs of legs. Crabs bend and unbend legs consistently, and the same pair of left and right leg never operates simultaneously [6].

The leg consists of a series of movable articulated elements, whose mass is reduced towards the distal end. All joint allows movements around the $z$ and $y$ axis; this leads to leg flexion and rotation in plane. While walking the center of gravity of the crab is moving horizontally. Due to the rotation in the joints and the leg flexion and extension, the animal can move the tip of the leg in a straight parallel line to the direction of motion.

The leg is working as a mechanical lever, which moves with a large force relatively of small weight over long distances, thus providing a fast walking. The mass of the limbs decreases from the base to the distal end [7]. 



\section{KinEMATIC MODEL}

Most walking robots are very complex mechanical systems, featuring in variable structures. During this study, three basic concepts for the locomotion system of a robot are found for flexible moving [10]. First are the multi-legged robots, there are concepts from 2 to 8 legged robots with a lot of different joint and leg position combinations [11]. Crawler robot could have configurations like a tank or a land-mines detecting and clearing robot. Third are the robots on wheels [12].

Potential use for walking robots is based on their advantages over wheeled vehicles. A walking platform can explore rough terrain with obstacles, like a forest or rocky environment, where a wheeled vehicle does not present that flexibility. Thus, there are some advantages for using legged robots in traditional vehicle applications, such as military missions, inspection of complex or dangerous scenarios, terrestrial, forestry and agricultural tasks and civil projects, for example. Nevertheless, legged robots are also used for experimental studies on the behavior of living animals and for testing ArtificialIntelligence (AI) techniques.

The available options in legged robots are enormous, with configurations varying among 2 legged (Humanoid), 4 legged (Quadrupeds), 6 legged (Hexapod) and the 8 legged (Octopod) configurations like spiders. 
In this thesis it is modeled and simulated the spider crab, that has 10 legs (Decapod), but for the purpose of locomotion simulation it is considered a simpler model of the crab using just 8 legs (Octopod).

\subsection{KineMATICS}

All machines are made up of mechanisms that are designed to ensure compliance with the required functions. Depending on the complexity circuit machines, can have multiple mechanisms simultaneously [14].

A mechanism is a technical system consisting of mobile units, racks, and kinematic pairs forming the kinematic chain. In general, the quality of the structure is determined by the mechanism: simple design, manufacturability units, efficiency, reliability, durability, size and weight [14].

A kinematic pair is a combination of two adjoining units, allowing their relative motion. In the higher kinematic pairs the contact element is a line or point, as can be seen is Table 7 (cylinder-plane, ball-plane). In the lower kinematic pairs the contact element is a surface, as presented in Table 7 (translational, rotational, and spherical) [14]. 
Table 7 Types of kinematic pairs [14]

\begin{tabular}{|c|c|c|c|}
\hline Name & Constructive image & Image & Number \\
\hline Translational & & & $(W=1)$ \\
\hline Rotational & & & $(\mathrm{W}=1)$ \\
\hline $\begin{array}{l}\text { Spherical } \\
\text { with finger }\end{array}$ & & & $(\mathrm{W}=2)$ \\
\hline Spherical & & & $(W=3)$ \\
\hline Cylinder-plane & & & $(W=4)$ \\
\hline Ball-plane & & & $(W=5)$ \\
\hline
\end{tabular}

\subsection{NUMBER OF DEGREES OF FREEDOM}

An absolutely free rigid body (link), while in three-dimensional space, can make a maximum of six independent movements: three rotational (around the axes $x, y, z$ ) and three translational motions, along the same axis, as depicted in Figure 19 [14].

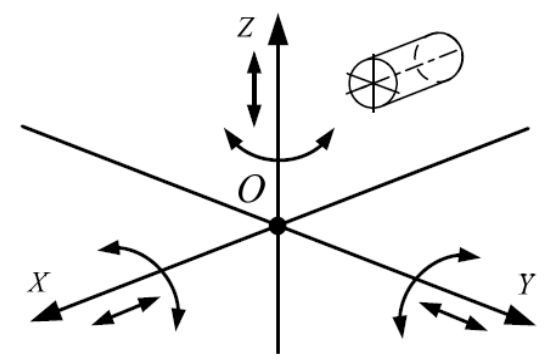

Figure 19 The scheme of free movements of the body in three dimensions [14] 
The number of degrees of freedom of a mechanical system is the number $(S)$ of independent parameters defining the position of all elements of the system. A free body in space has six degrees of freedom $(S=6)$, because it can perform six independent movements - three translations along the coordinate axes and three rotations - around the same axes [14].

To determine the number of degrees of freedom of spatial mechanisms Malyshev formula (6) applies [14]:

$$
S=6 n-5 p_{1}-4 p_{2}-3 p_{3}-2 p_{4}-p_{5}
$$

Where:

$n$ - number of mobile units,

$p_{1}$ - number of a one-mobile $(S=1)$ kinematic pairs,

$p_{2}$ - number of two-mobile $(S=2)$ kinematic pairs,

$p_{3}$ - number of three-mobile $(S=3)$ kinematic pairs,

$p_{4}$ - number of four-mobile $(S=4)$ kinematic pairs,

$p_{5}$ - number of five-mobile $(S=5)$ kinematic pairs.

Maja brachydactyla has four pairs of legs, and one pair of pincers. To correctly model the crab, it is needed to define the number of spatial degrees of freedom of the pincer (Figure 20) and single leg (Figure 21) of the Maja brachydactyla. Figure 20 represents the mechanism of the pincer (simple kinematic scheme). There are indicated the segments (from 1 to 5), the joints and the rotation above these joints. 


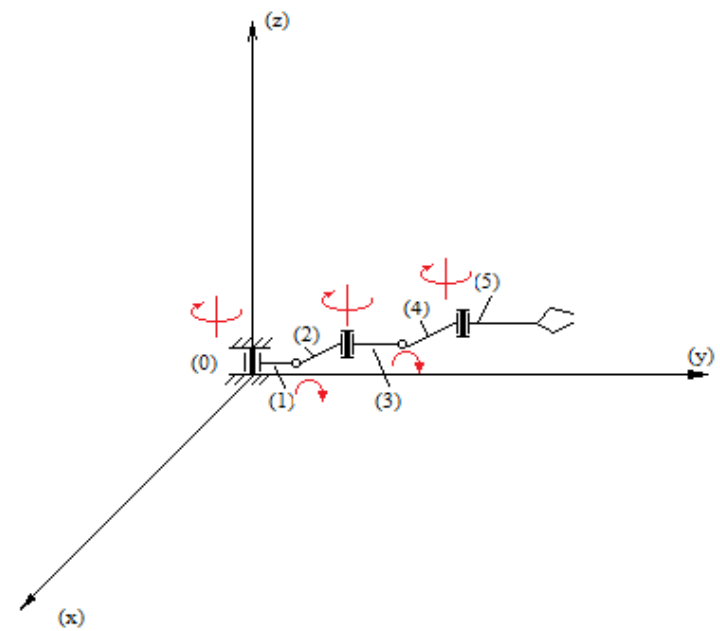

Figure 20 Mechanism of the pincer

Calculations of the number of degrees of freedom of a pincer are as follows:

$n=5$,

$p_{1}=5$ (links $\left.0-1,1-2,2-3,3-4,4-5\right)$,

$p_{2}=0$

$p_{3}=0$,

$p_{4}=0$,

$p_{5}=0$

$$
S=6 \cdot 5-5 \cdot 5-4 \cdot 0-3 \cdot 0-2 \cdot 0-0=5 .
$$

The pincer has five degrees of freedom. Links 0-1, 2-3, and 4-5 are moving around $z$ axis, links 1-2 and 3-4 are moving around $x$ axis, but all have different amplitudes (see Tables 3 and 4).

Revolute joints are used to construct the kinematic model (see Figures 20 and 21). There are six revolute joints that make rotational movements about the $z$ and $x$ axis; therefore the number of mobile units $(n)$ is six. In this case $p_{1}$ is easily calculated: in the scheme it is needed to be counted the one-mobile kinematic pairs. All of them will be one-mobile, because the revolute joint has mobility equal to one. 


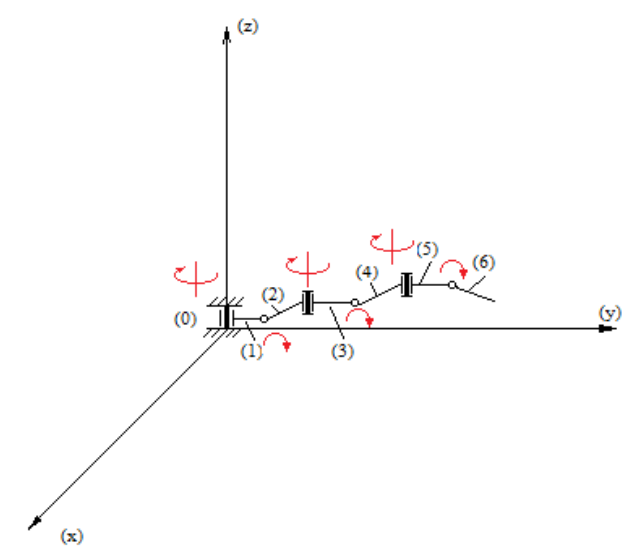

Figure 21 Mechanism of a single leg

For this case, calculations of the number of degrees of freedom of a single leg are as follows:

$n=6$,

$p_{1}=6$ (links $\left.0-1,1-2,2-3,3-4,4-5,5-6\right)$,

$p_{2}=0$,

$p_{3}=0$

$p_{4}=0$

$p_{5}=0$

$$
S=6 \cdot 6-5 \cdot 6-4 \cdot 0-3 \cdot 0-2 \cdot 0-0=6
$$

The legs of the spider crab have six degrees of freedom. Links 0-1, 2-3, and 4-5 are moving around $z$ axis, and links 1-2, 3-4, and 5-6 are moving around $x$ axis and all of them have different amplitude of motion (see Tables 3 and 4). Amplitudes of motion of the other legs of the crab are a little different, but since the "working" principle is the same, the number of degrees of freedom will not be affected.

In this project the kinematic scheme of the crab legs was changed. The first and second segments from each leg were connected in one, and all joints were changed to revolute around the $z$ axis.

The reasons for this is that the first and second segment of the legs were too small, only about $12 \mathrm{~mm}$, and it was hard to draw them in the SolidWorks environment and to make a control system in Simulink. However, these changes do not make a significant difference 
on the movement of the crab. The masses and lengths of the segments and body were not changed, and the data was taken as being the real one. Rotation of the segments was changed from revolute around the $z$ and $y$ axis to revolute about the $z$ axis. These changes were made since the simulations are going to be used to study the crab moving sideways, and the movements of the legs about the $y$ axis are used when the crab makes movements such as climbing on stones or rocks. Figure 22 shows the new kinematic model of leg. Implementing the above mentioned changes, the modeled leg of the spider crab has five degrees of freedom.

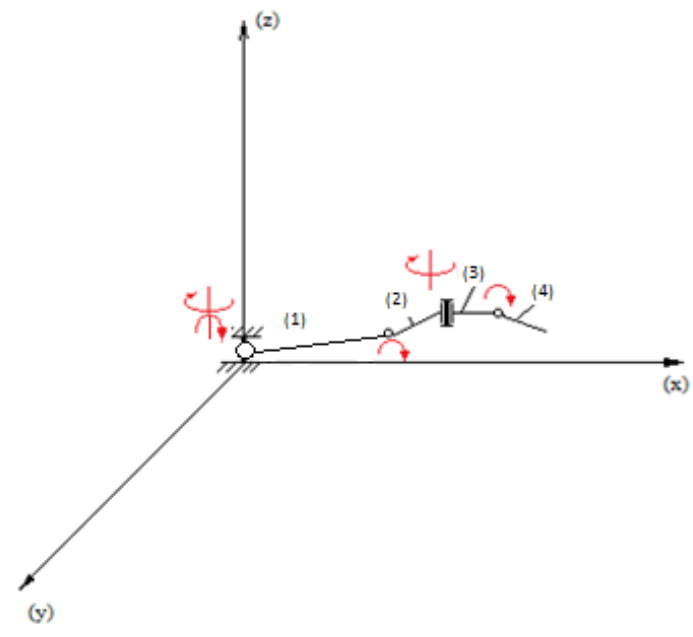

\section{Figure 22 Mechanism of a single leg}

In this situation, the computation of single leg degrees of freedom is:

$n=4$,

$p_{1}=3($ links 1-2, 2-3, 3-4),

$p_{2}=1($ link $0-1)$,

$p_{3}=0$,

$p_{4}=0$,

$p_{5}=0$,

$$
S=6 \cdot 4-5 \cdot 3-4 \cdot 1-3 \cdot 0-2 \cdot 0-0=5 .
$$




\subsection{SimMechanics Kinematic Model}

SimMechanics is a Simulink library package of the MATLAB environment, designed to simulate the mechanical motion of solids. Its main purpose is to model the spatial movements of solid-state machines in the engineering design stage, using the laws of theoretical mechanics [20].

Using the SimMechanics library, integrated into Simulink, it is possible to use all features of MATLAB, in particular, adding to the model of a mechanical system components from other libraries in Simulink and extensions of the system. The SimMechanics package can solve spatial problems of statics, kinematics and dynamics of multilink mechanical objects.

\subsubsection{SimMechanics Library Blocks}

SimMechanics library is a collection of blocks in the form of graphic icons with original titles in English. The SimMechanics library has seven main sections, as can be seen in Figure 23:

- Bodies;

- Joints;

- Constraints \& Drivers;

- Sensors \& Actuators;

- Force Elements;

- Interface Elements;

- Utilities.

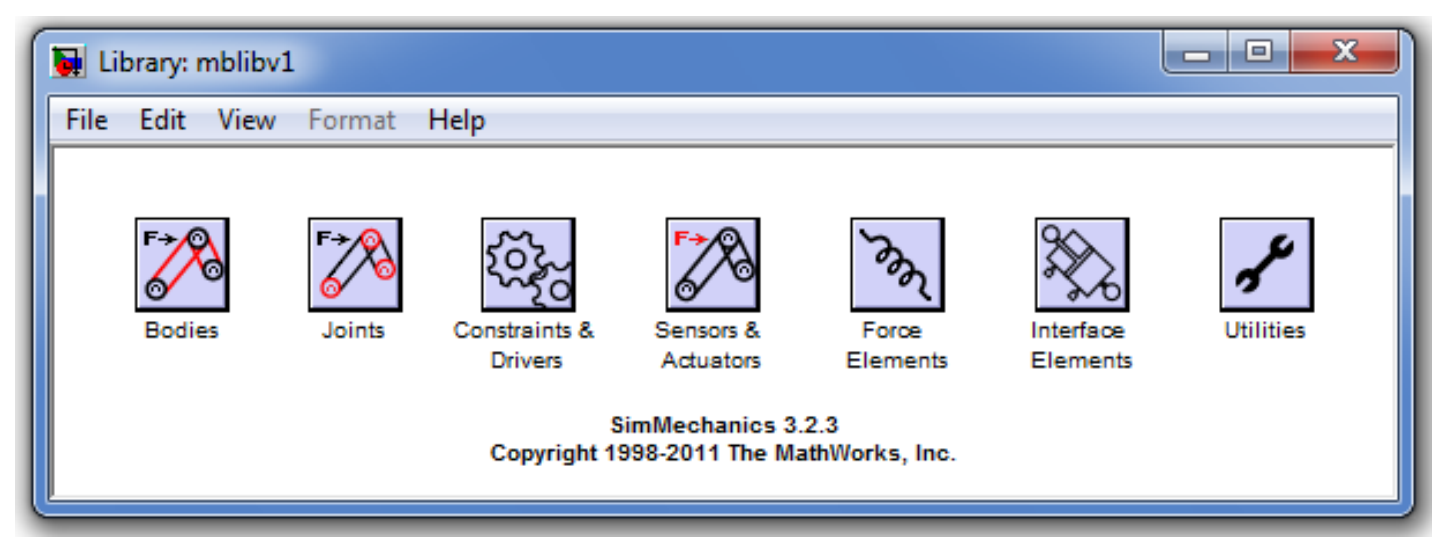

Figure 23 SimMechanics library

Each section contains blocks of a certain group. In the sequel these groups of blocks are examined in more detail. And more detailed will be described blocks that were used for this work. 


\subsubsection{Blocks of solid bodies (Bodies)}

This section of the SimMechanics library (see Figure 24) can be regarded as fundamental. It is necessary to begin creating a mechanical model, although it contains only four blocks.

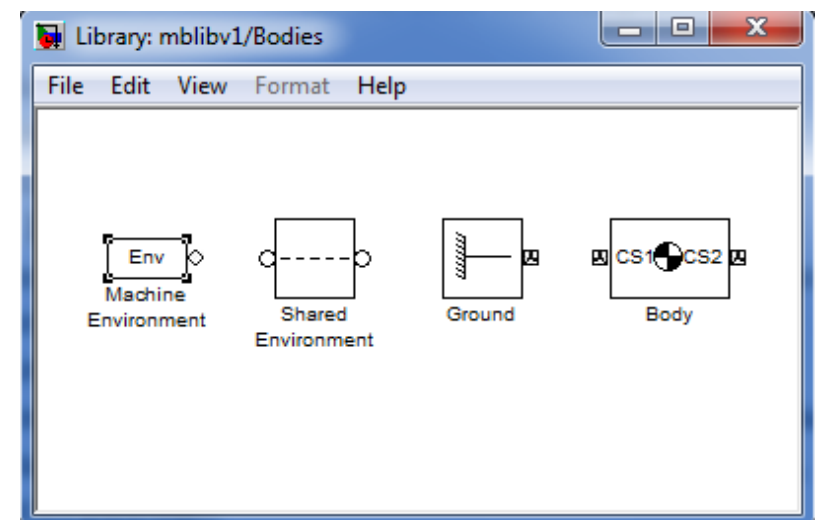

\section{Figure 24 SimMechanics Bodies library}

The Body block is a solid rigid body (separate link mechanism) with user-defined parameters.

The set of parameters are:

- body weight (Mass) which can be expressed in different units;

- the tensor of inertia about its center of mass (Inertia), which is a matrix of size $3 \times 3$ :

$$
H=\left\{\begin{array}{ccc}
J_{i x} & 0 & 0 \\
0 & J_{i y} & 0 \\
0 & 0 & J_{i z}
\end{array}\right\}
$$

Where $J_{i x}, J_{i y}, J_{i z}$ are the axial moments of inertia about the axes of their own local coordinate system associated with its center of mass. The expressions for calculating the elements of the inertia tensor for some of the most common symmetric bodies, of simple geometric form, are given in Table 8 . 
Table 8The elements of the tensor of inertia for bodies of simple shape

\begin{tabular}{|c|c|c|c|}
\hline Shape of the body & $J_{i x}$ & $J_{i y}$ & $J_{i z}$ \\
\hline $\begin{array}{c}\text { Thin rod with length } L \text { along the } Z \\
\text { axis }\end{array}$ & $1 / 12\left(m \cdot L^{2}\right)$ & $1 / 12\left(m \cdot L^{2}\right)$ & 0 \\
\hline Sphere with radius $R$ & $2 / 5\left(m \cdot R^{2}\right)$ & $2 / 5\left(m \cdot R^{2}\right)$ & $2 / 5\left(m \cdot R^{2}\right)$ \\
\hline $\begin{array}{c}\text { Cylinder with radius } R \text { and height } h \\
\text { with rotation about } Z \text { axis }\end{array}$ & $\frac{1}{4} m\left(R^{2}+\frac{1}{3} h^{2}\right)$ & $\frac{1}{4} m\left(R^{2}+\frac{1}{3} h^{2}\right)$ & $1 / 2\left(m \cdot R^{2}\right)$ \\
\hline $\begin{array}{c}\text { Rectangular parallelepiped with } \\
\text { sides } a, b \text { and } c \text { along axes } X, Y \text { and } \\
Z\end{array}$ & $\frac{1}{12} m\left(b^{2}+c^{2}\right)$ & $\frac{1}{12} m\left(a^{2}+c^{2}\right)$ & $\frac{1}{12} m\left(a^{2}+b^{2}\right)$ \\
\hline $\begin{array}{c}\text { Cone with radius } R \text { and height } h, \\
\text { with rotation about } Z \text { axis }\end{array}$ & $\frac{1}{4} m\left(\frac{3}{5} R^{2}+h^{2}\right)$ & $\frac{1}{4} m\left(\frac{3}{5} R^{2}+h^{2}\right)$ & $3 / 10\left(m \cdot R^{2}\right)$ \\
\hline $\begin{array}{c}\text { Ellipsoid with dimensions } a, b \text { and } \\
c \text { along axes } X, Y \text { and } Z\end{array}$ & $\frac{1}{5} m\left(b^{2}+c^{2}\right)$ & $\frac{1}{5} m\left(a^{2}+c^{2}\right)$ & $\frac{1}{5} m\left(a^{2}+b^{2}\right)$ \\
\hline
\end{tabular}

The main part of the crab's body was designed as an ellipsoid shape, and the legs were considered as "small" cylinders. To calculate the moment of inertia for the body it was needed: mass $(m)$, length of the body $(L)$, width of the body $(W)$ and thickness $(T)$. For computing the inertia moment $(J)$ about the rotation axis were used the formulas presented in Table 8.

For calculating the axial moments of inertia about $x, y$ and $z$ axis of the body expressions (8), (9), and (10) were used:

$$
\begin{gathered}
J_{i x}=\frac{1}{5} m\left(L^{2}+T^{2}\right) \\
J_{i x}=\frac{1}{5} \cdot 526.7\left(14.2^{2}+5.8^{2}\right)=24784.4 \mathrm{~g} \cdot \mathrm{cm}^{2} \\
J_{i y}=\frac{1}{5} m\left(W^{2}+T^{2}\right) \\
J_{i y}=\frac{1}{5} \cdot 526.7\left(11.7^{2}+5.8^{2}\right)=17963.63 \mathrm{~g} \cdot \mathrm{cm}^{2}
\end{gathered}
$$




$$
\begin{gathered}
J_{i z}=\frac{1}{5} m\left(W^{2}+L^{2}\right) \\
J_{i z}=\frac{1}{5} \cdot 526.7\left(11.7^{2}+14.2^{2}\right)=135660.75 \mathrm{~g} \cdot \mathrm{cm}^{2}
\end{gathered}
$$

Where:

$m$ - mass of the body $(\mathrm{g})$,

$L$ - length of the body $(\mathrm{cm})$,

$W$ - width of the body $(\mathrm{cm})$,

$T$ - thickness (cm).

The leg of the crab has six segments, connected with revolute joints, and each segment of the leg was taken as a cylinder. For calculations were used expressions (11), (12), and (13):

$$
\begin{gathered}
J_{i x}=\frac{1}{4} m\left(R^{2}+\frac{1}{3} h^{2}\right) \\
J_{i x}=\frac{1}{4} \cdot 1.6\left(0,8^{2}+\frac{1}{3} 1.25^{2}\right)=0.464 \mathrm{~g} \cdot \mathrm{cm}^{2} \\
J_{i y}=\frac{1}{4} m\left(R^{2}+\frac{1}{3} h^{2}\right) \\
J_{i x}=\frac{1}{4} \cdot 1.6\left(0.8^{2}+\frac{1}{3} 1.25^{2}\right)=0.464 \mathrm{~g} \cdot \mathrm{cm}^{2} \\
J_{i z}=1 / 2\left(m \cdot R^{2}\right) \\
J_{i z}=1 / 2\left(1.6 \cdot 0.8^{2}\right)=0.512 \mathrm{~g} \cdot \mathrm{cm}^{2}
\end{gathered}
$$

Where:

$m$ - mass of the segment $(\mathrm{g})$,

$l-$ length of the segment $(\mathrm{cm})$, 
$R$ - radius of the segment $(\mathrm{cm})$.

All results of the axial moment's calculations are presented in Table 9. These results were used to fill the Body setting window (Figure 25).

Table 9 Axial moments of inertia of each segment

\begin{tabular}{|c|c|c|c|c|c|c|c|}
\hline & \multirow{2}{*}{$\begin{array}{c}\text { Axial } \\
\text { moments of } \\
\text { inertia }\end{array}$} & \multicolumn{6}{|c|}{ Segment number } \\
\hline & & 1 & 2 & 3 & 4 & 5 & 6 \\
\hline \multirow{3}{*}{ 童 } & $J_{i x}\left(\mathrm{~g} \cdot \mathrm{cm}^{2}\right)$ & 0.464 & 0.117 & 3.486 & 0.826 & 0.751 & 0.214 \\
\hline & $J_{i y}\left(\mathrm{~g} \cdot \mathrm{cm}^{2}\right)$ & 0.464 & 0.117 & 3.486 & 0.826 & 0.751 & 0.214 \\
\hline & $J_{i z}\left(\mathrm{~g} \cdot \mathrm{cm}^{2}\right)$ & 0.512 & 0.148 & 0.612 & 0.255 & 0.192 & 0.014 \\
\hline \multirow{3}{*}{ 赵 } & $J_{i x}\left(\mathrm{~g} \cdot \mathrm{cm}^{2}\right)$ & 0.867 & 0.325 & 7.026 & 1.178 & 0.181 & 0.241 \\
\hline & $J_{i y}\left(\mathrm{~g} \cdot \mathrm{cm}^{2}\right)$ & 0.867 & 0.325 & 7.026 & 1.178 & 0.181 & 0.241 \\
\hline & $J_{i z}\left(\mathrm{~g} \cdot \mathrm{cm}^{2}\right)$ & 1.218 & 0.186 & 1.162 & 0.331 & 0.231 & 0.023 \\
\hline \multirow{3}{*}{ רీ } & $J_{i x}\left(\mathrm{~g} \cdot \mathrm{cm}^{2}\right)$ & 1.093 & 0.305 & 10.674 & 1.650 & 0.426 & 0.348 \\
\hline & $J_{i y}\left(\mathrm{~g} \cdot \mathrm{cm}^{2}\right)$ & 1.093 & 0.305 & 10.674 & 1.650 & 0.426 & 0.348 \\
\hline & $J_{i z}\left(\mathrm{~g} \cdot \mathrm{cm}^{2}\right)$ & 1.228 & 0.172 & 1.379 & 0.593 & 0.425 & 0.020 \\
\hline \multirow{3}{*}{ ज্ } & $J_{i x}\left(\mathrm{~g} \cdot \mathrm{cm}^{2}\right)$ & 1.127 & 0.264 & 14.921 & 2.601 & 3.243 & 0.620 \\
\hline & $J_{i y}\left(\mathrm{~g} \cdot \mathrm{cm}^{2}\right)$ & 1.127 & 0.264 & 14.921 & 2.601 & 3.243 & 0.620 \\
\hline & $J_{i z}\left(\mathrm{~g} \cdot \mathrm{cm}^{2}\right)$ & 1.355 & 0.215 & 1.825 & 0.630 & 0.406 & 0.039 \\
\hline
\end{tabular}




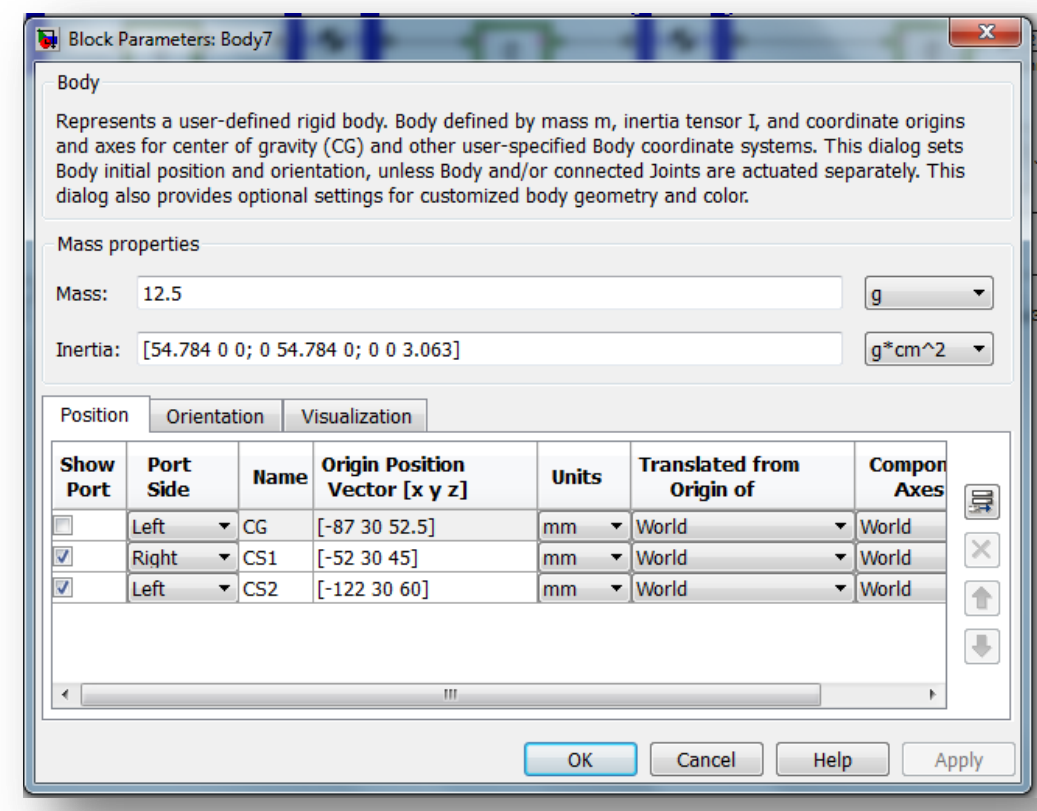

Figure 25 Leg segments setting window (Body setting window)

The Ground block (see Figure 24) is a fixed frame (base), rigidly connected to the absolute inertial coordinate system of the Earth. Availability of this block is necessary in any mechanical model and separate mechanism (otherwise the modeling starts with an error).

The block Machine Environment is a set-up parameter block making simulation environment for the machine (mechanism). The block Machine Environment is associated with the mechanical block Ground, as can be seen in Figure 26.

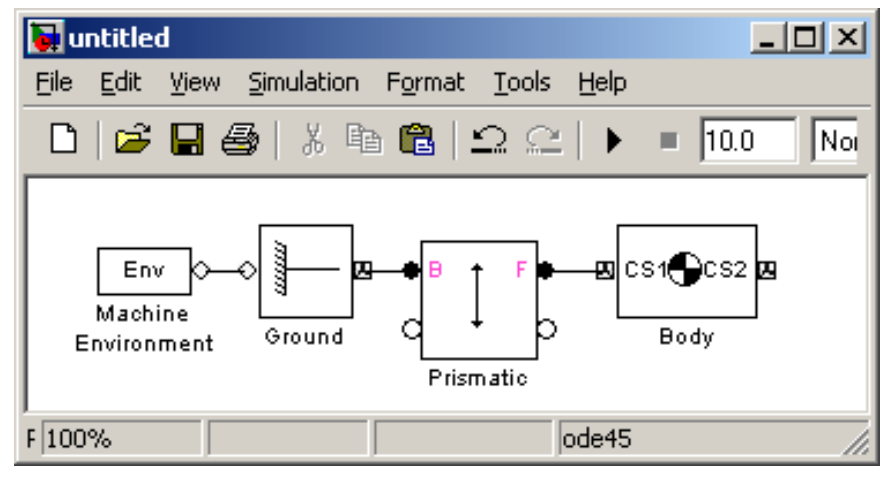

Figure 26 A simple model of a mechanical system with a block Machine Environment 


\subsubsection{Joint Blocks}

The section Joints of the SimMechanics library is the second largest, after the Bodies partition (see Figure 27). It contains blocks of the type articulation with a different number of degrees of freedom, which interconnect the individual blocks Body (Ground and Body block). Because of this, the bodies (the links of the mechanism) are able to implement relative motion between them.

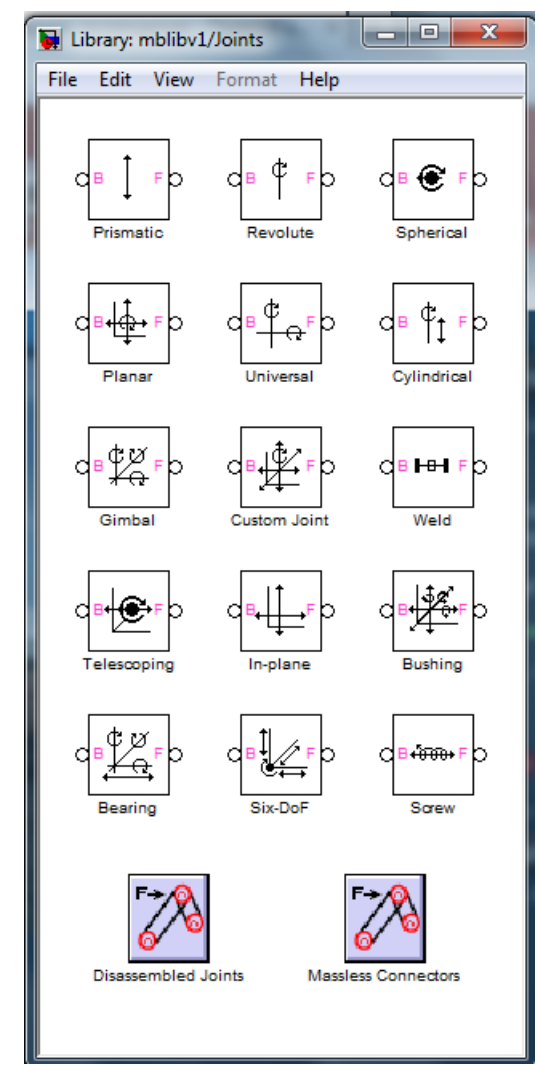

\section{Figure 27 The Joints Blocks}

The Joints section contains fifteen major blocks, simulating most kinds of articulations, namely: 1. Prismatic; 2. Revolute; 3. In-plane; 4. Universal; 5. Gimbal; 6. Spherical; 7. Planar; 8. Cylindrical; 9. Bearing; 10. Telescoping; 11. Bushing; 12. Six-DoF; 13. Screw; 14. Weld; 15. Custom Joint. The icons on the block section Joints provide visual information about their possible motion, even without a description.

The Revolute joint (see Figure 27) provides one rotational degree of freedom between bodies. This joint was extensively used to build the kinematic model of the crab's legs in SimMechanics (see Figure 28). 


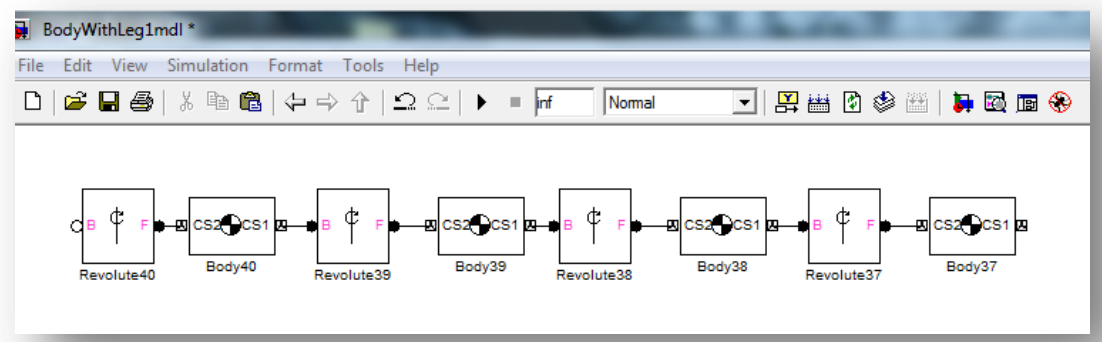

\section{Figure 28 Kinematic model of the crab's legs}

All legs of the crab were modeled in the same way, and were connected to the body through revolute joints (see Figure 29). The model presented in this figure is in its simplest form, without sensors, actuators, and control system.

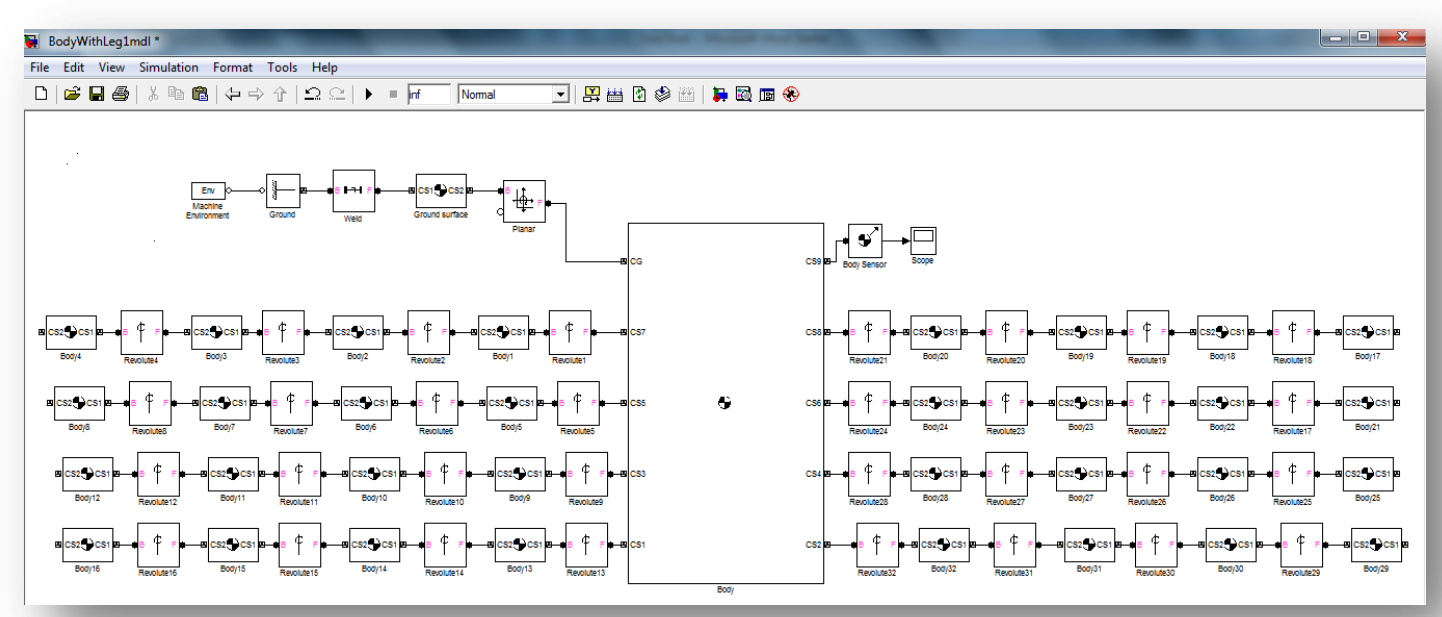

Figure 29 The kinematic model of the crab

\subsection{SOLIDWORKS MODELING}

SolidWorks was used to model the Spider crab. The general purpose of SolidWorks is the provision of through the process of design, engineering analysis and manufacture of products of any complexity and purpose, including the creation of online documentation and data exchange with other systems. 
In this project, SolidWorks was used to draw all single parts of the crab's body, and latter to connected everything in one model. Figure 30 represents a revolute joint made in SolidWorks. This joint was used to connect the leg segments, and implement the motion between them.

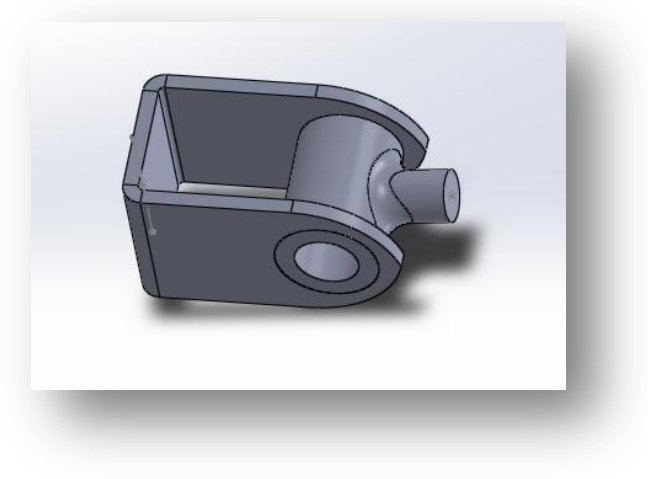

Figure 30 Revolute joint draw in SolidWorks

The body of the Maja brachydactyla crab has a lot of spines. It is not necessary for the kinematic model to draw these spines. The spines could be drawn, just to make the model more realistic, but that would take too much simulation time, and the model would be too computational heavy. That's why in SolidWorks a "smooth model" of the body was only been made, as can be seen in Figure 31.

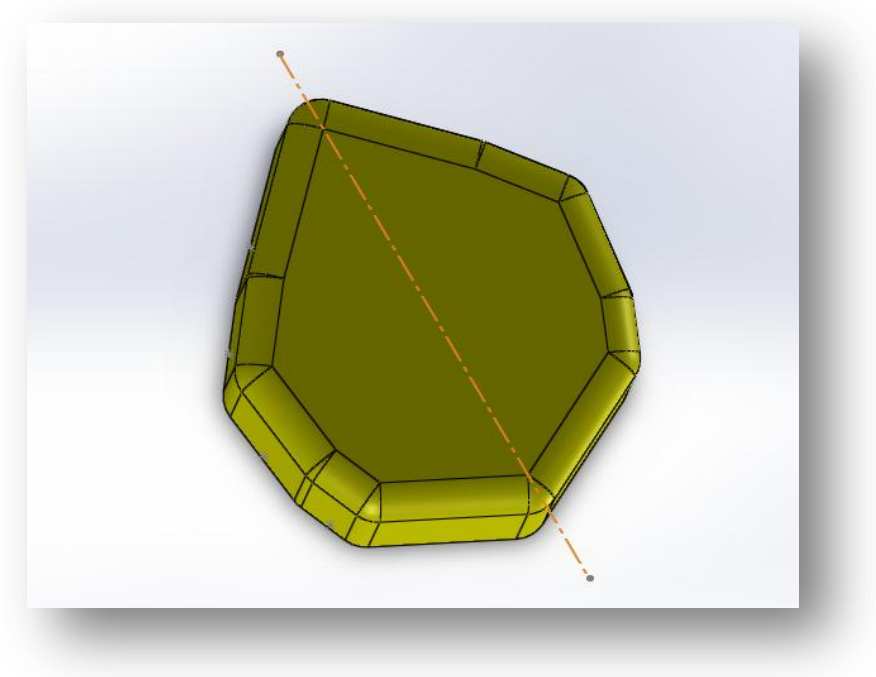

Figure 31 Body of the crab draw in SolidWorks 
When all individual parts were designed, they were assembled in one model (see Figure 32). This model is made using original data and has a geometric dimension equal to the real size of the crab measured in ELA.

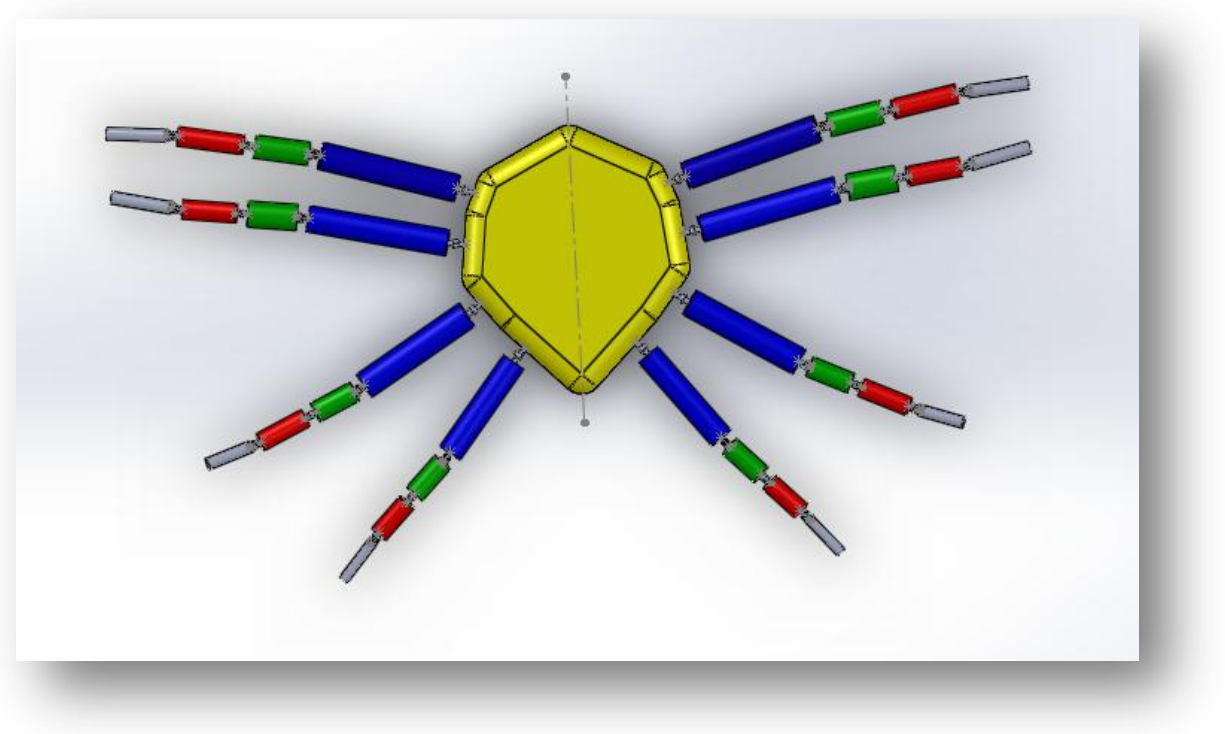

Figure 32 Full model of Spider crab in SolidWorks 



\section{DYNAMIC MODEL AND VISUALIZATION}

On the market today, there are many tools for computer-aided simulation technology, including mechatronic systems. Some of them are well known and popular with users, while others have appeared recently. Parts of these packages are universal and can be used to model any technology, not just technical systems. Others have a narrow specialization in any subject area.

Let us consider briefly the capabilities and features of an universal and fairly common visual structural modeling package, which can be used for the simulation of mechatronic systems, namely the MATLAB / Simulink package.

This package was designed to simulate and study dynamical systems in the broadest sense, including discrete and continuous, and hybrid models. It is distinguished by the relative simplicity and intuitive clarity of language input in conjunction with the reasonable requirements of the power of computers. 


\subsection{Dynamic Model Simulation in SimMechanics}

The SimMechanics toolbox of Matlab Simulink is used in order to make a dynamic simulation. SimMechanics extends Simscape with tools for modeling three-dimensional mechanical systems within the Simulink environment. The SimMechanics toolbox offers multi body simulation tools to build a model composed of bodies, joints, constraints, and force elements that reflects the structure of the system [30]. SimMechanics generates a 3D animation of the designed system dynamics. The model now has, in comparison with the kinematic model, mass, inertia, constraints, and 3D geometry. Therefore, the kinematic model variables (body position, joint positions) are loaded in the SimMechanics model. To make the legs controllable and move in the desired way, the actuators of each joint can be controlled separately for each leg.

The dynamic model is based on the kinematic model and on the real measurements of the spider crabs, meaning that the variables like length, radius and mass of the legs and body of the robot are parametrically programmed in the dynamic model. The main window of the model (see Figure 33) is made from different subsystems. White subsystem blocks are control blocks, and the yellow subsystem block is the "Robot Kinematics".

The yellow subsystem block "Robot Kinematics" (depicted in Figures 33 and 34) is based on the kinematic model developed in SimMechanics. In Figure 34, the gray Body block is the body of the crab, the eight blue subsystems represent the legs, and the green subsystems are ground contact blocks. The ground is fixed at $z=0$ and the position of the robot is connected with a 6 DOF block to the ground. 


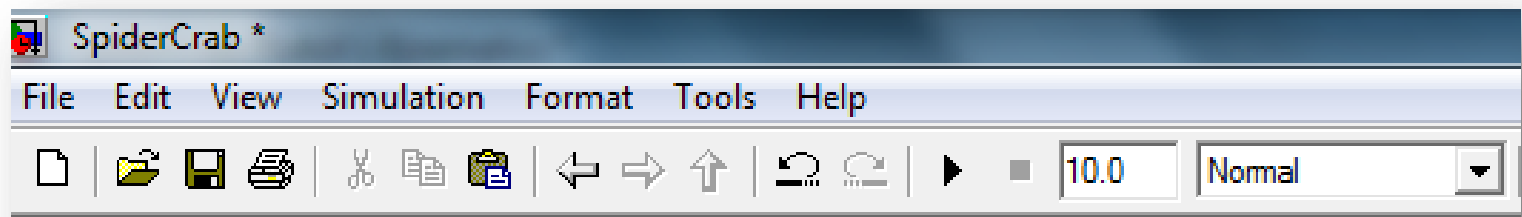

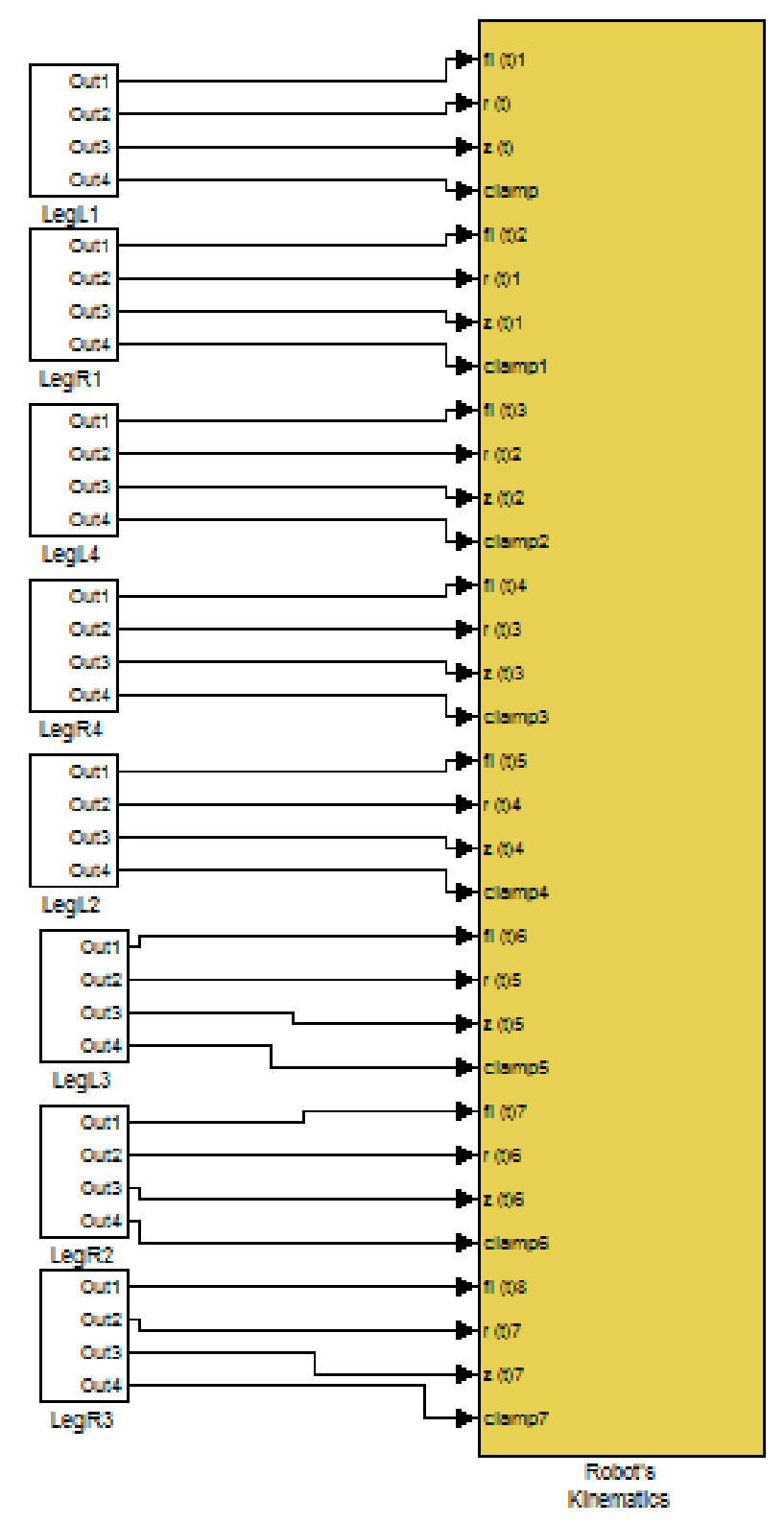

Figure 33 The main window of the Crab model in SimMechanics 


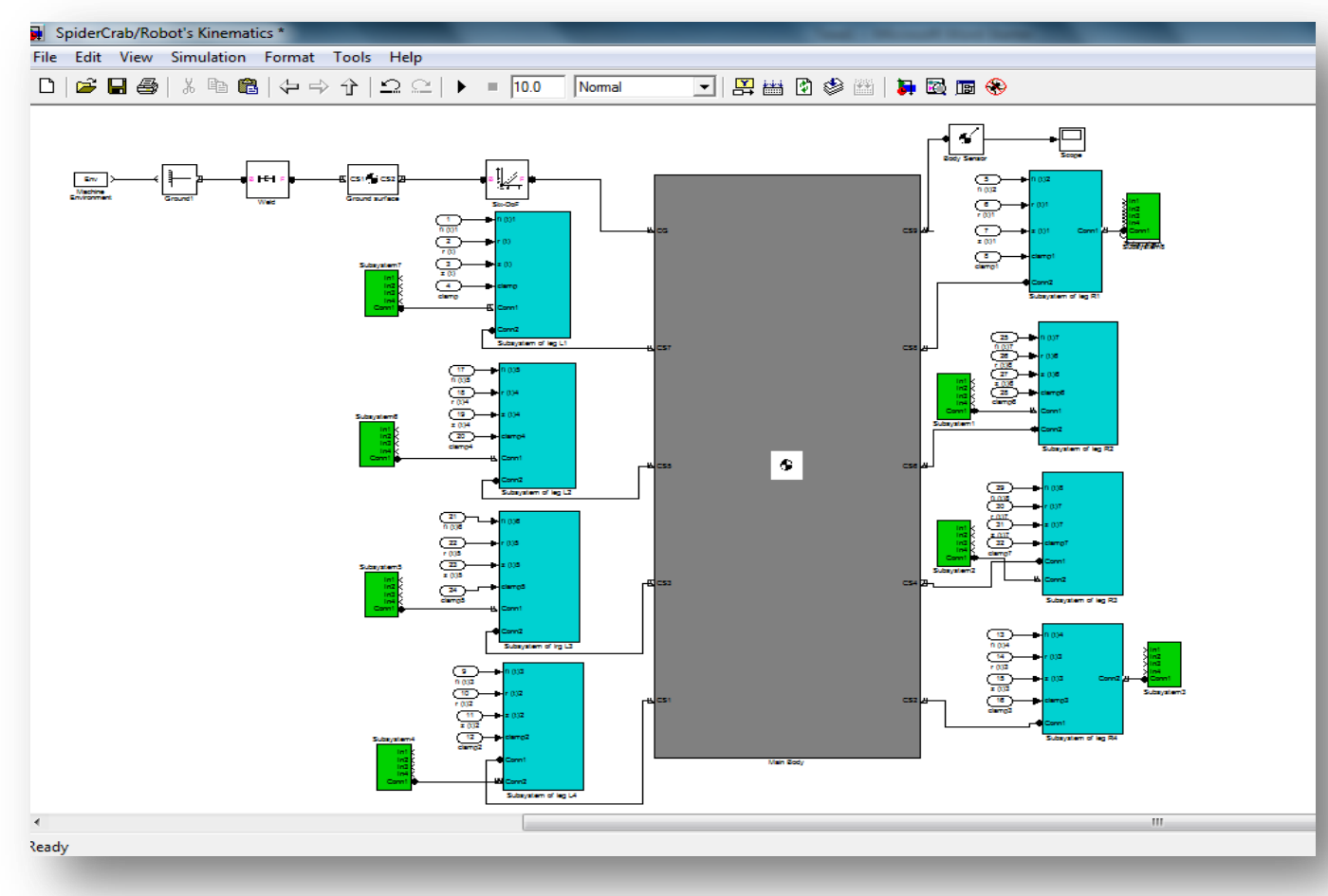

Figure 34 The SimMechanics model of the crab

Each leg has the same structure of the dynamic model of the leg represented on Figure 35. In this figure blue blocks are Body blocks, and green blocks are revolute joints, with joint sensors and actuators. There is also a PID Controller for each join. The acronym PID stands for Proportio-Integro-Differential control. Each of these, P, I and the D are terms in a control algorithm, and each has a special purpose. Sometimes certain of the terms are left out because they are not needed in the control design. This way is possible to have a PI, PD or just a P controller. In this work was used a PD controller, implemented through the following equation (14):

$$
P+D \frac{N}{1+N_{S}^{1}}
$$

Where:

$P$ - proportional gain,

$N$ - filter coefficient,

$D$ - derivative gain.

For the moving legs joints were adopted these values for the PD controller: $P=0.001$, $D=0.01$ and $N=0.01$ 


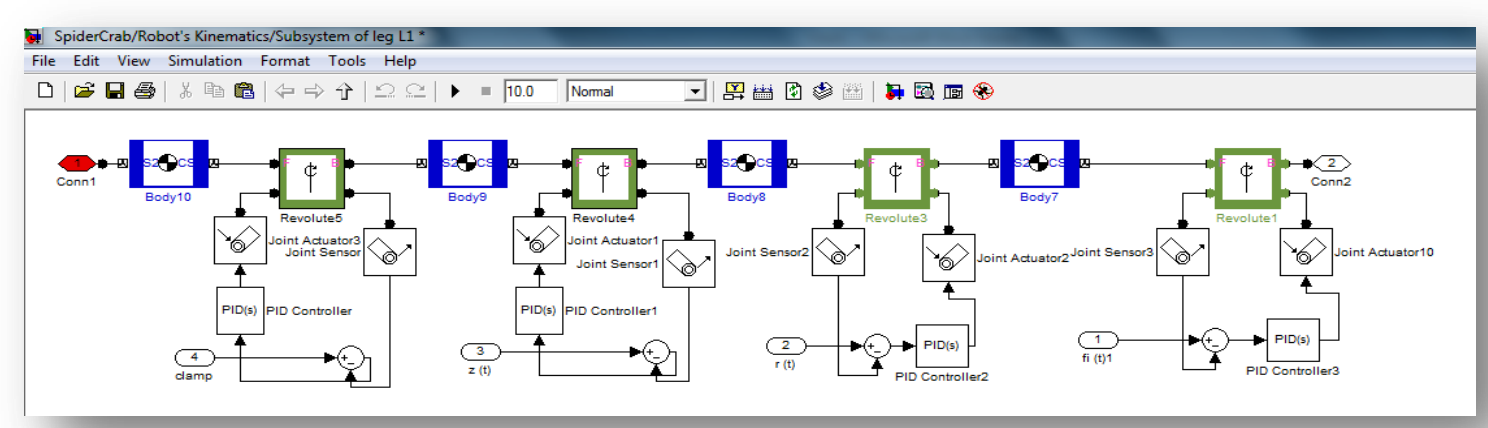

Figure 35 Dynamic model of a crab's leg in SimMechanics

\subsection{GROUND CONTACT}

In the beginning the coordinate system in the simulator is directly linked to the neutral point in the frame $(0,0,0)$, meaning that the robot starts with a preset body height directly centered above the zero frame point. The legs of the robot are connected to the body frame and to the robot coordinate system. On the contrary, the feet of the robot are observed in the world coordinate system to determine their $z$ coordinate. If the feet $z$ coordinate is zero or smaller than zero, this means that there is a contact with the ground and the forces of the ground should reflect to the feet, as shown in Figure 36. The ground is modeled as a parallel spring - damper system. The values for the spring and damper were iteratively chosen and it was experimentally verified that the model works correctly with Kcontact = $15[\mathrm{~N} / \mathrm{m}]$ and Dcontact $=5[\mathrm{Ns} / \mathrm{m}]$ so that the robot stands quickly stable without ground contact oscillation. With the implementation of this spring-damper model for the ground, the robot can stand at the ground at level $z=0$ (this situation is presented in Figure 37). Only when the feet are in contact with the ground, do the reaction forces actuate over the legs (see Figure 36, red subsystem block). 


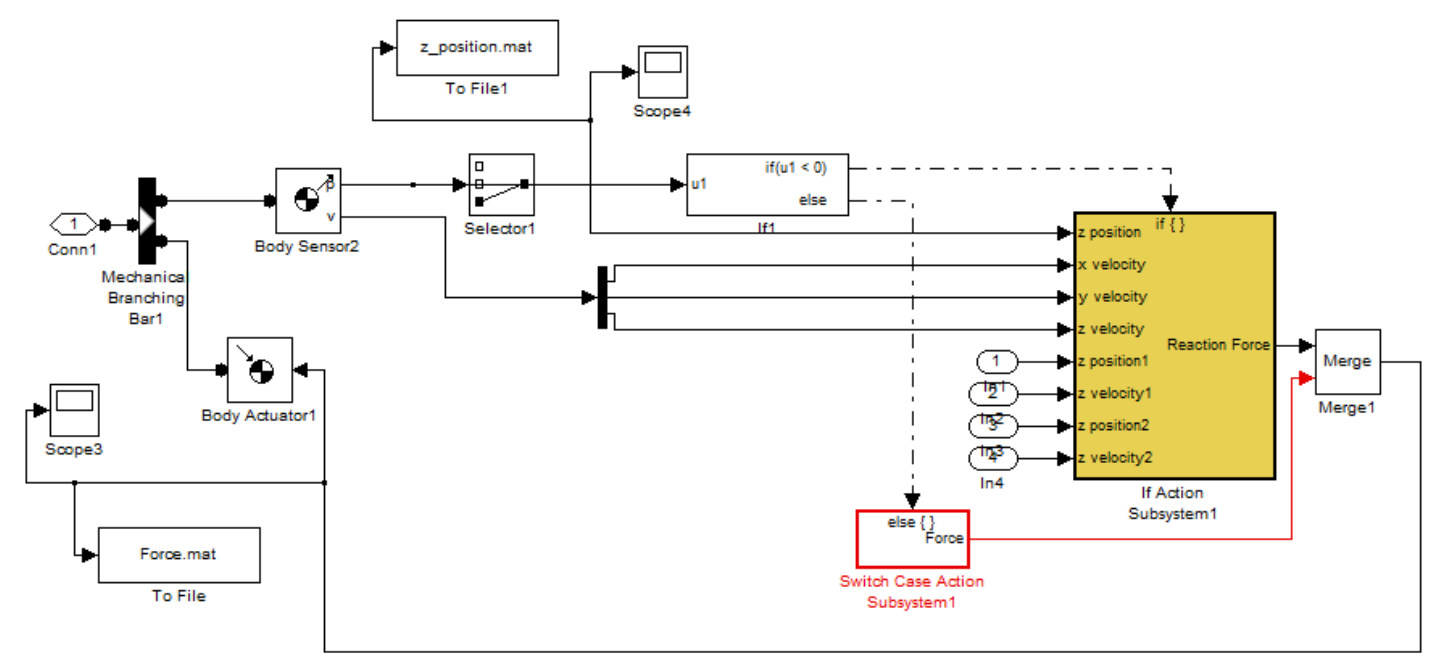

Figure 36 Ground contact model, which determines if the leg is on the ground or in the air

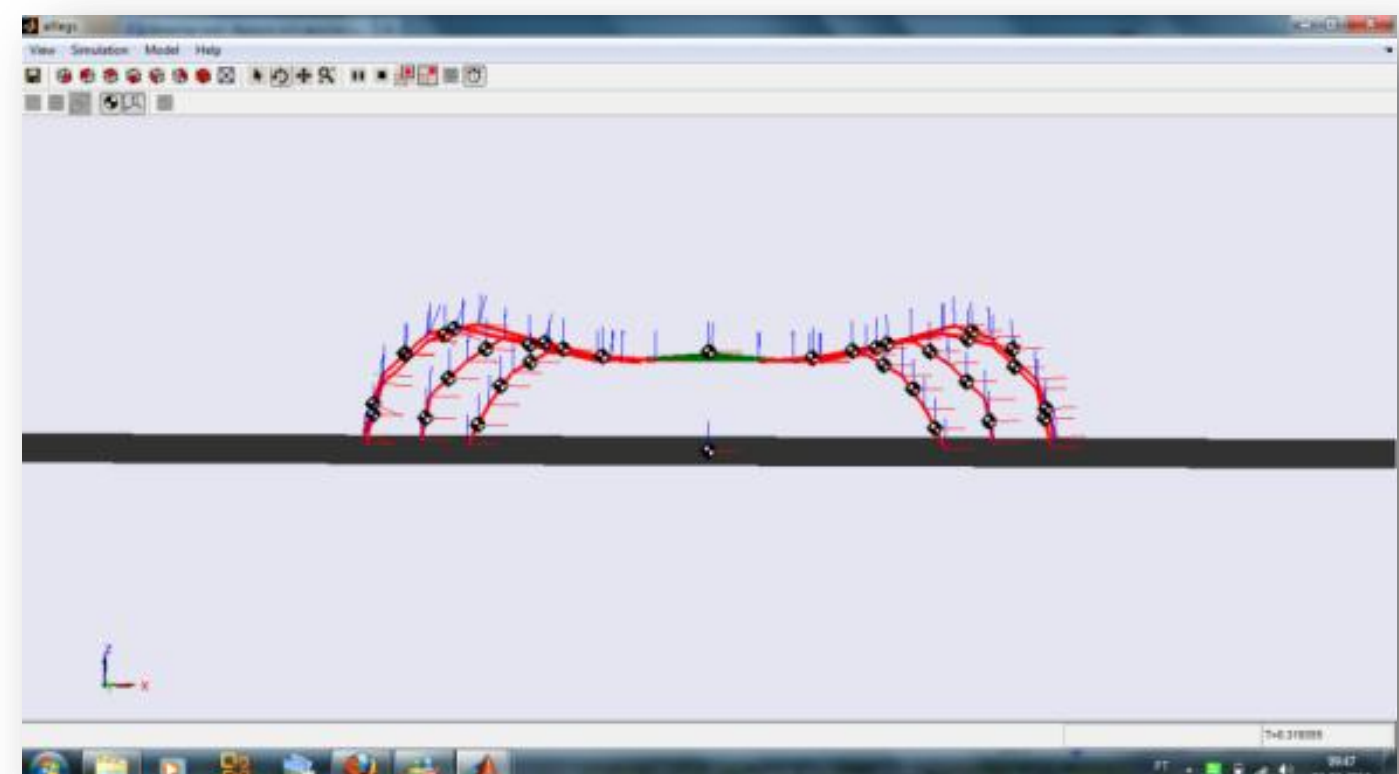

Figure 37 Visualization of the dynamic model, with the robot legs in contact with the ground

In order to allow the robot to walk in a given direction, friction has to be introduced when the feet touches the ground. To implement this effect over the simulation model the expressions (15) are used. 


$$
\begin{aligned}
& F_{n}= \begin{cases}-z \cdot K_{\text {contact }}-\dot{z} \cdot D_{\text {contact }} & \text { if } z \leq 0, \text { otherwise } \\
0 & \text { if } z \leq 0, \text { otherwise }\end{cases} \\
& F_{w x}= \begin{cases}-\left(2 /\left(1+e^{-10 \dot{x}}\right) \mu \cdot F_{n}\right) & \text { if } z \leq 0, \text { otherwise } \\
0 & \end{cases} \\
& F_{w y}=\left\{\begin{array}{l}
-\left(2 /\left(1+e^{-10 \dot{y}}\right) \mu \cdot F_{n}\right) \\
0
\end{array}\right.
\end{aligned}
$$

Basically $F_{w}=V \mu F_{n}$, with $F_{n}=z \cdot K_{\text {contact }}$, being $V$ a Sigmoid step function $2 /\left(1+e^{-10 \dot{x}}\right)$, depending of the contact speed but with a $(0,0)$ crossing. Here $\mu=0.2$ is the friction coefficient in the $x$ and $y$ directions for the ground contact.

\subsection{Modeling of Discrete-Positional Control System in SIMULINK}

Simulink is a visual programming environment, which can be used to create the basis of a discrete-positional control system, which will serve as the simulated movement of the operating point of the selected coordinate. Consequently, discrete-positional control system can be collected in robot control. This chapter will explain, step by step, how the discretepositional was used to control the movements of the spider crab.

The essence of the discrete-positional robot control system is presented in Figure 38.

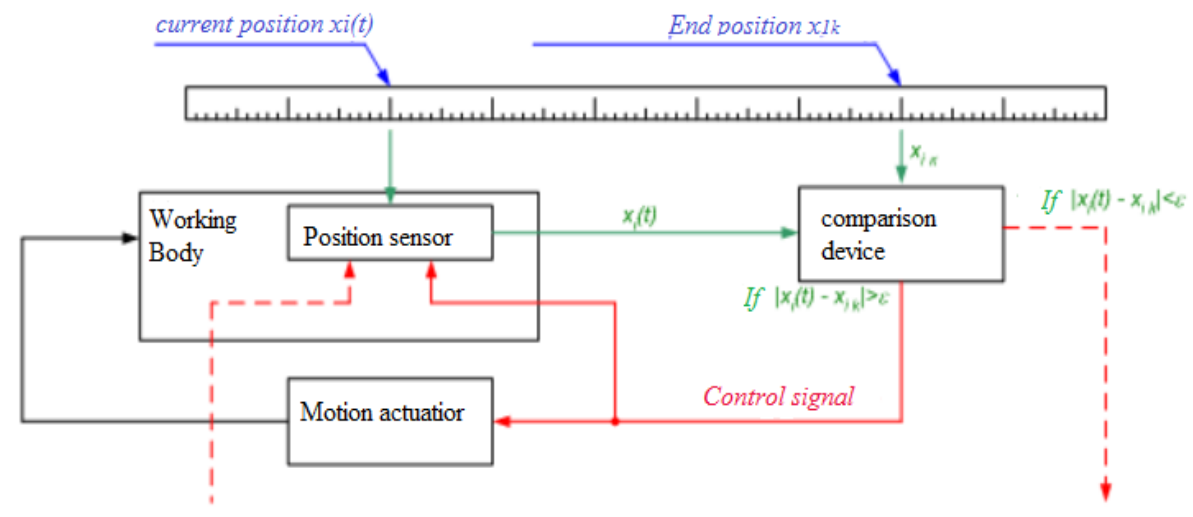

Figure 38 The general scheme of model management system

This scheme of work can be described mathematically, being the equations of motion of the working body for the first coordinate of $x_{1}(t)$, and control signals $u_{1}(t)$ and $u_{1 s}(t)$ as follows: 


$$
\begin{aligned}
& u_{1}\left(t_{1}\right)=1 ; \quad u_{1 z}\left(t_{1}\right)=0 ; \quad x_{1}\left(t_{1}\right)=x_{10} \\
& \begin{cases}x_{1}\left(t_{j}\right)=x_{1}\left(t_{j-1}\right)+k_{1} \Delta t ; & \left|x_{1}\left(t_{j-1}\right)-x_{1 k}\right|>\varepsilon ; \\
u_{1}\left(t_{j}\right)=1 ; & \\
u_{1 z}\left(t_{j}\right)=0 ; & \end{cases} \\
& \left\{\begin{array}{l}
x_{1}\left(t_{j}\right)=x_{1}\left(t_{j-1}\right) ; \\
u_{1}\left(t_{j}\right)=0 \\
u_{1 z}\left(t_{j}\right)=1
\end{array} \quad\left|x_{1}\left(t_{j}\right)-x_{1 k}\right|<\varepsilon\right.
\end{aligned}
$$

Where:

$t_{1}, t_{j}, t_{j-1}-$ the values of discrete time in the first, the current and previous points, respectively;

$\Delta t$ - sensor polling period;

$u_{1}\left(t_{j}\right), u_{1 s}\left(t_{j}\right)$ - values of control signals within the system administration of the first degree of freedom, and between the first and $s$-th, respectively;

$x_{1}\left(t_{1}\right), x_{1}\left(t_{j-1}\right), x_{1}\left(t_{j}\right)$ - position of the working body of the robot at the appropriate times; $x_{10}, x_{1 k}-$ initial position of the working body of the robot and the terminal point of the position;

$\varepsilon-$ accuracy (the accuracy of the comparison);

$k_{1}-$ velocity of the working body with the first degree of freedom.

The first equation describes the initial state of the system, and the next the system behavior over time, depending on the position sensor readings. To increase the visibility of the model is useful to distinguish the following component parts of the control system:

- parameters of the robot (including control system) - speed of movement in each joint positioning accuracy, polling period of sensors;

- analyzing and comparing the device - the elements of the error checking signals, etc.;

- forming elements of control commands;

- subsystem "drive" - the robot actuators, realizing the movement of the working bodies of the corresponding coordinate;

- total simulation time; 
- working signals and its dependence - the time dependence of $x_{i}(t), u_{i}(t)$ and $u_{i s}(t)$, according to equation (16).

Thus the implementation of the model shown in Figure 39, and described by equations (16) can be enlarged in the form of a simulation model, as shown in Figure 40.

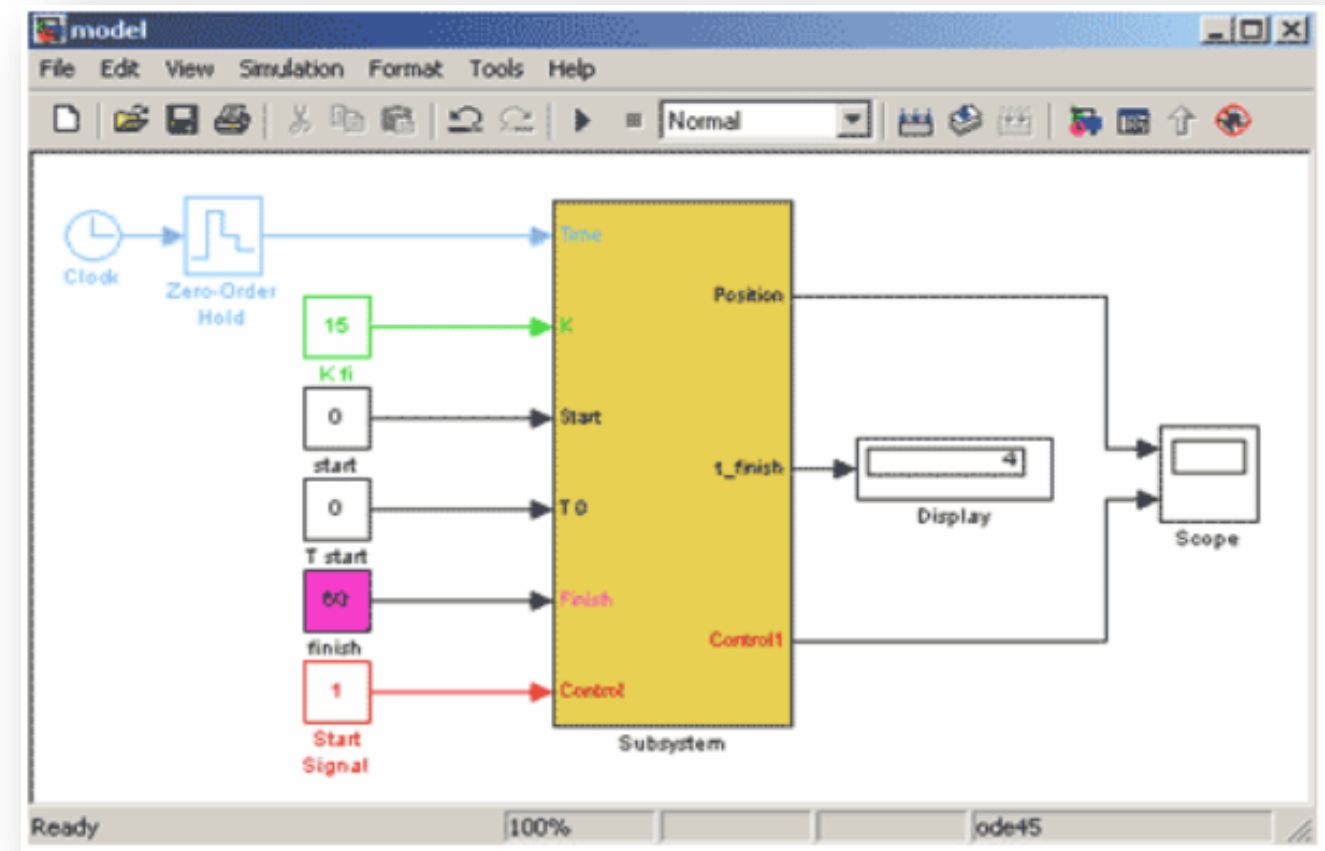

Figure 39 The integrated simulation model of the motion control

The input parameters of this model are:

- discrete time $t$, and a couple of blocks Clock and Zero-Order Hold;

- velocity of the working body of one of the coordinates (in this case, the rotation speed of the robot leg coordinate);

- initial position of the working body (start);

- $\quad$ start time of motion (T start);

- terminal point of the movement of the working body (finish);

- control signal (Start Signal). 
This subsystem outputs are three control signals:

- functional dependence of the coordinates of the working body along time $x_{i}(t)$ (Position);

- $\quad$ time to reach the terminal point of the working body ( $t$ finish);

- control signal to the subsequent movements of $u_{i s}(t)$ (Controll).

Let's consider the structure of the control subsystem (see Figure 40). The input signals (except the control signal) are combined by multiplexer and fed to input of functional mismatch analysis subsystem for current and end-coordinates. The control signal is supplied to the comparison unit, which analyzes the enabling or disabling of the sensor interrogation procedures, etc. If the signal is equal to +1 , the job passes to the next subsystem. If the signal is zero, then no change in the system occurs.
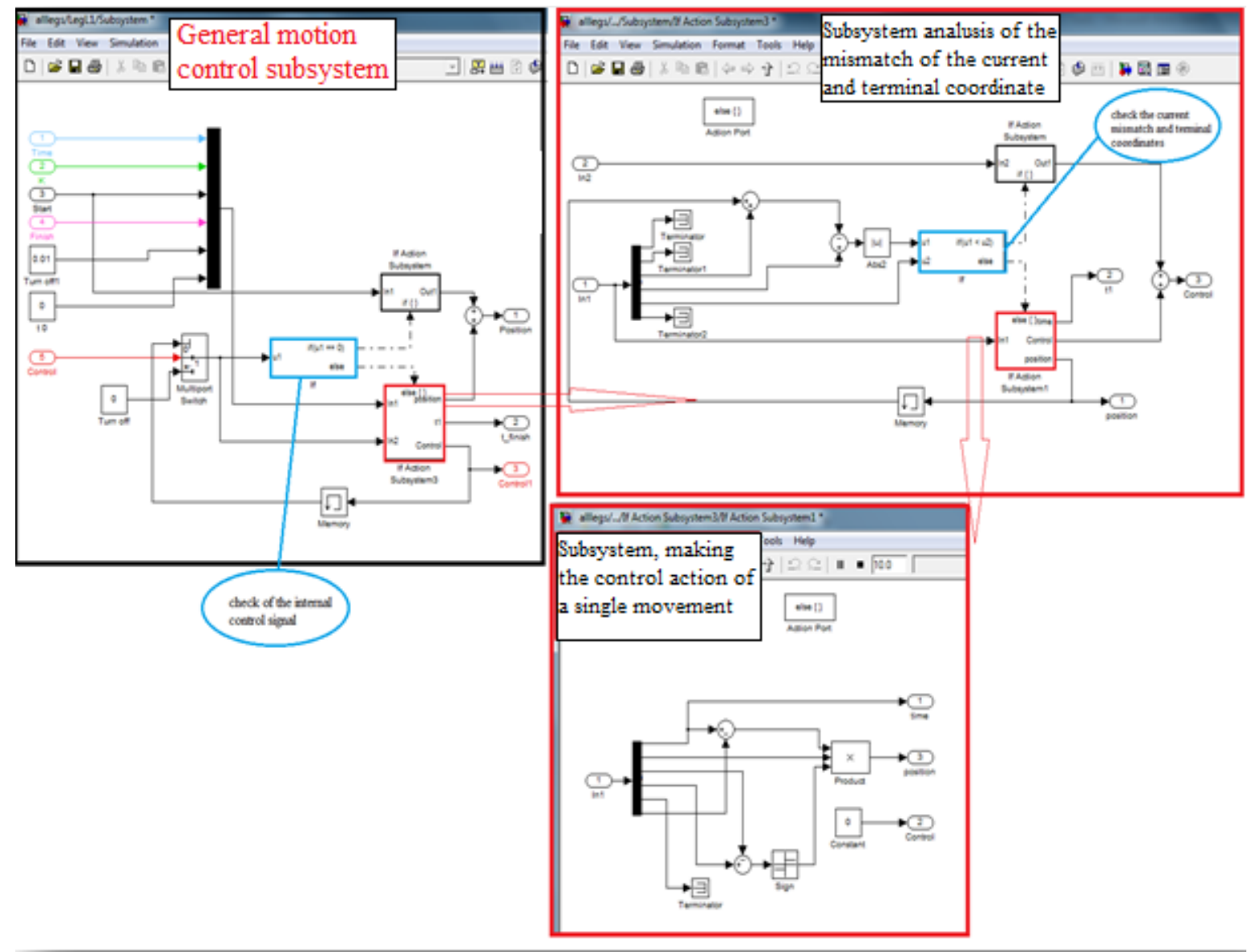

Figure 40 Decomposition of the control subsystem 
Thus, the complete cycle of motion of the robot can be modeled by the serial connection of blocks - management subsystems. A simulation model of the motion control system of the crab's leg is shown in Figure 41.

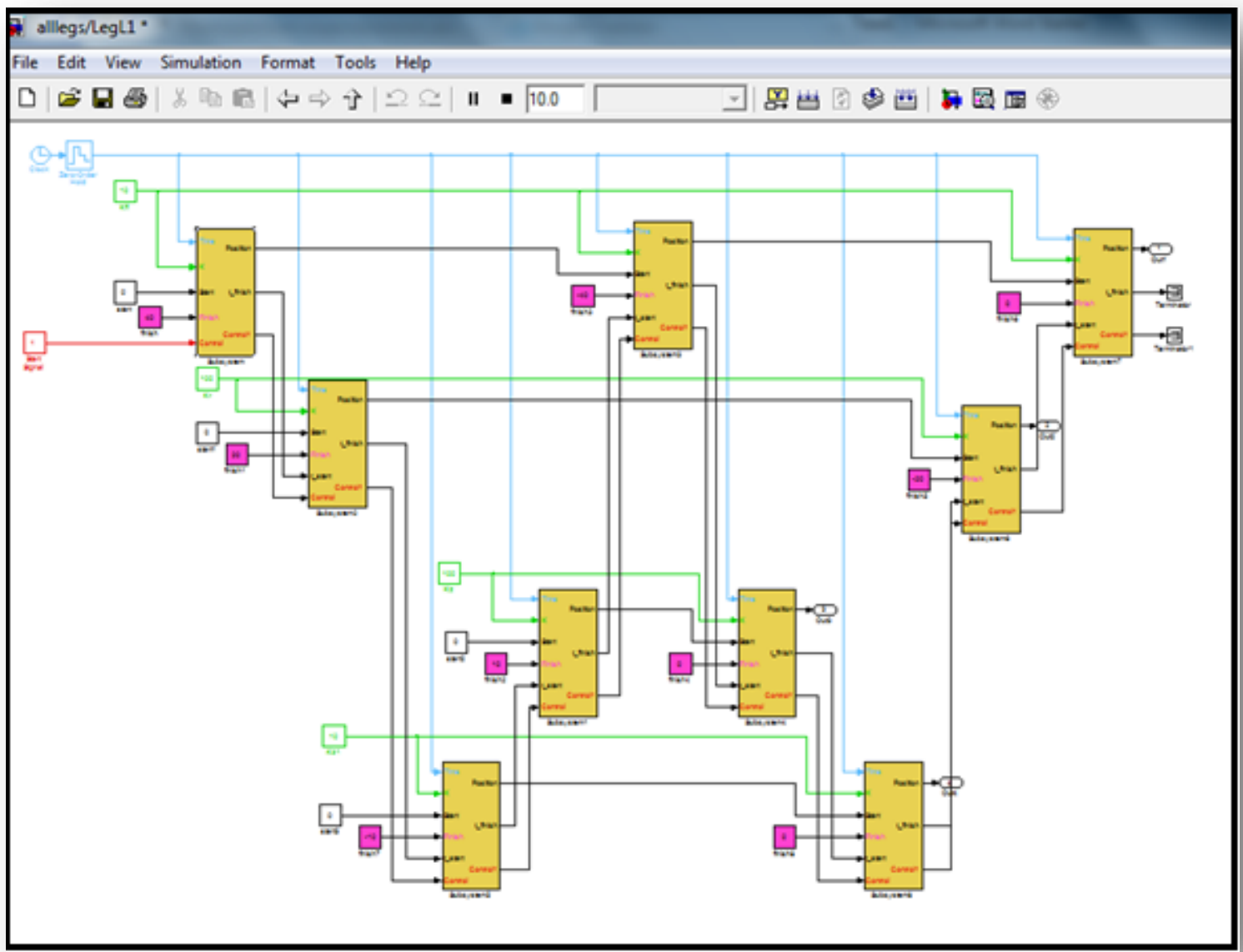

Figure 41 A simulation model of the control of one leg

To confirm the objectivity of the model, this system was connected to the model of the robot, which was made in SimMechanics. Simulation results are presented in the next chapter. 



\section{MOdel Simulation}

To analyze the simulation results of different dynamic systems, the best method is to perform the visualization, or animation, of the model while the simulation is running. The most widely used traditionally form is the visualization of the time dependencies of the studied parameters. Also used are graphic functions in polar coordinates, phase portraits, etc. However, if modeled the spatial motion of a mechanical system, most strikingly in the presentation of the results as a three-dimensional animation. This method of imaging the spatial displacements of the mechanical system, especially having a large number of degrees of freedom, allows a qualitative assessment of all its movements, and immediately concludes on the adequacy of the model. Presentation of results in the form of animation can significantly reduce the time it takes the researcher to analyze the model. Movement of the mechanism can be observed, during the simulation process, in a special visual observation SimMechanics window. The advantage of this option in the renderer is that the user does not spend time creating a virtual reality, the description of the geometry of bodies and their relationships, scenes and animations, etc. All of this has already been prepared and is automatically built-in in SimMechanics.

\subsection{Simulation With ONE LeG}

The first test of the mechanism model was made with only one leg (see Figures $42-44$ ), to check what happens to the entire body while the foot is in contact with the ground surface. For this test was used the three-dimensional animation functionality of SimMechanics, and also "Scope" blocks, to depict the graphics of several variables. 


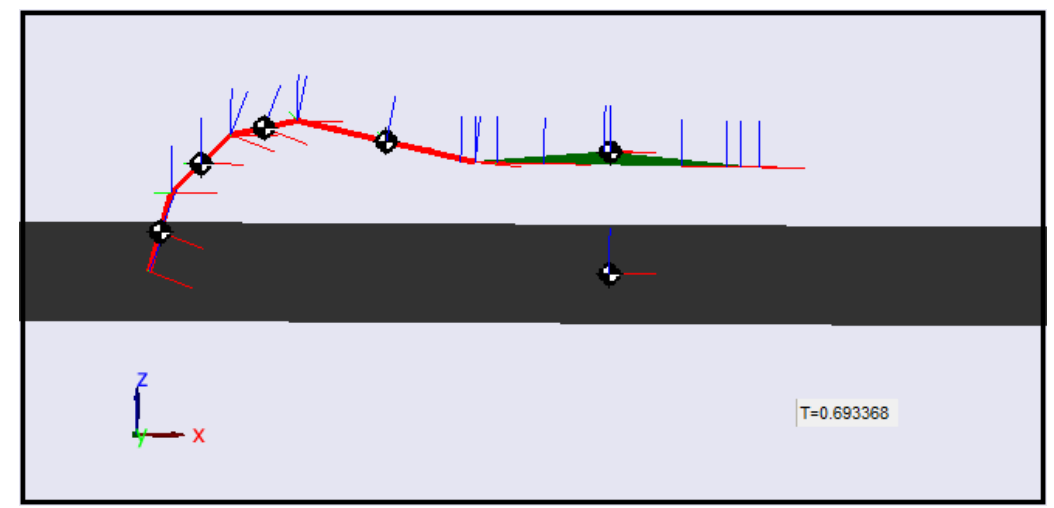

Figure 42 Simulation of the crab with just one leg $(t=0.6933 \mathrm{sec})$

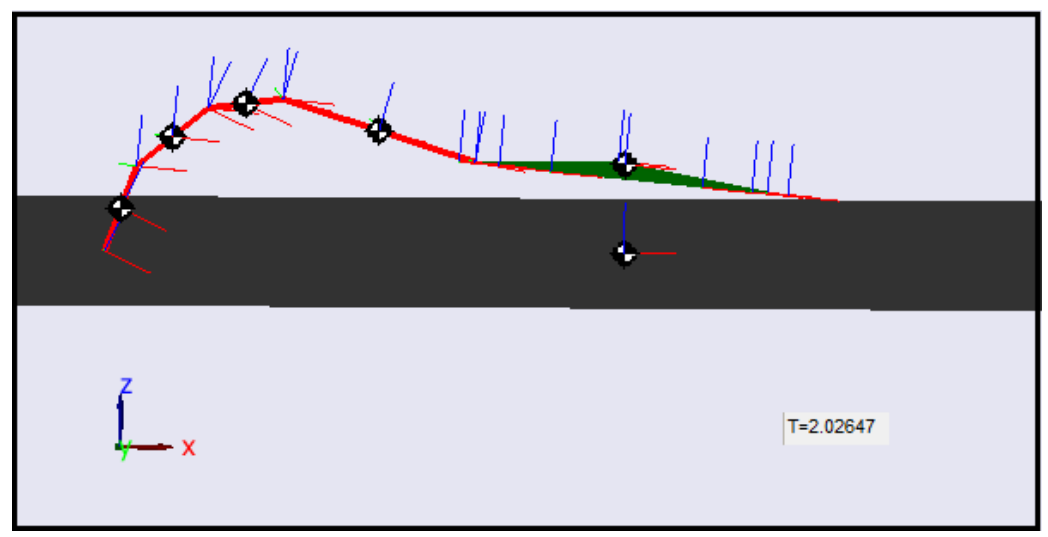

Figure 43 Simulation of the crab with just one leg $(t=2.0264$ sec $)$

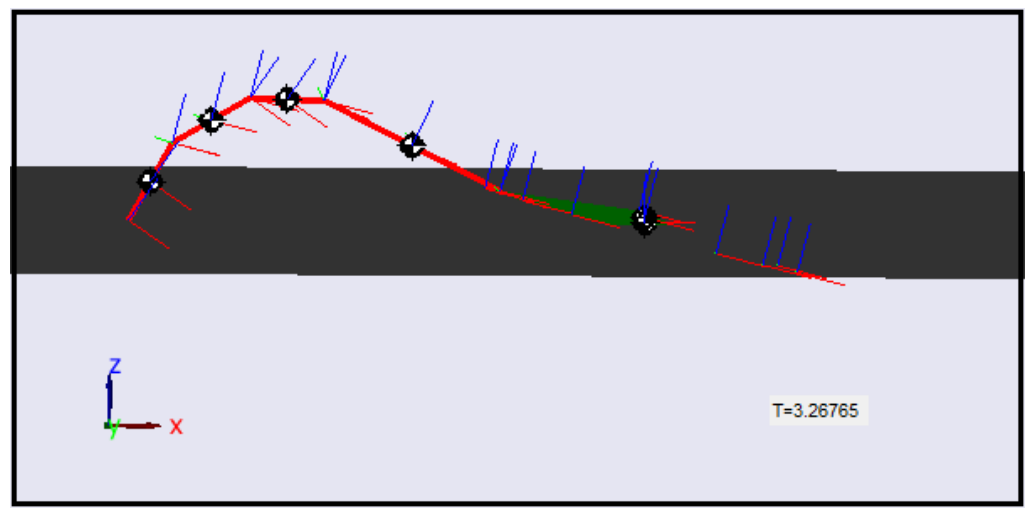

Figure 44 Simulation of the crab with just one leg $(t=3.2676 \mathrm{sec})$

These pictures show that the mechanism is working properly. There is a foot contact with the ground, and the leg does not go through the surface. It means that the ground contact subsystem (see Figure 36), that was made for this simulation, is working. Forces acting on the leg (see Figure 45) and gravity forces acting the body make the body fall down on the 
surface, while keeping the foot steady on place. This result is normal, and was expected, because the crab is standing on one leg and there is no support. The plots depicted in Figure 46 show the movement of the body in the $x, y$ and $z$ axis. $z$ position (red line) shows that the body is moving from position $50 \mathrm{~mm}$, and acting by gravity force falls down on the ground.

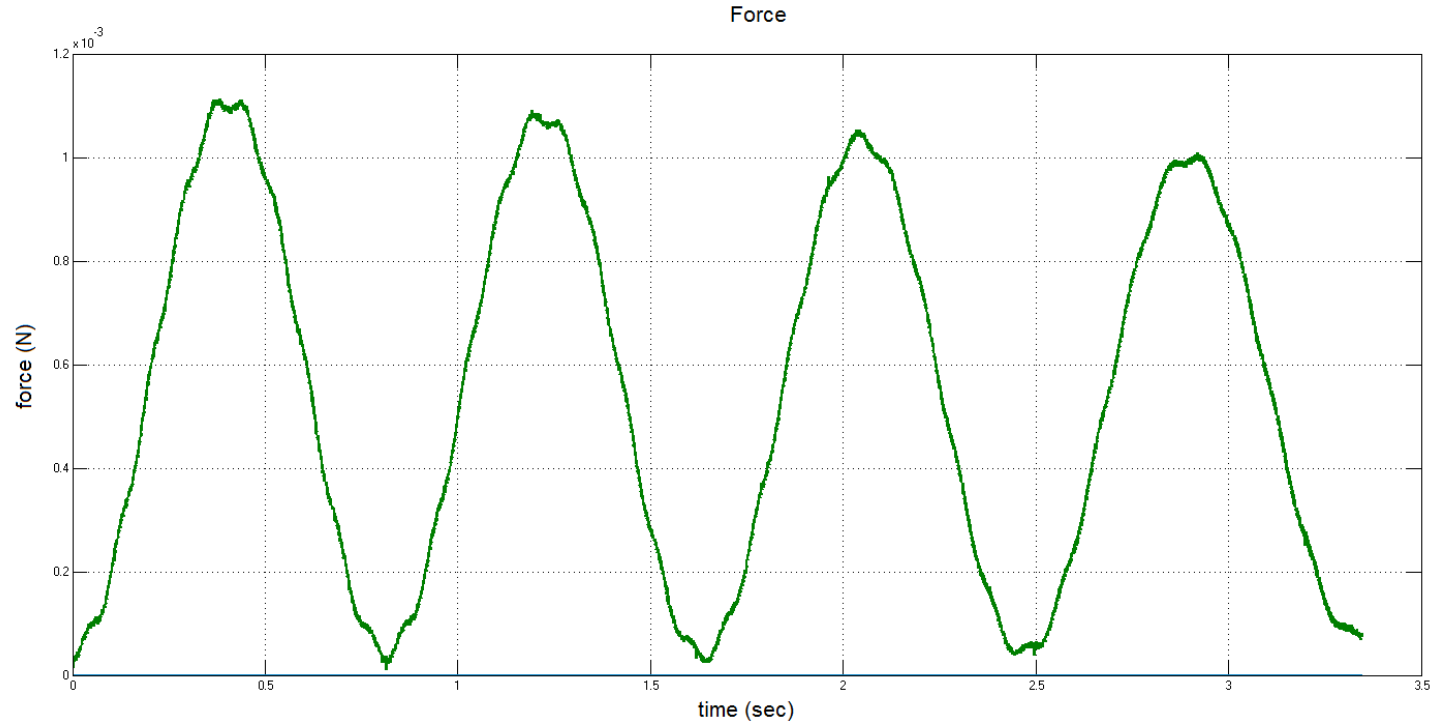

Figure 45 Plot of the normal force acting on the foot during simulation with one leg
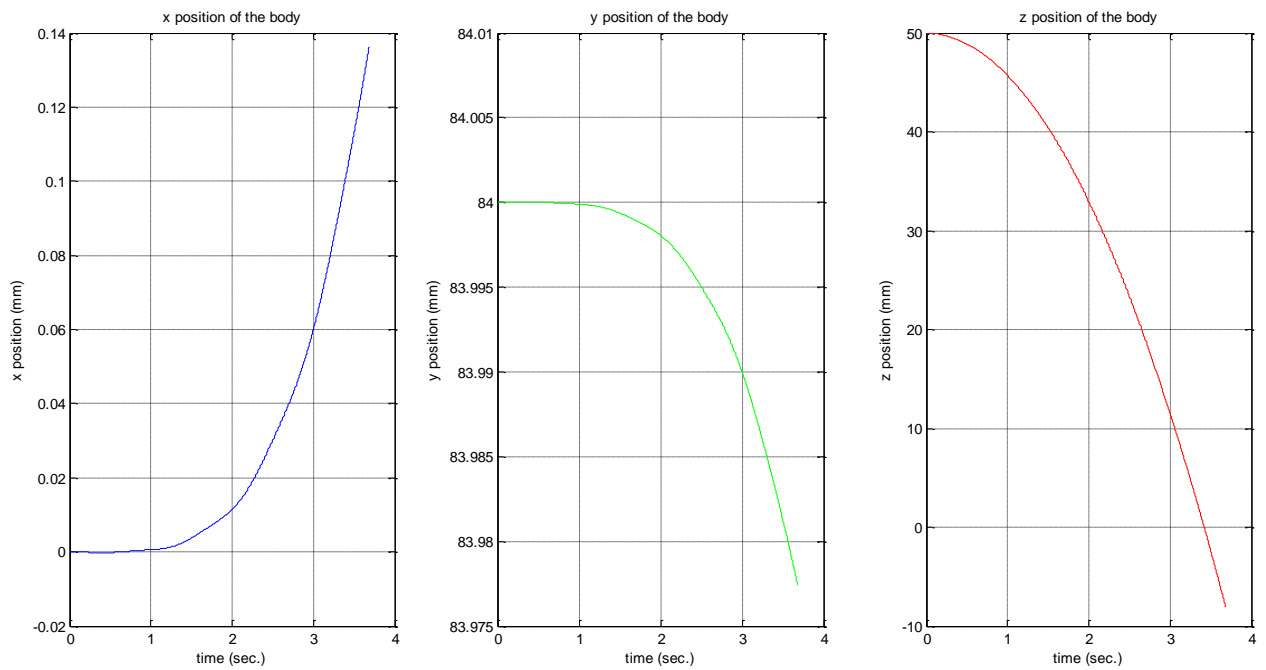

Figure 46 Plots of the crab body $x, y$ and $z$ positions during simulation with just one leg 


\subsection{Simulation OF The SpIDER Crab Locomotion}

Figure 47 represents the simulation of the Spider crab locomotion during 10 seconds. The model of the crab has eight legs, four from the left side and four from the right side. The legs were positioned in relation to the body, according to their positions on a real spider crab. The pictures show the movements of the legs, and body, relatively to the surface. For this simulation were used amplitudes of motion of the segments equal to the ones that were measured in laboratory (see table 5), and was implemented the same locomotion movement of the leg (see Figure 16). In Figure 47 it is possible to see that the center of mass of the crab moves against the center of mass of the ground.

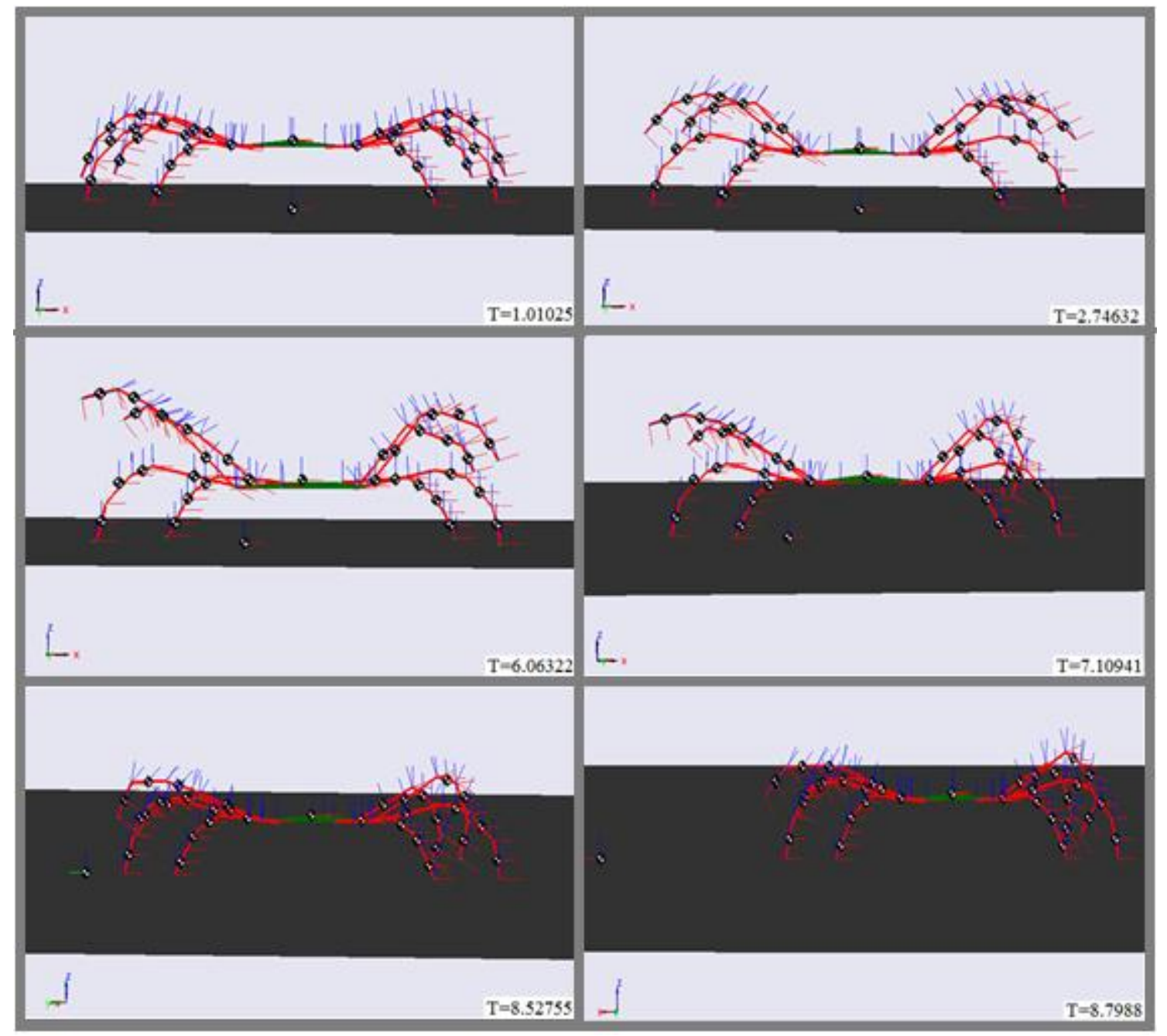

Figure 47 Simulation of the Spider crab locomotion (during 10 seconds)

There are four main moving legs, namely $L_{4}, L_{2}, R_{2}$ and $R_{3}$. While these legs are moving (transfer phase), the other legs are being used as a support for the body (support phase), but 
they are also moving with the entire body. This conclusion has been made studying the crab locomotion, and through the analysis of the chronograms.

The force plot corresponding to the reaction force of the ground on foot of $L_{4}$ (see Figure 48) shows that there are forces acting on the feet during the crab motion. The highest values $(0.9 \mathrm{~N})$ are when the leg starts to move. To get this plot the "Scope" was connected to the moving leg $\left(L_{4}\right)$. Theoretically the reaction force need to be about $0.6 \mathrm{~N}$, because the crab's body weight (526,7 $\mathrm{g}$ ) is equally distributed in all contact points (eight legs).

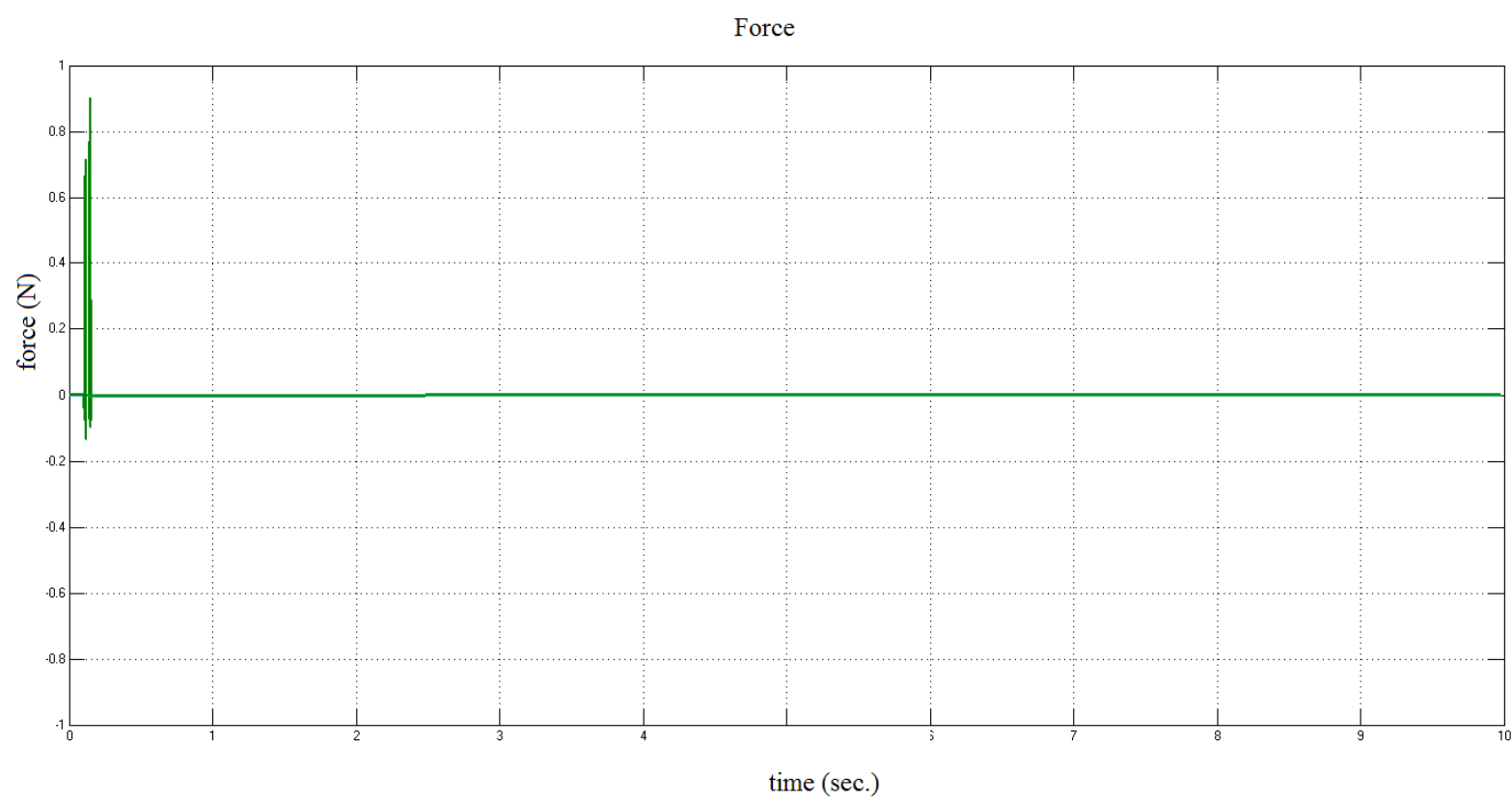

Figure 48 Plot of the normal force acting on the leg $\left(L_{4}\right)$

Figure 49 represents the plot of the reaction force acting on the leg $L_{3}$. This leg during the simulation of 10 seconds is a supporting leg. The force acting the leg $\left(L_{3}\right)$ has the highest value of $(0.3 \mathrm{~N})$. The difference between this and the expected value could be the problem of PD controller, which needs to be tuned. 


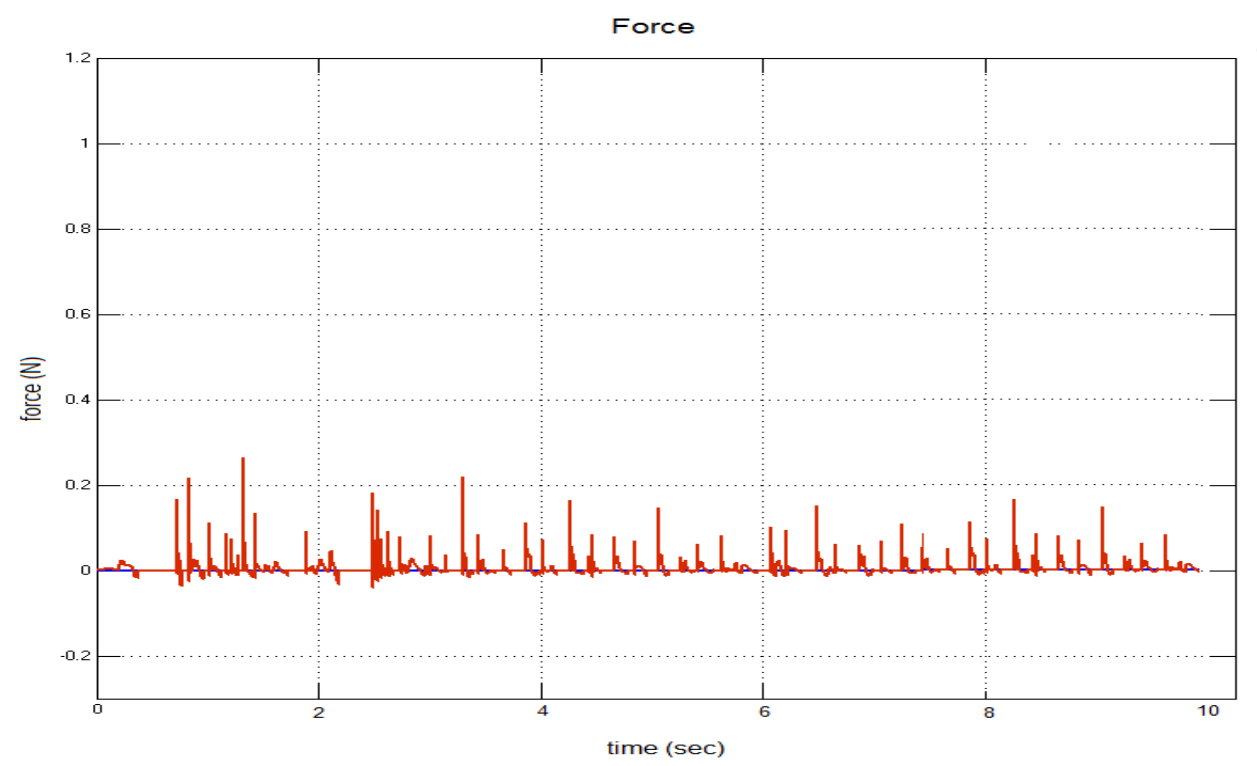

Figure 49 Plot of the force acting on the leg $\left(L_{3}\right)$

The $z$ position is represented in Figure 50, were it is presented the $z$ coordinate of the foot of leg $L_{4}$. It is possible to conclude that there is ground contact only in the beginning of the simulation. The scope is connected to the distal part of the leg, and from this plot it is possible to see the trajectory of the moving leg.

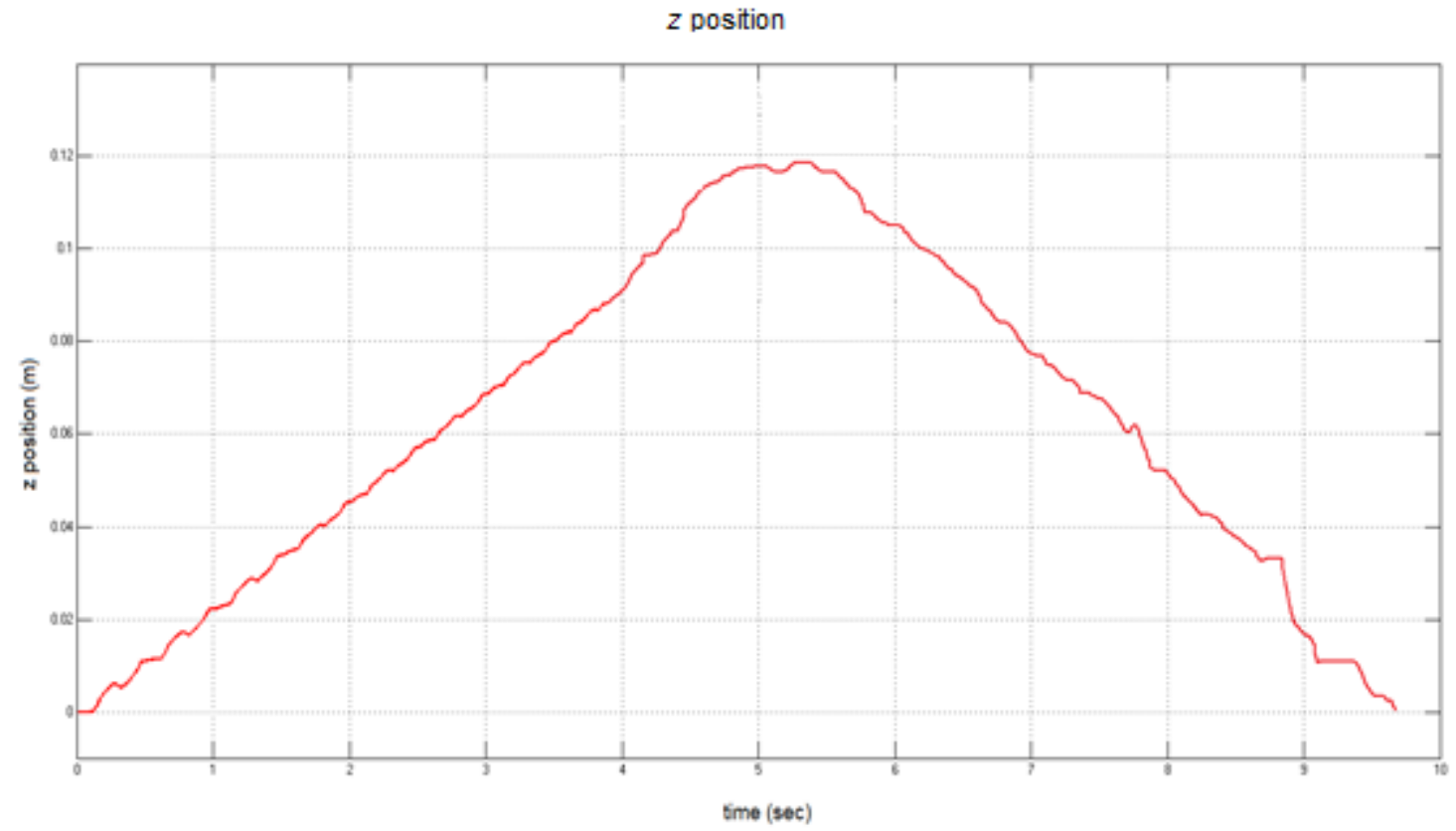

Figure $50 \quad$ Plot of leg $L_{4} z$ position during simulation 
The ground contact of the leg $L_{3}$ is presented on the chart of Figure 51. In this case the scope was connected to the distal end of this leg. This leg is not moving during the simulation, but acting by the forces the leg a little bit penetrates into the ground and then raises about the ground just less than $0.0005 \mathrm{~mm}$, as can be seen from the plot.

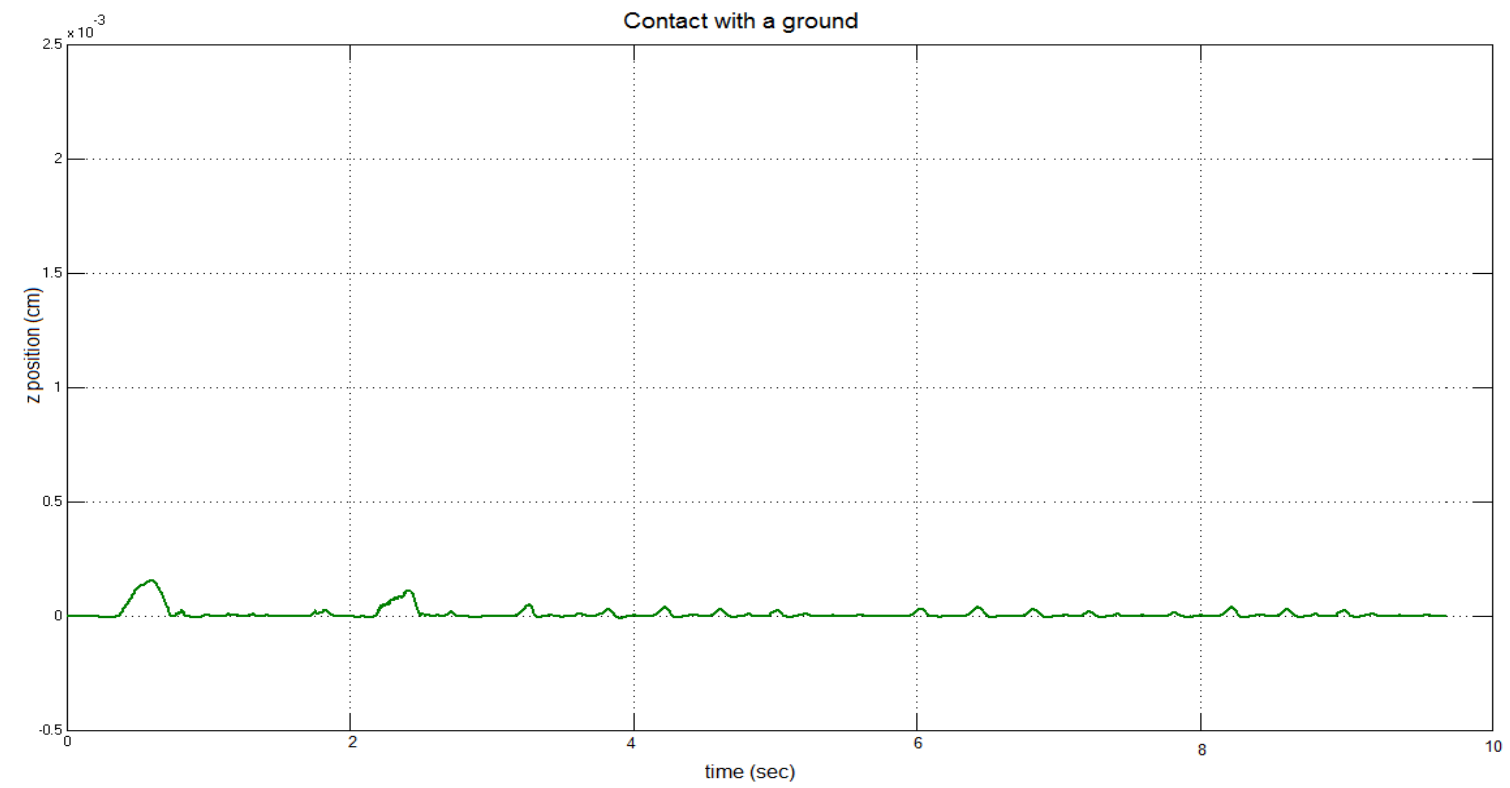

Figure 51 Plot of leg $L_{3}$ ground contact during simulation

During the simulation the crab is moving in the $x y$ plane. On Figure 52 are presented plots of the crab's body $x, y$ and $z$ positions (blue is $x$ axis, $y$ is green and red is $z$ axis). 

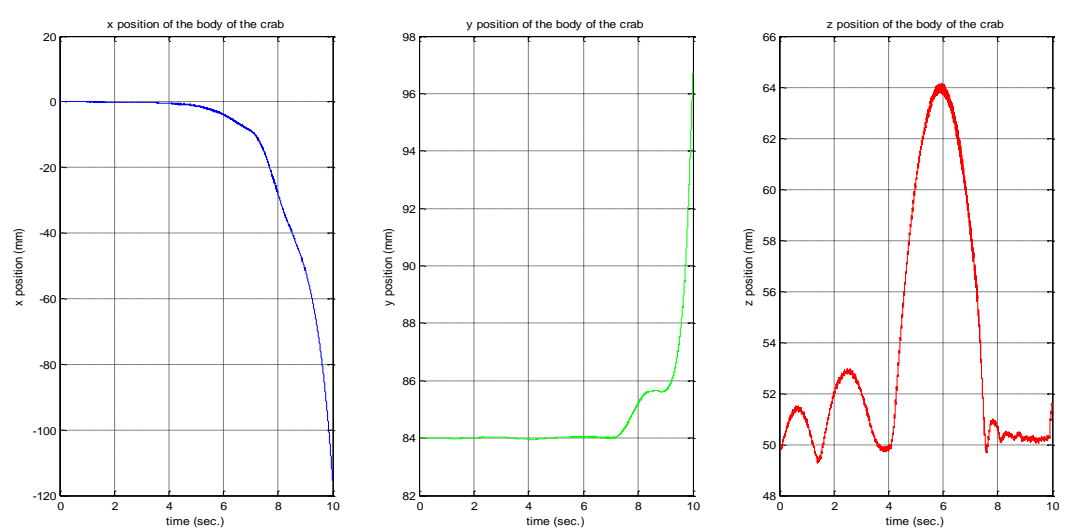

Figure 52 Plots of the crab's body $x, y$ and $z$ positions during simulation

Figure 53 represents the plot of the output of the PD controller, which is connected to the leg $\left(L_{4}\right)$. During the simulation on fourth second amplitude start increase and decrease, it means that controller is not tuned very well, and legs of the crab start shake a little bit. Tuning PD controller during the simulation was taken these results, because they are the best from all simulations that was done.

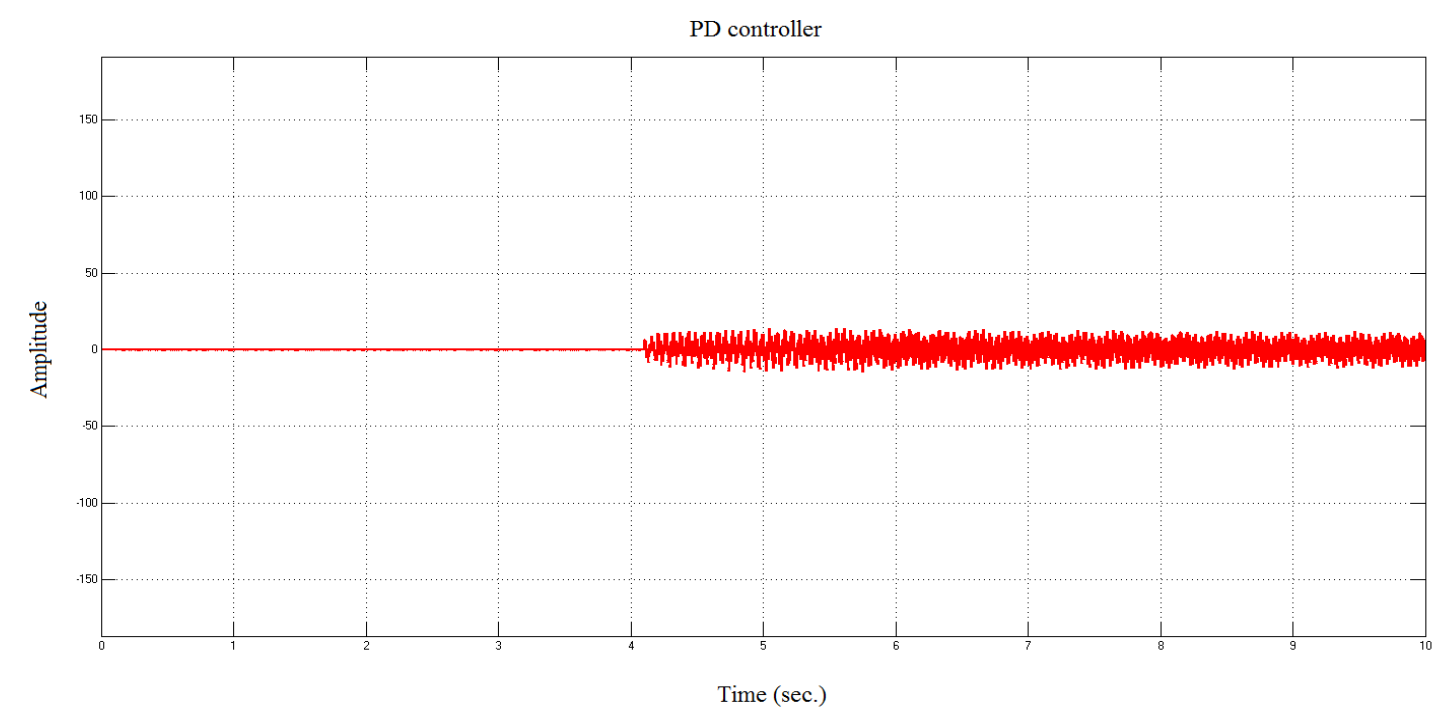

Figure 53 Plots of PD controller during simulation, connected to leg $\left(L_{4}\right)$ 


\section{CONCLUSIONS AND PERSPECTIVES FOR FUTURE DEVELOPMENTS}

\subsection{CONCLUSION}

The idea of this thesis is to gain knowledge of biological beings, whose evolution occurred over millions of years, and apply this knowledge in practice, by implementing the same methods of locomotion on the machines we build. It is believed that this way it is possible to develop machines with capabilities similar to those of biological beings in terms of locomotion skills and energy efficiency.

In this thesis, modeling and simulation of the Spider Crab (Maja brachydactyla) might be an option for a new type of biologically inspired robot. The strategy has been to use the animal's design and behavior as the default in the design and control of the robot using the biological design, and to solve engineering problems. To better understand what the Maja brachydactyla is, its anatomy, life cycles, reproduction and migration of the crab was studied. In laboratory were measured the parts of its body, was studied the locomotion and 
trajectory of the movements of the crab, to implement a more realistic, and based on real data, simulation model.

According to our studies, it was verified that eight legs give more "freedom" and stability while walking over different surfaces. The algorithm presented in this master thesis allows the crab to walk sideways. The crab model was implemented and programmed in Matlab / SimMechanics and in SolidWorks. The legs are all individual controlled, but the robot legs are not equally constructed in shape, size and mass. In the dynamic environment, gravity and mass are affecting the model and the model gets more realistic. Model parameters (mass, length, diameter, motion amplitudes) are the same as the real crab has. The kinematic model has been changed a little ( 2 segments were jointed in one), to make model not so complex, but not to change the biomechanical properties of the Spider Crab. The dynamic model has a ground contact model implemented in order to make the robot stand on the ground surface. Friction is implemented to give the feet a reaction force to the ground, and to make the robot move in the desired direction was used discrete-positional control system. Closer attention was given Spider crab's biology and biomechanical aspects in the design of this robot. As a result, a robot that is moving in an "animal like" manner was modeled.

\subsection{PERSPECTIVES FOR FUTURE DEVELOPMENTS}

To further develop the simulation programs described in this thesis toward a Spider crab the following development steps are needed:

- To achieve higher walking speeds it is necessary to investigate the dynamic algorithms;

- To tune the PD controller parameters for each joint of the leg, to make the model walk with better performance and faster;

- It is necessary to design an algorithm for the general path planner in order to make the robot walk according to a desired trajectory;

- In the future it is necessary for the robot to climb on the rocks, walk on the sand surface, and enter to the water, as a real Spider crab does. These extra features will reduce the balance of robot, so it is necessary to investigate dynamic balancing algorithms; 
- The development of a real robot biologically inspired in the "Maja brachydactyla", will be the final objective for future work. 


\section{References}

[1] Carl Meyer. "Maja Squinado, the European Spider Crab: Biology and Fishery". University of Hawaii. Retrieved October 4, 2010.

[2] Maja squinado, The European Spider Crab Biology and Fishery; http://www2.hawaii.edu/ carlm/spider.html; Last access: September 18, 2012.

[3] Spider crabs - spiny substrates on legs; http://davehubbleecology.blogspot.pt/2011/09/spider-crabs-spiny-substrates-onlegs.html; Last access: September 19, 2012.

[4] Spiny Spider Crabs; http://www.glaucus.org.uk/spider.htm; Last access: September 19, 2012.

[5] Биомеханика ходьбы; http://spinet.ru/conference/post56043.html; Last access: September 19, 2012.

[6] Отряд РАКООБРАЗНЫЕ ДЕСЯТИНОГИЕ (DECAPODA); http://www.floranimal.ru/orders/6966.html; Last access: September 19, 2012.

[7] Локомоция беспозвоночных с членистыми конечностями; http://filogenez.ru/index248.html; Last access: September 19, 2012.

[8] Лазарев Ю. Ф. Моделирование процессов и систем в MATLAB: Учебный курс. - СПб.: Питер; Киев: Издательская группа ВНV, 2005. - 512 р.

[9] SimMechanics User's Guide. Version 2. The MathWorks, Inc., November 2002.

[10] The robocup dutch committee; http://www.robocup.nl; Last access: September 19, 2012.

[11] robots_will_win; http://community.livejournal.com/; Last access: September 19, 2012.

[12] Manuel F. Silva, J. A. Tenreiro Machado; A Historical Perspective of Legged Robots; Journal of Vibration and Control, Vol. 13, No. 9-10, September-October 2007; ISSN 1077-5463; pp. 1447 - 1486.

[13] А.В. Воронин "МОДЕЛИРОВАНИЕ МЕХАТРОННЫХ СИСТЕМ" Издательство Томского политехнического университета 2008

[14] ЕВДОКИМОВ Ю.И. “СТРУКТУРА МЕХАНИЗМОВ. ОСНОВНЫЕ ПОНЯТИЯ И ОПРЕДЕЛЕНИЯ” НОВОСИБИРСК 2009

[15] Е.И. ЮреВИч "УПРАВЛЕНИЕ РОБОТАМИ И РОБОТОТЕХНИЧЕСКИМИ СИСТЕМАМИ" Санкт-Петербург 2000

[16] Волкоморов С.В., Каганов Ю.Т. Карпенко А.П. “Моделирование и оптимизация некоторых параллельных механизмов // Информационные технологии,” Приложение, 2010, №5. 
[17] Impulsiniu apkrovu veikiamos neteisines dinamines systemos "Neigalus zmogusvezimelis-transporto priemone" judesio stabimulo tyrimas; http://vddb.library.lt/fedora/get/LT-eLABa-0001:E.02 2005 D_20051102_09574534370/DS.005.0.01.ETD Last access: September 26, 2012.

[18] Каганов Ю.Т., Карпенко А.П. “Математическое моделирование кинематики и динамики робота-манипулятора типа «хобот». 2. Математические модели секции манипулятора, как механизма параллельной кинематики типа «гексапод»" Наука и образование: электронное научно- техническое издание, 2009, 11. [Электронный ресурс] (http://technomag.edu.ru/doc/133731.html).

[19] Колесов Ю.Б., Сениченков Ю.Б. “Имитационное моделирование сложных динамических систем” [Электронный ресурс] (http://www.exponenta.ru/soft/others/mvs/ds_sim.asp).

[20] Махов, А.А. Моделирование механических систем с помощью пакета расширения SimMechanics [Электронный ресурс] (http://exponenta.ru/educat/systemat/mahov/simmechanics.asp).

[21] Altendorfer R., Moore N., Komsuoglu H., Buehler M., Brown H. B., Jr., McMordie D., Saranli U., Full R., Koditschek D. E. RHex: "A biologically inspired hexapod runner" J. Autonoumos Robots.2001.Vol. 11.P. 207-213.

[22] Aoustin Y., Formal'sky A. M. "Control strategy for dynamic locomotion design of walking quadruped” Proc. IFAC Workshop, Motion Control 98.1998.P. 401-407.

[23] Hirai K., Hirose M., Haikawa Y., Takenaka T. "The development of Honda humanoid robot " Proc. IEEE Conf. on Robotics and Automation.-1998.-P. 13211326.

[24] Hong Y. S., Lee H. K., Yi S. Y., Lee C. W. "The design and control of a jointed-leg type of a quadrupedal robot for locomotion on irregular ground" Robotica.1999.Vol. 17, no. 4.-P. 383-389.

[25] “Теория механизмов и машин. Терминология : учеб. Пособие” Н. И. Левитский, Ю. Я. Гуревич, В. Д. Плахин [и др.]; под ред. К. В. Фролова. - М. : Изд-во МГТУ им. Н. Э. Баумана, 2004.

[26] K. Ichiryu and D. Kawashima. Development of landmines detecting and clearing robot. Advances in Automation and Robotics, October:62-66, 2005.

[27] http://www.livingmechanics.com/chapter14.html

[28] Mark R. Cutkosky, Scott L. Delp, and Kenneth J. Waldron. Design, simulation, and stability of ahexapedal running robot, 2004.

[29] M.H.P. Dekker. Advice and implementation of a friction model in simmechics, 2010.

[30] Simmechanics. http://www.mathworks.com/products/simmechanics/; Last access: September 19, 2012.

[31] В.С. Щербаков, М.С. Корытов, А.А. Руппель, В.А. Глушец, С.А. Милюшенко "Моделирование и визуализация движений механических систем в matlab" Омск-2007 


\section{Appendix A-Measurements of the second specimen}

The second spider crab that was measured, presented in Figure 54, was also female; but it was missing 2 right legs $\left(R_{3}\right.$ and $\left.R_{2}\right)$. Parameters of the second specimen are presented on Table 10 and 11. Measurements were made in the same order as for the first crab.

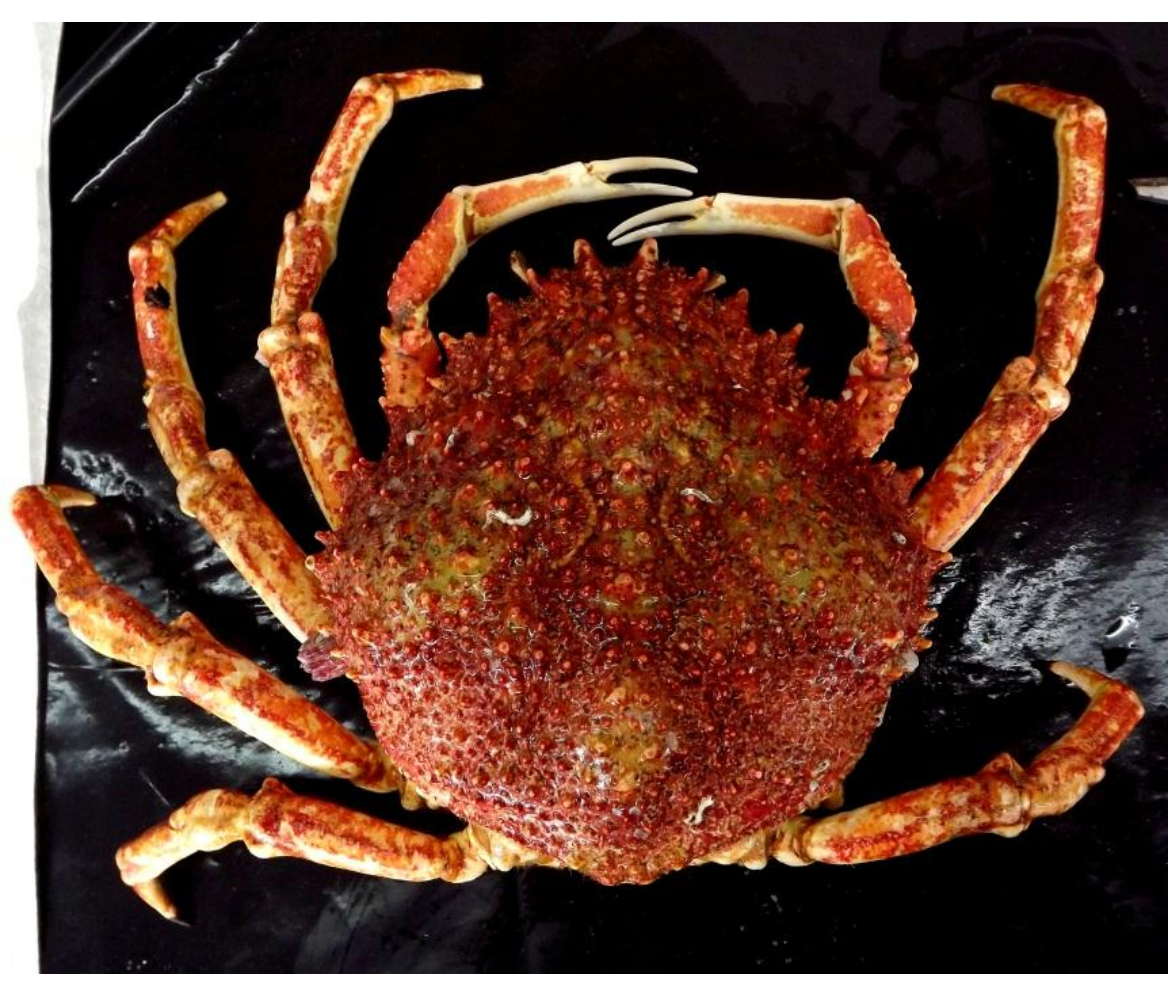

Figure 54 Photo of the second specimen of Maja brachydactyla 
Table 10

\begin{tabular}{|c|c|c|c|c|c|c|}
\hline $\begin{array}{c}\text { Leg } \\
\text { Number }\end{array}$ & $\begin{array}{c}\text { Segments } \\
\text { of leg } n\end{array}$ & $\begin{array}{l}\text { Movement } \\
\text { of the leg } \\
\text { between } \\
\text { joints } \\
\text { around } \\
\text { axis: }\end{array}$ & $\begin{array}{l}\text { Amplitude } \\
\text { of } \\
\text { movement } \\
\text { between } \\
\text { joints } \alpha\left(^{\circ}\right)\end{array}$ & $\begin{array}{c}\text { Length of } \\
\text { the } \\
\text { segment } \\
l_{x}(\mathrm{~mm})\end{array}$ & $\begin{array}{l}\text { Diameter } \\
\text { of the } \\
\text { segment } \\
d_{x}(\mathrm{~mm})\end{array}$ & $\begin{array}{l}\text { Mass of } \\
\text { the } \\
\text { segment } \\
m_{x}(\mathrm{~g})\end{array}$ \\
\hline \multirow{6}{*}{$\begin{array}{c}\text { left leg } \\
\left(\boldsymbol{L}_{\mathbf{4}}\right)\end{array}$} & 1 & $z$ & $90^{\circ}$ & 13 & 20 & 4.0 \\
\hline & 2 & $y$ & $100^{\circ}$ & 15 & 11 & 2.8 \\
\hline & 3 & $z$ & $20^{\circ}$ & 45 & 14 & 7.4 \\
\hline & 4 & $y$ & $120^{\circ}$ & 27 & 11 & 3.2 \\
\hline & 5 & $z$ & $70^{\circ}$ & 30 & 10 & 3.2 \\
\hline & 6 & $y$ & $90^{\circ}$ & 30 & 6 & 0.7 \\
\hline \multirow{6}{*}{$\begin{array}{l}\text { left leg } \\
\left(\boldsymbol{L}_{3}\right)\end{array}$} & 1 & $z$ & $90^{\circ}$ & 15 & 20 & 4.6 \\
\hline & 2 & $y$ & $90^{\circ}$ & 18 & 12 & 3.0 \\
\hline & 3 & $z$ & $20^{\circ}$ & 56 & 14 & 9.7 \\
\hline & 4 & $y$ & $120^{\circ}$ & 39 & 14 & 5.0 \\
\hline & 5 & $z$ & $80^{\circ}$ & 38 & 10 & 4.3 \\
\hline & 6 & $y$ & $90^{\circ}$ & 32 & 7 & 0.9 \\
\hline \multirow{6}{*}{$\begin{array}{l}\text { left leg } \\
\left(\boldsymbol{L}_{2}\right)\end{array}$} & 1 & $z$ & $90^{\circ}$ & 17 & 20 & 5.9 \\
\hline & 2 & $y$ & $100^{\circ}$ & 13 & 13 & 3.0 \\
\hline & 3 & $z$ & $20^{\circ}$ & 64 & 15 & $1 ., 9$ \\
\hline & 4 & $y$ & $100^{\circ}$ & 35 & 13 & 5.0 \\
\hline & 5 & $z$ & $90^{\circ}$ & 47 & 11 & 5.5 \\
\hline & 6 & $y$ & $90^{\circ}$ & 38 & 6 & 1.2 \\
\hline \multirow{6}{*}{$\begin{array}{l}\text { left leg } \\
\left(\boldsymbol{L}_{\mathbf{1}}\right)\end{array}$} & 1 & $z$ & $90^{\circ}$ & 18 & 18 & 6.0 \\
\hline & 2 & $y$ & $90^{\circ}$ & 17 & 13 & 3.5 \\
\hline & 3 & $z$ & $20^{\circ}$ & 70 & 15 & $1 ., 0$ \\
\hline & 4 & $y$ & $120^{\circ}$ & 36 & 15 & 6.2 \\
\hline & 5 & $z$ & $80^{\circ}$ & 47 & 11 & 5.9 \\
\hline & 6 & $y$ & $90^{\circ}$ & 39 & 7 & 1.3 \\
\hline \multirow{6}{*}{$\begin{array}{l}\text { left claw } \\
\qquad\left(\boldsymbol{L}_{\boldsymbol{c}}\right)\end{array}$} & 1 & $z$ & $90^{\circ}$ & 13 & 19 & 5.6 \\
\hline & 2 & $y$ & $120^{\circ}$ & 19 & 14 & 5.1 \\
\hline & 3 & $z$ & $60^{\circ}$ & 46 & 16 & 7.0 \\
\hline & 4 & $y$ & $120^{\circ}$ & 36 & 13 & 5.9 \\
\hline & 5 & $z$ & $120^{\circ}$ & 66 & 9 & 5.4 \\
\hline & 6 (claw) & $y$ & $30^{\circ}$ & 32 & 4 & 0.7 \\
\hline
\end{tabular}


Table 11

Measurements of the right legs of the second specimen

\begin{tabular}{|c|c|c|c|c|c|c|}
\hline $\begin{array}{c}\text { Leg } \\
\text { Number }\end{array}$ & $\begin{array}{c}\text { Segments } \\
\text { of leg } n\end{array}$ & $\begin{array}{l}\text { Movement } \\
\text { of the leg } \\
\text { between } \\
\text { joints } \\
\text { around } \\
\text { axis: }\end{array}$ & $\begin{array}{l}\text { Amplitude } \\
\text { of } \\
\text { movement } \\
\text { between } \\
\text { joints } \alpha\left(^{\circ}\right)\end{array}$ & $\begin{array}{l}\text { Length of } \\
\text { the } \\
\text { segment } \\
l_{x}(\mathrm{~mm})\end{array}$ & $\begin{array}{l}\text { Diameter } \\
\text { of the } \\
\text { segment } \\
d_{x}(\mathrm{~mm})\end{array}$ & $\begin{array}{c}\text { Mass of } \\
\text { the } \\
\text { segment } \\
m_{x}(\mathrm{~g})\end{array}$ \\
\hline \multirow{6}{*}{$\begin{array}{l}\text { right leg } \\
\quad\left(\boldsymbol{R}_{\mathbf{4}}\right)\end{array}$} & 1 & $z$ & $90^{\circ}$ & 17 & 19 & 3.6 \\
\hline & 2 & $y$ & $110^{\circ}$ & 11 & 11 & 2.2 \\
\hline & 3 & $z$ & $20^{\circ}$ & 49 & 12 & 7.0 \\
\hline & 4 & $y$ & $120^{\circ}$ & 31 & 13 & 3.2 \\
\hline & 5 & $z$ & $70^{\circ}$ & 31 & 11 & 3.1 \\
\hline & 6 & $y$ & $90^{\circ}$ & 28 & 6 & 0.8 \\
\hline \multirow{6}{*}{$\begin{array}{l}\text { right leg } \\
\quad\left(\boldsymbol{R}_{\mathbf{1}}\right)\end{array}$} & 1 & $z$ & $90^{\circ}$ & 14 & 19 & 5.7 \\
\hline & 2 & $y$ & $90^{\circ}$ & 17 & 13 & 3.1 \\
\hline & 3 & $z$ & $20^{\circ}$ & 70 & 15 & 1.5 \\
\hline & 4 & $y$ & $120^{\circ}$ & 41 & 14 & 6.0 \\
\hline & 5 & $z$ & $90^{\circ}$ & 47 & 11 & 6.0 \\
\hline & 6 & $y$ & $90^{\circ}$ & 27 & 7 & 1.2 \\
\hline \multirow{6}{*}{$\begin{array}{l}\text { right claw } \\
\qquad\left(\boldsymbol{R}_{\boldsymbol{c}}\right)\end{array}$} & 1 & $z$ & $90^{\circ}$ & 13 & 21 & 4.8 \\
\hline & 2 & $y$ & $120^{\circ}$ & 31 & 13 & 5.3 \\
\hline & 3 & $z$ & $90^{\circ}$ & 42 & 14 & 7.1 \\
\hline & 4 & $y$ & $130^{\circ}$ & 40 & 13 & 5.8 \\
\hline & 5 & $z$ & $130^{\circ}$ & 67 & 9 & 5.2 \\
\hline & 6 (claw) & $y$ & $30^{\circ}$ & 30 & 4 & 0.9 \\
\hline
\end{tabular}

During the experiments, and while cutting the legs of the crab for measurements, it was verified that the mass of the body of the crab without legs is $M_{b}=580.8 \mathrm{~g}$.

$$
\Delta M=M-M_{b}=526.7-335=310.2 \mathrm{~g}
$$

From expression (17) it is possible to compute the difference between the crab's mass with and without legs. By calculating the masses obtained during the measurements, it is found a difference of 4 grams.

$$
\sum m_{L}=m_{L(4)}+m_{L(3)}+m_{L(2)}+m_{L(1)}+m_{L(c)}+
$$




$$
\begin{gathered}
+m_{R(4)}+m_{R(3)}+m_{R(2)}+m_{R(1)}+m_{R(c)} \\
\sum m_{L}=10.1+15.1+17.8+20.1+13.4+10.6+15.2+17.1+20.5+14.1=154 \mathrm{~g} \\
\sum m_{x}=m_{L x(4)}+m_{L x(3)}+m_{L x(2)}+m_{L x(1)}+m_{x(c)}+ \\
+m_{R x(4)}+m_{R x(3)}+m_{R x(2)}+m_{R x(1)}+m_{R x(c)} \\
\sum m_{x}=9.9+14.4+17.7+19.9+12.9+10.4+14.6+16.6+20.1+13.5=150 \mathrm{~g} .
\end{gathered}
$$

